\title{
Characterization of Atmospheric Particulate Matter in Mountaintop Mining and Non-mining Areas in West Virginia with Known Health Differences
}

\author{
Laura M. Kurth \\ West Virginia University
}

Follow this and additional works at: https://researchrepository.wvu.edu/etd

\section{Recommended Citation}

Kurth, Laura M., "Characterization of Atmospheric Particulate Matter in Mountaintop Mining and Nonmining Areas in West Virginia with Known Health Differences" (2013). Graduate Theses, Dissertations, and Problem Reports. 510.

https://researchrepository.wvu.edu/etd/510

This Dissertation is protected by copyright and/or related rights. It has been brought to you by the The Research Repository @ WVU with permission from the rights-holder(s). You are free to use this Dissertation in any way that is permitted by the copyright and related rights legislation that applies to your use. For other uses you must obtain permission from the rights-holder(s) directly, unless additional rights are indicated by a Creative Commons license in the record and/ or on the work itself. This Dissertation has been accepted for inclusion in WVU Graduate Theses, Dissertations, and Problem Reports collection by an authorized administrator of The Research Repository @ WVU.

For more information, please contact researchrepository@mail.wvu.edu. 


\title{
Characterization of Atmospheric Particulate Matter in Mountaintop Mining and Non-mining Areas in West Virginia with Known Health Differences
}

\author{
Laura M. Kurth \\ Dissertation submitted to the \\ School of Public Health \\ at West Virginia University \\ in partial fulfillment of the requirements \\ for the degree of \\ Doctor of Philosophy \\ in \\ Public Health Sciences \\ Michael Hendryx, Ph.D., Chair \\ Bean Chen, Ph.D. \\ Matthew Gurka, Ph.D. \\ Michael McCawley, Ph.D. \\ Timothy Nurkiewicz, Ph.D. \\ Department of Epidemiology \\ Morgantown, West Virginia \\ 2013
}

Keywords: Particle Size; Particle Mass; Lung Deposition; Coal Mining; Appalachia

Copyright 2013 Laura M. Kurth 


\section{ABSTRACT \\ Characterization of Atmospheric Particulate Matter in Mountaintop Mining and Non- mining areas in West Virginia with Known Health Differences}

\section{Laura M. Kurth}

Introduction: Mortality and morbidity rates in the Appalachian region are higher than in the national population. People who live in Appalachian areas where coal mining is prominent have increased health problems compared to people in non-mining areas of Appalachia. Health disparities remain higher in mining areas even after adjusting for lifestyle and demographic effects illustrating that additional factors, such as environmental influences, are associated with adverse health outcomes. Coal mines and coal mining activities result in the production of atmospheric particulate matter (PM), which is associated with environmental and human health effects. Environmental studies of air and water quality in southwest West Virginia provide evidence of air contamination and surface and ground water contamination around coal mining areas, including mountaintop mining (MTM) sites. However, there is a gap in research regarding characterization of PM around MTM areas and the health effects from PM in MTM areas. The objective of this project was to assess the potential health hazard of PM by characterizing atmospheric PM in coal and non-mining areas to identify PM elemental composition, concentration, size distribution to determine inhaled deposited dose, and environmental dry deposition.

Methods/Results: In the first study, particle size distribution and concentration data were collected to calculate deposited lung dose at MTM and non-mining sites. This study was divided into two parts to examine variability in particle size distribution and concentration measurements within sampling areas and seasonal variability within and between MTM and non-mining sites was evaluated. Particle number concentrations and deposited lung dose were elevated around the MTM sites demonstrating elevated risk to humans. In the second study, a primary analysis of semi-quantitative data was conducted to identify the most abundant elements contributing to coarse PM at MTM and non-mining sites. Crustal elements dominated all samples and MTM sites had elevated siliceous materials and the non-mining PM was primarily from combustion sources. The final study quantified environmental dry deposition for inorganic materials at mining and non-mining sites. Results from this study revealed the mining sites contained elevated flux estimates and elevated concentrations of crustal and anthropogenic inorganic materials.

Conclusions: Atmospheric PM at the MTM areas in this study pose an increased hazard to human health due to elevated dose to human lungs, particle count, and chemical composition. This research extends exposure assessment literature by directly estimating the inhaled dose and concentration of particles that residents of high disease rate areas receive. Furthermore, threats to the environment were noted due to elevated dry environmental deposition flux estimates for elements in PM depositing in the environment around mining areas. Our findings demonstrate the need to address air quality issues and regulate mining-related sources of PM in MTM areas to decrease health disparities in the Appalachian coal mining areas. 


\section{DEDICATION}

It is an honor to dedicate this dissertation to my husband. Matt, thank you for graciously putting up with all the times when I put my school work before spending time with you. Thank you for keeping me grounded and helping me set goals and prioritize my workload so I could manage to also enjoy the world that exists outside academia. I'm grateful for your encouragement and am privileged to have you by my side for what is to come.

\section{ACKNOWLEDGEMENTS}

I would like to express my sincerest thanks to my advisor and dissertation committee chair Dr. Michael Hendryx. I truly appreciate your willingness to mentor me and the freedom you gave me to pursue my interests related to this topic. I would also like to thank the rest of my committee, Dr. Bean Chen, Dr. Matt Gurka, Dr. Mike McCawley, and Dr. Tim Nurkiewicz, for their feedback, comments, and questions. They challenged me to submerge myself in related literature and discover all I could about my research topic. Specifically, I owe a special thanks to Dr. McCawley who invested so much time into teaching me about aerosols. I never imagined I would develop such an interest in aerosols...or be able to comprehend the concepts he was teaching me. In between many laughs, near-death experiences, and sing-a-longs Dr. McCawley educated me about how particles move, deposit, and change...always teaching me something new and seemingly making me think.

I would also like to acknowledge Travis Knuckles for the considerable amount of time he spent collaborating and serving as a very knowledgeable resource. Many thanks to William Orem, Calin Tatu, Mark Engle, Nicholas Geboy, and Allan Kolker and the numerous other researchers and staff from the U.S. Geological Survey based out of Reston, VA that we collaborated with on this project for data collection and analysis. Specifically, thanks to Ruth Wolf who worked to determine the process, digestion, and analysis methods of the surrogate surface samplers.

I am most grateful for the support of my fellow graduate students, specifically, my classmates Sarah Geiger, Molly Matthews-Ewald, and Rose Pignataro. These three ladies (along with their amazing families) are the most supportive and wonderful friends, collaborators, colleagues, study partners, and therapists. 
I would like to extend my gratitude to the School of Public Health faculty and staff. In particular, thanks to my professors who shared their knowledge through countless hours of teaching and advising. Also, thanks to Dr. Keith Zullig for initiating this entire ordeal by guiding me through the stages of my first research project and for opening the doors to my first professional experiences in the field of public health. Moving to Morgantown for my $\mathrm{PhD}$ program brought about so many wonderful life changes, and I am grateful that Dr. Zullig encouraged me to apply to WVU four years ago.

I would like to acknowledge Drs. Kolin Brown, Marcela Redigolo, Weiqiang Ding, Harley Hart, and all others at the WVU Shared Research Facilities for their training and assistance with the Scanning Electron Microscope.

Finally, thanks to my parents (and grandparents) for providing me with unrestricted opportunities for education. I appreciate their encouragement and the environment my parents and siblings created to foster learning. 


\section{TABLE OF CONTENTS}

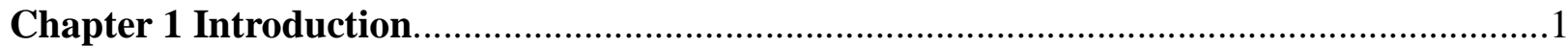

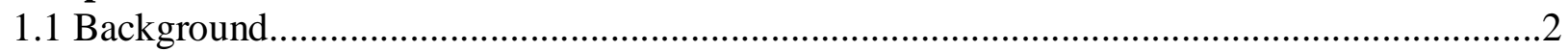

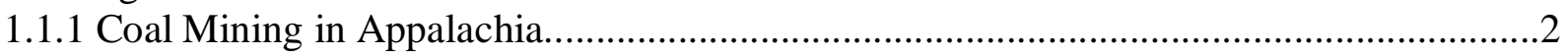

1.1.2 Environmental Hazards Associated with MTM...............................................................

1.1.3 Health in Appalachia.....................................................................................................

1.1.4 Determining Dose from Particulate Matter......................................................................

1.1.5 The Health Effects of Particulate Matter.............................................................................11

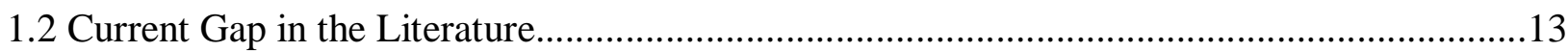

1.3 The Purpose of the Current Research..................................................................................

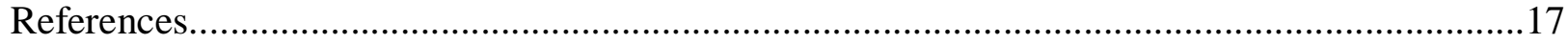

Chapter 2 Particle Size Distribution and Concentration in West Virginia Areas with Health

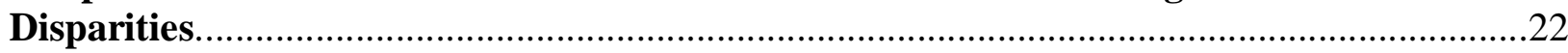

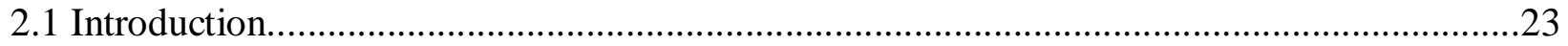

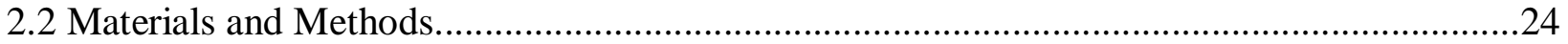

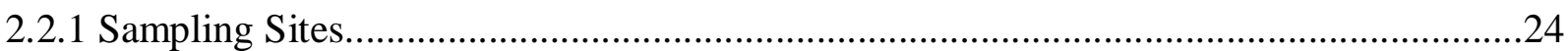

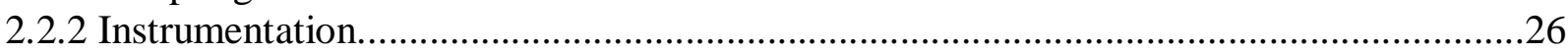

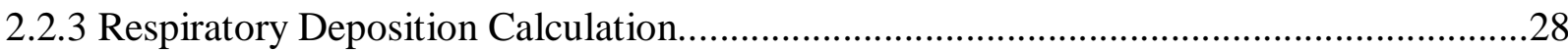

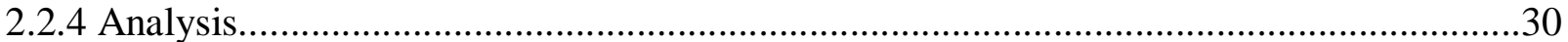

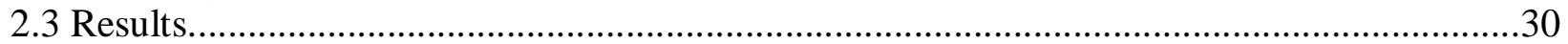

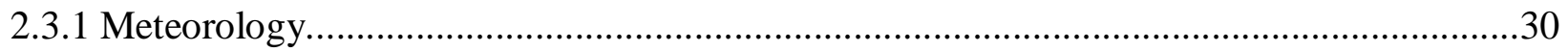

2.3.2 Concentration Comparisons.......................................................................................30

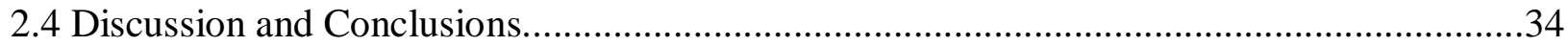

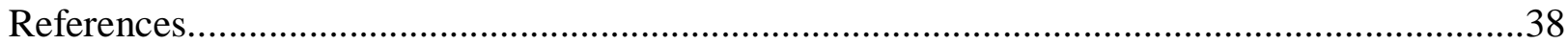

Chapter 3 Atmospheric Particulate Matter Concentration Measurements in West Virginia

Mountaintop Mining and Non-Mining Areas Over a Year Period........................................40

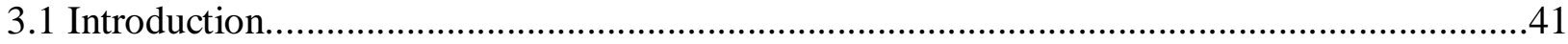

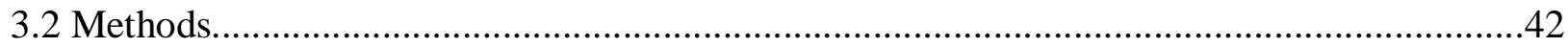

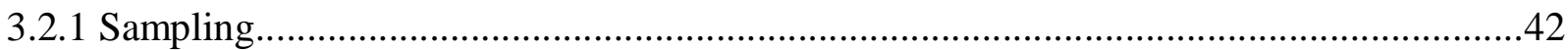

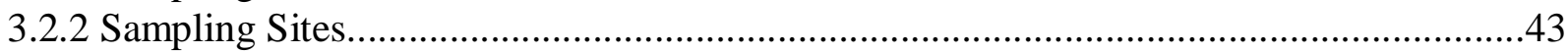

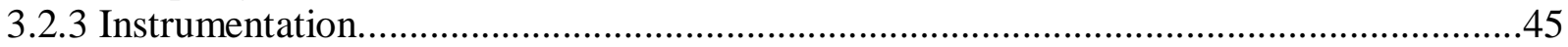

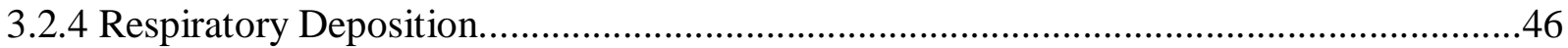

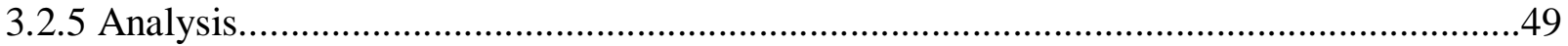

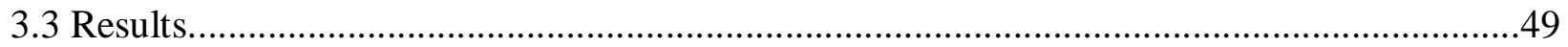

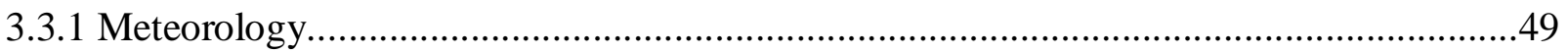

3.3.2 Seasonal and Monthly Variation.....................................................................................50

3.4 Discussion and Conclusions..........................................................................................58

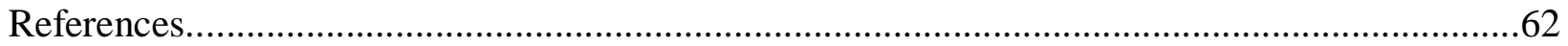

Chapter 4 Elemental Concentration of Atmospheric Particulate Matter in West Virginia Mountaintop Mining Areas...........................................................................................65

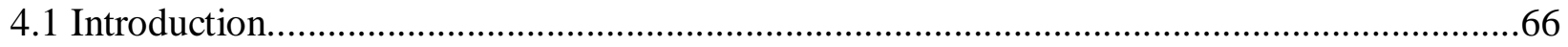

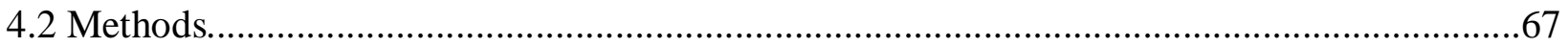




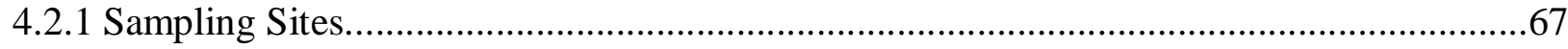

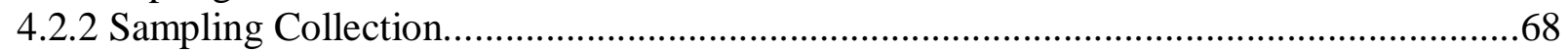

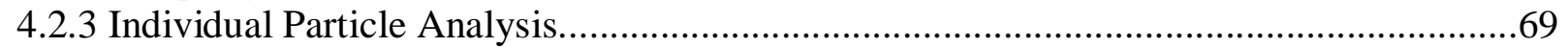

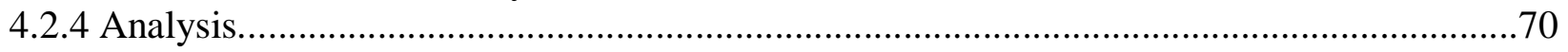

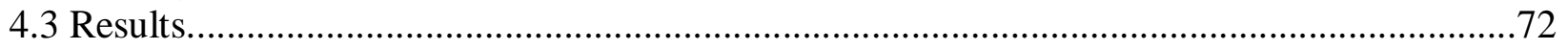

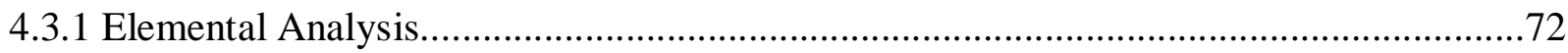

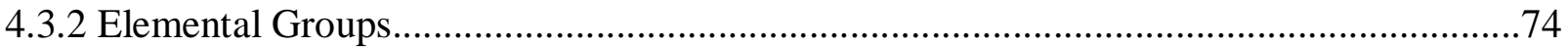

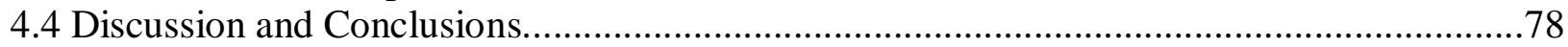

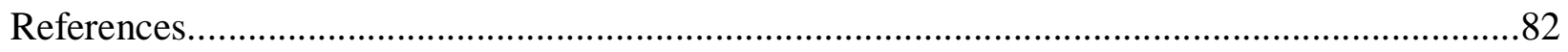

Chapter 5 Inorganic Constituents of Atmospheric Particulate Matter in West Virginia Coal

Mining Areas................................................................................................................. 85

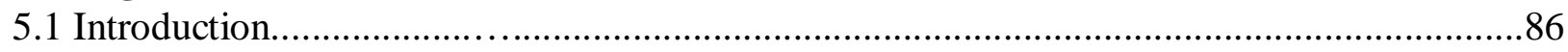

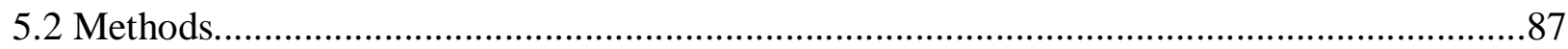

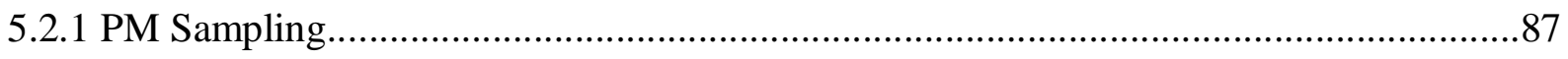

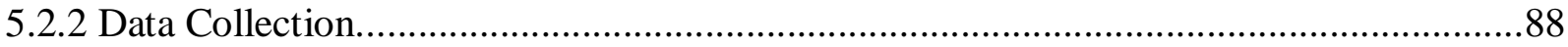

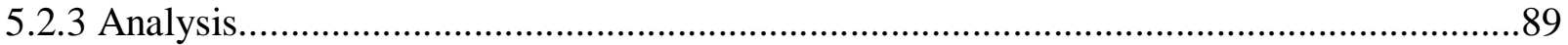

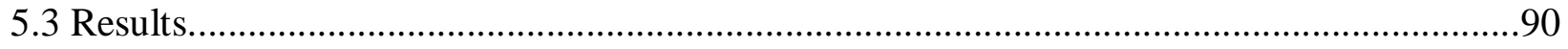

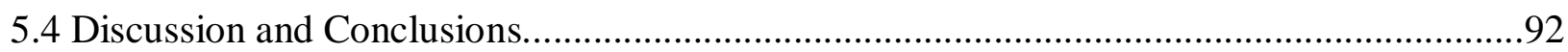

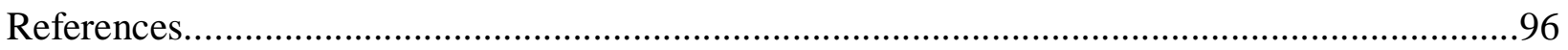

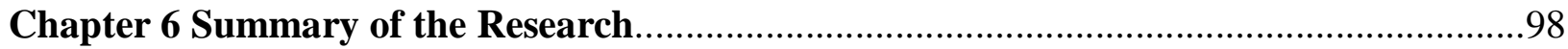

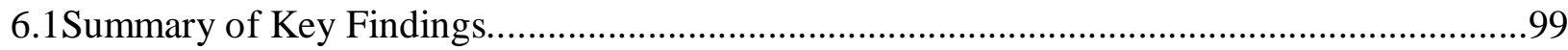

6.2 Discussion.................................................................................................................100

6.2.1 Characteristics of PM Relevant to Health.....................................................................100

6.2.2 Evaluating Standard PM Measures............................................................................103

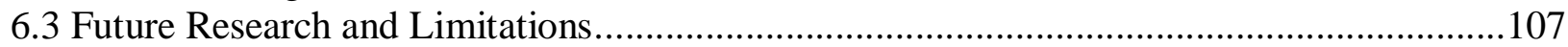

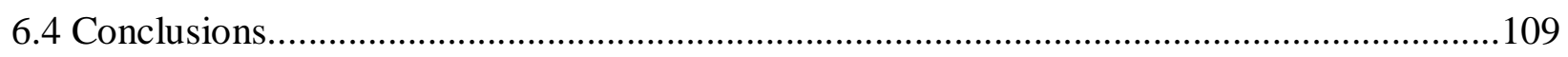

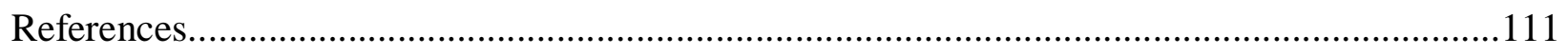

Appendix A: Schematic of Particle Sizing Equipment..............................................................114

Appendix B: Justification for Selecting Annual Sampling Sites.................................................117 
Chapter 1

Introduction 


\subsection{Background}

\subsubsection{Coal Mining in Appalachia}

The Appalachian Region includes the mountainous, largely rural area from southern New York to northern Mississippi encompassing 13 states and 420 counties (ARC, 2009) (Figure 1). This region faces socioeconomic, educational, and health inequalities (ARC, 2009; Behringer \& Friedell, 2006; Halverson et al., 2004; Wood, 2005). The per capita personal income falls well below the national average and the percent of adults with a college degree in the region is one third lower than that of the nation (ARC, 2009).

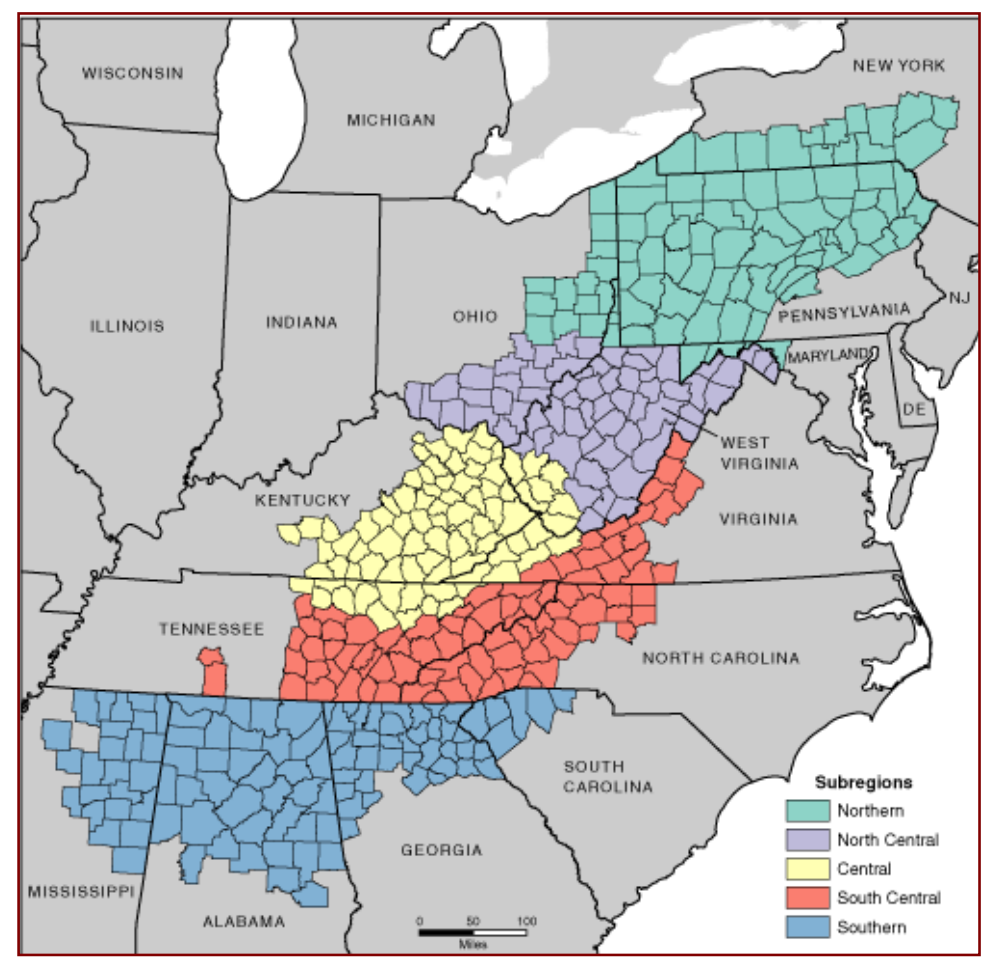

Figure 1 The Appalachian Region including 13 states and 420 counties. The region is subdivided into five sub regions classified by similar topographic, demographic, and economic characteristics (ARC, 2012).

The economy of Appalachia has become more diversified with the addition of manufacturing and service industries to one previously dependent on coal mining, forestry, and heavy industry (ARC, 2012). Still, Appalachia remains one of the nation's leading coal producing regions (US EIA, 2009). The most productive Appalachian coal mining states include West Virginia, Kentucky, Pennsylvania, and Ohio. West Virginia, a rural, mountainous state and the only state located entirely in Appalachia, contributes about 8\%, or 37 billion tons of coal, 
annually to total U.S. coal production (KET, 2005). Within the Appalachian region, coal mining areas are distinguished from other areas as poverty rates are highest in Appalachian communities with heavy mining compared to those with less mining (Hendryx, 2009).

A relatively new form of surface mining called mountaintop mining (MTM) is practiced in eastern Kentucky, southern West Virginia, western Virginia, and eastern Tennessee (U.S. EPA, 2010). MTM involves unearthing large amounts of non-coal-bearing vegetation, rock, and dirt from mountaintops to reach coal seams. The exposed non-coal overburden, composed of crushed shale, coal debris, sandstone, and other materials, is removed with explosives and excavation equipment to expose coal seams under the mountaintop for extraction (U.S. EPA, 2010). The overburden is set aside for regrading and reclamation activities or removed from the mountaintop and deposited in nearby valley fill sites (U.S. EPA, 2010) (Figure 2).

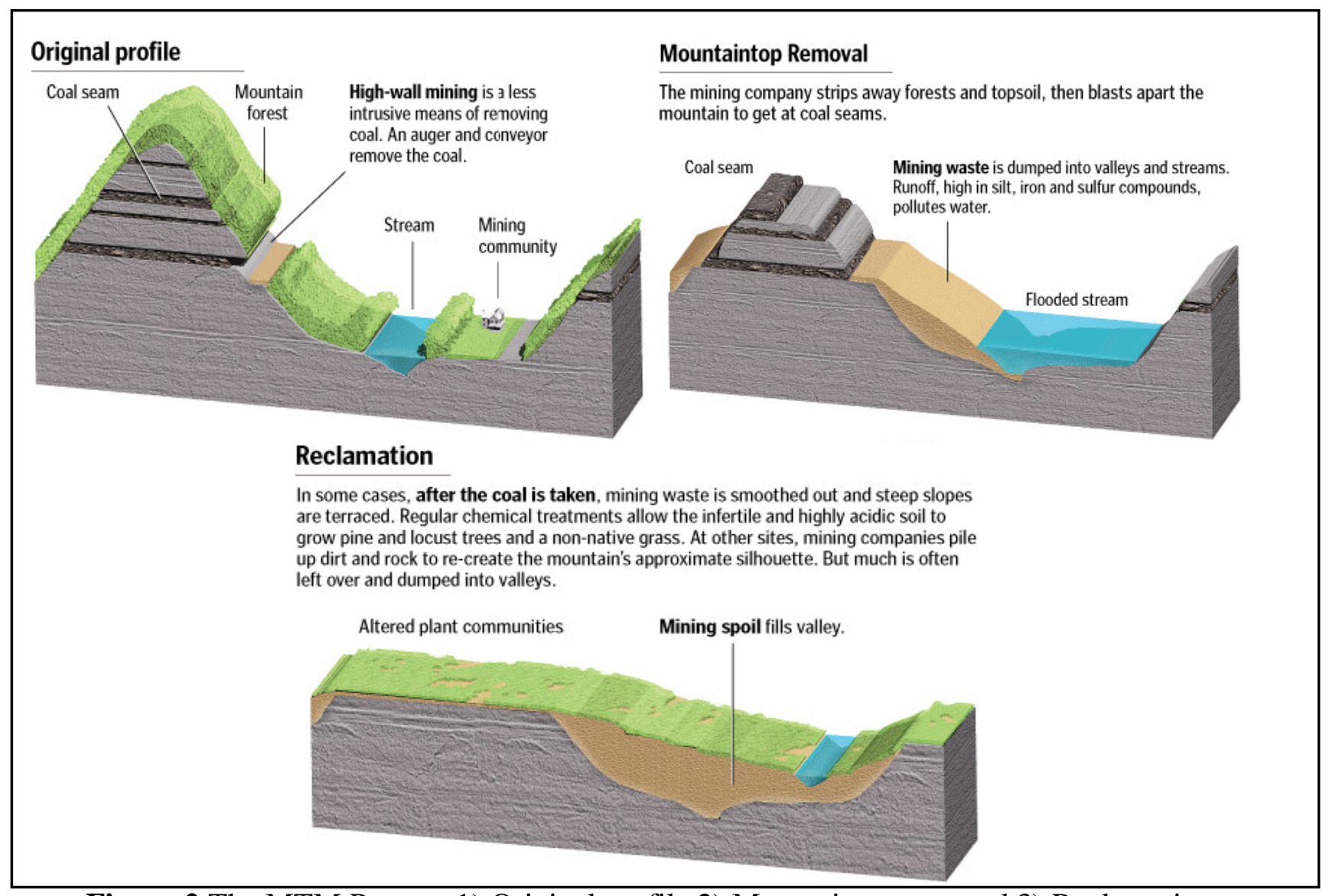

Figure 2 The MTM Process:1) Original profile 2) Mountaintop removal 3) Reclamation (Stearns, 2010).

During the 1970s, the demand for coal increased as a result of the 1970 energy crisis. MTM surfaced as a more economical form of coal mining because it relied heavily on 
mechanization as compared to underground mining. The successes of the MTM method accelerated it into the 1980s and MTM increased during the 1990s to obtain cleaner burning, low-sulfur coal in compliance with amendments to the Clean Air Act in 1990 (U.S. EPA, 2010). The southern West Virginia coalfields hold a wealth of low-sulfur coal that can be obtained quickly and cheaply by MTM to meet the demands for low-sulfur coal. The MTM technique is highlighted in this project due to elevated environmental and human health risks associated with this particular coal mining method compared to other methods.

\subsubsection{Environmental Hazards Associated with MTM}

The impacted area from MTM is relatively large as one particular MTM operation overtook 25 square miles of mountaintop and the surrounding area (McQuaid, 2009). In 2006, over 500 Appalachian peaks were reported as leveled or partially leveled by surface mining and MTM (Geredien, 2006). The EPA regulates placement of the valley fill sites, and additional MTM regulations were set forth in the Surface Mining Control and Reclamation Act of 1977 (U.S. EPA, 2010). In spite of regulations, coal mining and related coal processes contribute excess hazardous pollutants that contaminate the water and air around MTM areas and pose health threats to MTM community residents (Kirk et al., 2005; Mastin, 2005; Pond et al., 2008; U.S. EPA, 2010).

Overburden deposited in valley fill sites buries valley streams and results in contaminated water (Pond et al., 2008). In the valley fill sites, precipitation and groundwater seep through the unconsolidated overburden dissolving minerals and metals in the water (Pond et al., 2008). The result is an increased measure of total dissolved solids at sites downstream of MTM operations compared to measurements from these sites prior to MTM initiation. Water conductivity, total dissolved solids, hardness, alkalinity, $\mathrm{Ca}^{2+}, \mathrm{Mg}^{2+}, \mathrm{K}^{+}, \mathrm{Na}^{+}$, and $\mathrm{SO}_{4}$ measurements were also greater downstream after MTM was initiated (Kirk et al., 2005; Lindberg et al., 2011). Conductivity of water is affected by the presence of inorganics (S, Ni, $\mathrm{Mg}, \mathrm{N}$, and total dissolved solids). $\mathrm{Ca}^{2+}$ is present as a result of calcium oxide and sodium hydroxide used to neutralized the acidity of water. Sulfur was likely the result of coal waste that forms sulfuric acid and is a reliable indicator of upstream mining activity (Lindberg et al., 2011). Elevated water contaminants damage aquatic life and concentrations of contaminants persist in the water for decades after mining activity ends (Lindberg et al., 2011). Impairment of streams 
as reported by a stream condition index was correlated with cancer mortality rates in nearby areas (Hitt \& Hendryx, 2010).

Air quality impacts from MTM are a concern in areas with excessive health disparities as air contaminants may contribute to the increased health problems. Preliminary air quality measurements around mining and non-mining sites showed the highest particulate matter (PM) mass concentration at MTM sites compared to other mining and non-mining sites. Other mining and non-mining sites had progressively better air quality based on $\mathrm{PM}_{2.5}$, (particulates with an aerodynamic diameter less than or equal to $2.5 \mu \mathrm{m}$ ), $\mathrm{PM}_{10}$ (particulates with an aerodynamic diameter less than $10 \mu \mathrm{m}$ ), and total suspended particle (TSP) measurements (Hendryx et al. 2009). Explosives used as a regular part of the mining process to remove spoil contain ammonium-nitrate and diesel fuel and release $\mathrm{CO}_{2}, \mathrm{CO}, \mathrm{NO}, \mathrm{SO}_{2}$, and $\mathrm{NH}_{3}$ (Ayers et al., 2007; MSHA, 2010). Combustion, used with MTM blasting and other coal processes, produces fine particle matter, which may be inhaled and deposit in the lungs (Hinds, 1999).

An examination of the air around MTM and non-mining areas collected in collaboration with the U.S. Geological Survey explored the contaminants from MTM coal activity. Sized particulate matter was collected with a powerful high-volume sampler for particle composition analyses, and geochemical window-wipes were obtained for inorganic and organic analyses of longitudinal PM. Preliminary results for the window wipes indicated MTM activity did not contribute excess anthropogenic contaminants $\left(\mathrm{SO}_{4}, \mathrm{~V}, \mathrm{Ni}, \mathrm{Cu}, \mathrm{As}\right.$, and $\left.\mathrm{Cd}\right)$ to MTM sites compared to non-mining sites based on concentration. However, a greater concentration of crustal elements (Al, Ti, Fe, Ga, Rb, and rare earth elements) was present at higher concentrations in the window wipe samples collected from the MTM sites compared to nonmining sites. An estimated 80-96\% of the elements at the MTM sites were the result of local source contribution during the sampling period. This suggests that MTM provides little additional contribution of anthropogenically-dominated contaminates to the air compared to areas without mining nearby, but MTM does contribute additional elements from local crustal sources (Kolker et al., 2012). However, fluctuations in elemental contaminants across seasons from MTM and non-mining sites have not been determined.

\subsubsection{Health in Appalachia}


Mortality and morbidity rates are higher in the Appalachian region compared to the national population (Behringer \& Friedell, 2006; Halverson et al., 2004). Lifestyle determinants of adverse health effects, including smoking and obesity, are disproportionally higher in Appalachia, and the area's geographic, social, and economic factors exacerbate health status disparities (Behringer \& Friedell, 2006; Halverson et al., 2004; Wood, 2005).Appalachia’s primarily rural setting isolates many residents from medical resources and quality health care (Behringer \& Friedell, 2006; Halverson et al., 2004).

The region’s widespread health disparities are more prominent in Appalachian coal mining counties compared to non-mining counties (Behringer \& Friedell, 2006; Halverson et al., 2004; Hendryx \& Ahern, 2008). Adults in Appalachian coal mining areas had a 1.2 (95\% CI=1.141.30) greater odds of reporting cardiovascular disease, 1.29greater odds of reporting angina or coronary heart disease (95\% CI=1.19-1.39), and 1.19(95\% CI=1.10-1.30)greater odds of experiencing a heart attack compared to those living in non-mining, non-Appalachian areas (Hendyx \& Zullig, 2009). Adults residing in heavy ( $>4$ million tons of annual coal produced)coal mining areas of West Virginia had a 1.1 (95\% CI=1.01-1.25) greater odds of reporting cardiopulmonary disease, 1.3 (95\% CI=1.05-1.61) greater odds of reporting lung disease, 1.3 (95\% CI=1.13-1.49) greater odds of reporting hypertension, and 1.7 (95\% CI=1.012.84) greater odds of reporting kidney disease compared to adults in non-mining areas of West Virginia (Hendryx \& Ahern, 2008). Among both males and females residing in Appalachian coal mining counties with heavy mining for the years 2000-2004, there was a greater risk of total cardiovascular mortality, chronic heart mortality, total respiratory mortality, chronic respiratory mortality, and chronic kidney disease (Hendryx, 2009).

Recent studies have focused on health outcomes in Appalachian areas practicing MTM. Residents of MTM areas have significantly greater age-adjusted total mortality rates compared to residents of non-mining areas in central Appalachian states (Hendryx, 2011). The adjusted prevalence ratio for births with congenital anomaly was greater $(1.26,95 \% \mathrm{CI}=1.21-1.32)$ in Kentucky, Tennessee, Virginia, and West Virginia MTM and greater in other coal mining areas (1.10, 95\% CI=1.05-1.16) compared to non-mining referent areas (Ahern et al., 2011). Residents of MTM areas had significantly higher rates of birth defects, such as circulatory/respiratory, central nervous system, musculoskeletal, gastrointestinal, urogenital, and 'other' birth defects (Ahern et al., 2011). Residents of MTM counties had significantly lower health-related quality 
of life including more days of poor physical health, poor mental health, and activity limitations $(\mathrm{p}<0.01)$ (Zullig \& Hendryx, 2011). Age-adjusted chronic cardiovascular rates were greater in MTM Appalachian counties compared to non-mining Appalachian counties ( $\beta=24.7, \mathrm{SE}=9.3$, $\mathrm{p}<0.009$ ) (Esch \& Hendryx, 2011). Those living in MTM areas under study had 2.03 (95\% $\mathrm{CI}=1.32-3.13$ ) greater odds of reporting cancer as compared to those living in a non-mining area after adjusting for age, sex, smoking, occupational history, and family cancer history (Hendryx et al., 2011).

\subsubsection{Determining Dose from Particulate Matter}

Particulate matter is a combination of solid particles and liquid droplets of a variety of sizes, shapes, and compositions suspended in the air. Particles originate directly from natural sources (pollen, dust, forest fires) and anthropogenic sources (motor vehicles, factories, construction activity, agriculture).Primary particles undergo dynamic growth processes, and photochemical and thermal reactions in the atmosphere convert primary particles to secondary particles. Particles move throughout the atmosphere based on external forces, particle velocity, and interactions with gases and other particles. Particles may deposit to surfaces, be inhaled into the respiratory system, or accumulate in the air and grow or change composition (Hinds, 1999).

Particle size distributions characterize ambient PM as multi-modal with particles forming three modes. The three expected modes in urban aerosol include: (1) a smaller sized, monodisperse nuclei mode ( $\left.\mathrm{PM}_{.01}\right)$ which contributes to the majority of overall particle number in a sample; (2) a nonuniform agglomeration or accumulation mode ( $\left.\mathrm{PM}_{.05}\right)$; and (3) a particle mode of larger, "coarse” particles $\left(\mathrm{PM}_{9}\right)$ which contributes to the majority of overall mass concentration in a sample (Figure 3). The nuclei mode includes mostly combustion particles that coagulate quickly to create larger particles. The accumulation mode consists of combustion particles, coagulated nuclei-mode particles, and smog particles. The coarse mode particles are dust, salt, and mechanically generated particles that are large in size (Hinds, 1999). 


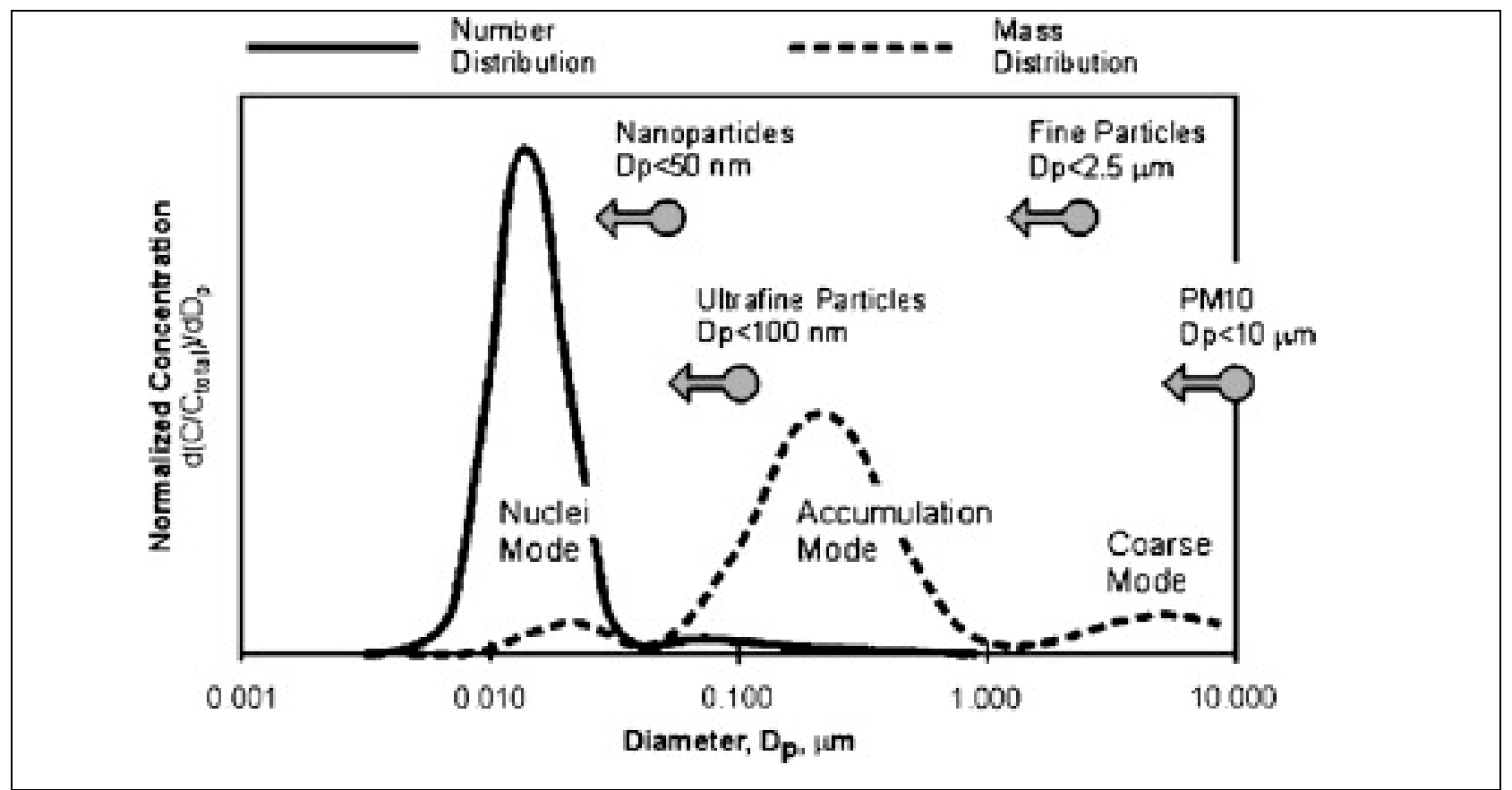

Figure 3 Schematic of typical bimodal PM composition of diesel particles from Mazzarella et al. (2007).

Advancements in aerosol technology have made it possible to measure more complex particle properties. A variety of particle properties, including mass concentration, mass-based particulate size distribution, number concentration, number-based particle size distribution, particle shape and morphology, particle density, and particle surface area, are used to describe and measure PM (Wilson \& Suh, 1997). Prior epidemiological and toxicological studies haveprovided insight into the PM properties associated with human health hazards, but the reliability of the common measures actually being used to measure health risk in epidemiology studies $\left(\mathrm{PM}_{10}\right.$ andPM $\left.\mathrm{P}_{2.5}\right)$ is questionable based on theories of particle deposition and conclusions on toxicity of paricle number concentration.

The U.S. Environmental Protection Agency (EPA) monitors PM with the partially sizeclassified, mass-based standards of $\mathrm{PM}_{10}$ (particulates with an aerodynamic diameter less than 10 $\mu \mathrm{m}$ ) and $\mathrm{PM}_{2.5}$ (particulates with an aerodynamic diameter less than or equal to $2.5 \mu \mathrm{m}$ ) (U.S. EPA, 2012). The $\mathrm{PM}_{10}$ mass concentration measure is predominately influenced by larger, coarse particles that include resuspended dust particles and particles formed by mechanical processes. Larger particles remain in the atmosphere for a short time and have a typical half-life of minutes to hours before they impact onto other surfaces or deposit out of the atmosphere by gravitational settling (Wilson \& Suh, 1997). $\mathrm{PM}_{2.5}$ are smaller, fine particles primarily formed by the conversion of atmospheric gases into particles or by processes that break larger PM down 
into smaller PM. $\mathrm{PM}_{2.5}$ remain in the air for longer periods of time with a half-life of days to weeks. Smaller particles can travel hundreds to thousands of kilometers depending on weather patterns before depositing (Wilson \& Suh, 1997). $\mathrm{PM}_{2.5}$ includes motor vehicle combustion particles and coagulated nuclei mode particles (Hinds, 1999; Wilson \& Suh,1997).

The EPA's $\mathrm{PM}_{10}$ andPM $\mathrm{M}_{2.5}$ measures are based on the amount of mass per unit volume for two size categories and provide little, if any, relevant details on complete size distribution, number concentration, and health risks of $\mathrm{PM}$ sampled. $\mathrm{PM}_{10}$ and $\mathrm{PM}_{2.5}$ are measures of exposure or penetration and refer to the capability of a particle to reach the lung but not necessarily deposit. A more accurate measure of health risk is respiratory dose or deposition, which denotes the proportion of inhaled particles that adhere to the lung surface through particle deposition processes (Lippman et al., 1980). Deposited particles generate a physiological response, and deposition depends on respiratory tract and breathing characteristics, as well as particle properties (Lippmann et al., 1980). When studying health risks associated with PM exposure, aerosol sampling techniques should obtain parameters that will effectively measure respiratory deposition, such as complete particle size distributions to calculate dose.

Small PM pose adverse biological effects because particle size is the most significant predictor of the region of deposition in the lungs (Anderson et al., 2008). Particles with a diameter less than $0.1 \mu \mathrm{m}$ are ultrafine particles (UFPs). UFPs are more efficient at penetrating deep into the alveolar region compared to larger PM $(>5 \mu \mathrm{m})$. Deposition efficiency for particles less than $0.1 \mu \mathrm{m}$ is high in the alveolar region, which may result in particles passing through the alveolar cell membrane to induce physiological response (Figure 4). UFPs are nearly indistinguishable by $\mathrm{PM}_{10}$ and $\mathrm{PM}_{2.5}$ mass measures alone because UFPs contribute little to $\mathrm{PM}_{10}$ and $\mathrm{PM}_{2.5}$ mass (Donaldson et al. 2001; Lippmann et al., 1980).

Particle surface area contributes to the toxicity of particles because UFPs have a greater surface area per unit mass (Kim \& Jaques, 2004; Oberdorster et al., 2005; Sioutas et al., 2005). The ratio of surface to total atoms increases with decreasing particle size and the surface atoms determine the bulk properties of a particle. The metal and organic surface components of UFPs are greater per unit mass compared to larger particles of the same chemistry (Xia et al., 2008). Relatively larger amounts of surface elements result in more biological activity per unit mass, which can lead to undesirable responses including toxicity, oxidative stress, or cellular 
dysfunction (Oberdorster et al., 2005). In addition, the small size of PM $<0.1 \mu$ makes particles desirable catalysts for chemical reactions (Oberdorster et al., 2005).

The health risk of inhaled aerosols is measured more effectively with mass-based size distributions and number-based size distributions to determine deposited respiratory dose. The International Commission on Radiation Protection standards and formulas from Stahlhofen et al. (1989) determined the fraction of the sized particle mass or particle number depositing in a lung region. The model was derived from regional deposition data in human subjects based on the aerodynamic diameter of particles $0.5-20 \mu \mathrm{m}$ and thermodynamic equivalent diameter of particles 0.01-0.4 $\mu \mathrm{m}$. The model distinguished four regions including: (1) nasal region; (2) extrathoracic region (including pharynx, larynx, and upper part of the trachea); (3) tracheobronchial region; and (4) alveolar region. The method of deposition in the nasal and extrathoracic regions was primarily due to inertial impaction and gravitational sedimentation (Figure 4). Brownian diffusion is the primary mechanism of deposition in the alveolar and tracheobronchial regions, although other mechanisms of deposition do occur.

Size distributions were transformed into lognormal size distribution curves and fitted to normalized mass-based or number-based sized distributions. The geometric means and standard deviations of the corresponding distributions were calculated to obtain the total depositions of the modeled size distributions. The deposition fraction was calculated for the normalized size distributions that were integrated for each region to determine total deposition. The deposition fraction reports the dosimetry of inhaled particles by determining the percent deposition to the respiratory tract for a given size range of particles during respiration (Stahlhofen et al., 1989). The fraction of PM in one size category was multiplied by the deposition fraction for the midpoint size of the size category for the nose, extrathoracic region, tracheobronchial region, and alveolar regions (Stahlhofen et al., 1989). Deposition was calculated for 50\% oral and 50\% nasal breathing with the parameters: $Q$ (volumetric flow rate) $=116.7 \mathrm{~cm}^{3} / \mathrm{sec}, \mathrm{V}=500 \mathrm{~cm}^{3}$, $\mathrm{FRC}=3,300 \mathrm{~cm}^{3}$, and $\mathrm{f}=7$ breaths per minute. 


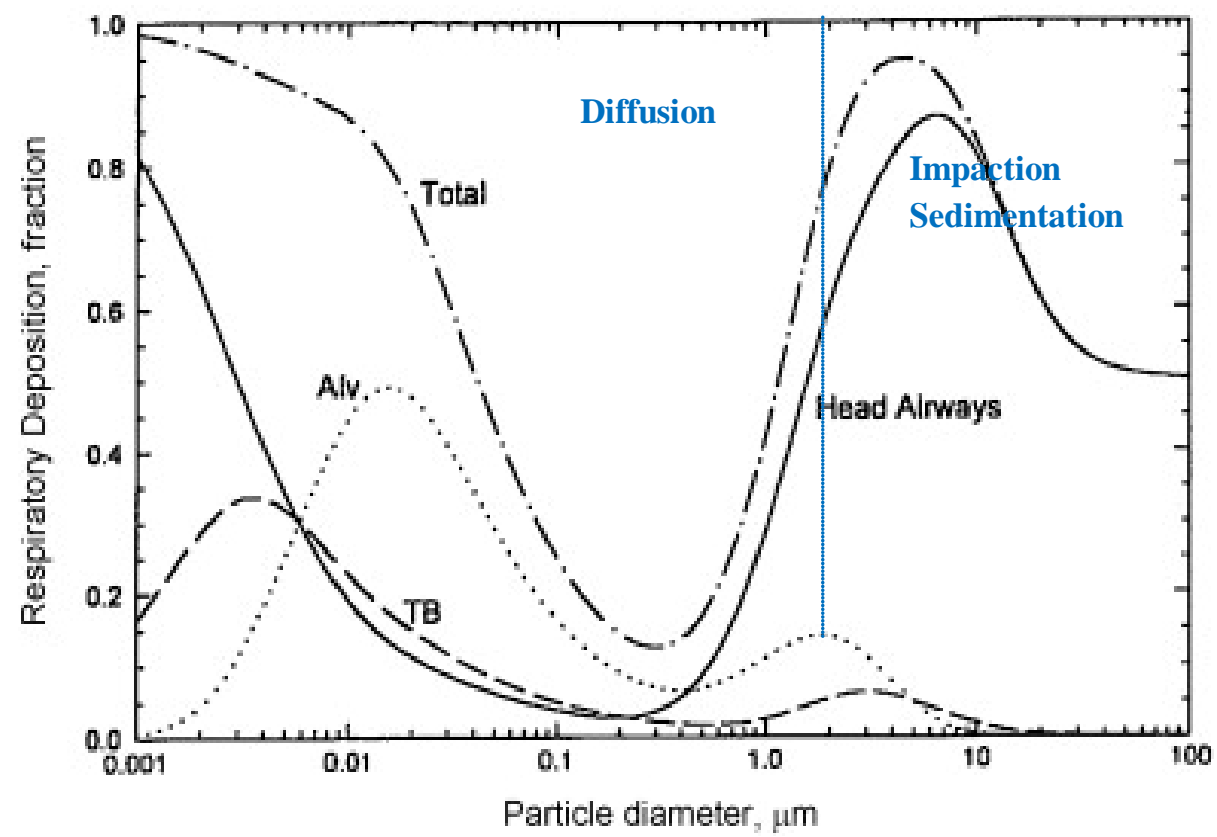

Figure 4 Particle deposition in the respiratory tract as a function of particle diameter for the nasal and extrathoracic region (Head Airways), tracheobroncial region (TB), alveolar-interstitial region (Alv), and total deposition (Total). The three deposition mechanisms accounting for the most deposition include: (1) inertial impaction (large particles with a high velocity are unable to follow the air stream and impact with a surface); (2) gravitational settling or sedimentation (deposition in small airways due to the small settling distance and low velocity of particles as well as increased forces of gravity on PM of larger masses); and (3) diffusion (particles $<0.1-0.5 \mu m$ undergo random Brownian motion depositing in the small airways and alveoli). Total and regional deposition as a function of particle diameter for nasal breathing (light exercise) based on the International Commission on Radiological Protection (ICRP) respiratory deposition models is presented showing the average deposition for males and females for particles 0.001 to $100 \mu \mathrm{m}$ (Hinds, 1999).

\subsubsection{The Health Effects of Particulate Matter}

The links between increased ambient PM and adverse health effects are well established. Epidemiological studies report that $\mathrm{PM}_{10}$ and $\mathrm{PM}_{2.5}$ are associated with respiratory outcomes including hospital admissions for asthma, COPD, and respiratory disease in general (Chen et al., 2004; Lin et al., 2002, 2003; Lin et al., 2004; Yang et al., 2003). Lung cancer development and mortality and cardiopulmonary disease mortality are reportedly related to elevated levels of ambient PM (Beeson, Abbey, \& Knutsem, 1998; Dockery et al., 1993; Pope et al., 2002). An association between excess cardiovascular morbidity and mortality and increased short- and long-term PM exposure was reported (Beeson et al. 1998; Dockery 2001; Dockery et al. 1993; 
Pope III et al. 2006; Schwartz 1994). Short-term PM exposure is correlated with an increased risk of myocardial infarction a few hours to one day after $\mathrm{PM}_{2.5}$ exposure and long-term $\mathrm{PM}_{2.5}$ exposure is also specifically related to ischemic heart disease, dysrhythmias, heart failure, and cardiac arrest mortality (Peters et al., 2001; Pope et al. 2004). Health effects are more closely associated with $\mathrm{PM}_{2.5}$ than $\mathrm{PM}_{10}$ (Wilson \& Suh, 1997).

Children and elderly sub-populations are more sensitive to health problems from increased PM. Adolescents are particularly at risk for health problems because they require more oxygen per unit of body weight, have higher respiration rates, and spend more time outside when compared to adults. High exposure to PM may impact a child's lung development and trigger asthma attacks (Bateson \& Schwartz, 2008; Gauderman et al., 2004). The elderly population experiences increased respiratory and cardiac mortality and mortality from PM exposure and often have pre-existing respiratory and cardiac health problems (HEI, 1999).

UFPs induce the greatest amount of inflammation per unit mass due to increased particle number, particle chemistry, and high deposition efficiency (Sioutas et al., 2005). Deposition of $\mathrm{PM}$ in the lungs may result in pumonary effects and diseases of other systems including cardiovascualr disease and central nervous system effects. There are three primary pathophysiological mechanisms by which inhaled PM initiate a response. After deposition of PM to respiratory tract surfaces, the first pathway of response results from pulmonary effects. Pulmonary effects stem from pulmonary cell injury and pulmonary inflammation. The local pulmonary inflammatory response can transpire into systemic effects from translocation of particles through the alveolar cell membrane into the vasculature and a cascading inflammatory response (Nurkiewicz et al., 2004).

The second pathway includes particle translocation into the systemic circulation resulting in direct interaction of particles with non-pulmonary tissue (Nurkiewicz et al., 2006; Oberdörster et al. 2004). A systemic response is also initiated by a local inflammatory response and is evident by increased inflammatory factors such as, cytokines, C-reactive proteins, leukocytes (white blood cells), and a state of oxidative stress (Tamagawa et al., 2008). Oxidative stress may result in vascular dysfunction, plaque buildup, atherosclerosis, and increased risk of cardiovascular problems.

The final mechanisms for health effects from deposited UFPs result from stimulation of pulmonary reflexes and neural mechanisms leading to activation of the autonomic nervous 
system. This induces respiration effects including decreased respiration, closure of the glottis and nares, and bronchoconstriction. Cardiovascular effects also result from hypertension or hypotension, increased heart rate and heart rate variability (Nurkiewicz et al., 2006; Pope and Dockery, 2006; Sorensen et al., 2003).

This study focuses particularly on the cardiovascular health outcomes associated with PM exposure. MTM areas in West Virginia have greater documented health problems, including cardiovascular health outcomes (Esch \& Hendryx, 2011; Hendryx \& Zullig, 2009). A toxicological analysis of PM from a West Virginia site in proximity to MTM examined microvascular reactivity after exposure to PM. Particles were extracted from a collection filter and intratracheally instilled in rats. Exposure to PM from MTM areas altered microvascular function in mesenteric and coronary arterioles including decreased endothelium-dependent dilation (Knuckles et al., 2013).

\subsection{Current Gap in the Literature}

People who live in Appalachian areas where coal mining is prominent experience vast health disparities compared to people in non-mining Appalachian areas (Ahern et al., 2011; Esch and Hendryx, 2011; Hendryx, 2009; Hendryx and Ahern, 2008; Hendryx et al., 2011; Hendryx and Zullig, 2009). Coal mining and coal mining activities emit particulate matter to surrounding areas. Associations were reported between increased $\mathrm{PM}_{10}$ and $\mathrm{PM}_{2.5}$ mass and excess hospital admissions, morbidity, and mortality for cardiovascular health effects (Dockery et al., 1993; Dockery, 2001; Dominici et al. 2006; Peters et al. 2001; Pope and Dockery 2006; Schwartz 1994). UFP induce more inflammation per unit mass and epidemiological studies link respiratory health effects, decreased peak expiratory flow, and cardiovascular mortality to UFP exposure (Sioutas et al., 2005). While the link between PM and health risk has been detailed by many epidemiology and toxicology reports, there is a gap in research regarding the characteristics of PM in the vicinity of rural West Virginia areas with MTM activity and its potential health risks. Furthermore, there is a discrepancy between the instrumentation currently used as the standard to measure health effects from PM and what is known about PM respiratory deposition.

Identifying the PM size distributions to determine respiratory dose, elemental composition of particles, and environmental dry deposition around MTM areas is necessary to 
characterize PM in areas with MTM. A significant barrier to progress in the field of PM dose assessment is using partially size-classified mass measures of $\mathrm{PM}_{10}$ and $\mathrm{PM}_{2.5}$ to assess respiratory dose in humans. Obtaining particle size distributions that include coarse, fine, and UFPs to estimate respiratory dose in MTM areas and comparable non-mining areas will provide a more direct method of studying the association between PM and disease compared to ecological methods used in the past (Hinds, 1999).

\subsection{Purpose of the Current Research}

The purpose of this project was to assess the potential health hazard of PM by characterizing atmospheric PM in mining and non-mining areas. The primary objective was to identify mass-based and number-based size distributions to determine inhaled deposited dose, mass and number concentrations, elemental composition of PM mass concentration samples, and environmental dry deposition of atmospheric PM in select MTM and non-mining areas of southern West Virginia with known health differences (Table 1). Fulfilling this objective will distinguish PM in select mining and non-mining areas in southern West Virginia with known health differences and determine the inhaled dose that residents of high disease rate areas receive to better associate PM and health outcomes. Obtaining measures of respiratory dose will extend exposure assessment literature. Conclusions from this project may impact widespread efforts to address and improve air quality in MTM areas and advance the health of people living in MTM areas. This study identifies which particle characteristics are correlated with areas of poor health but does not directly associate PM with health risk. 
Table 1 Summary of determined aerosol characteristics.

\begin{tabular}{|c|c|}
\hline Parameter & Method of Measurement \\
\hline TSP Mass Concentration & $\begin{array}{l}\text { Gravimetric analysis using } 37 \mathrm{~mm} \text { PTFE coated filters connected to } \\
\text { low-volume pumps. }\end{array}$ \\
\hline $\mathrm{PM}_{10}$ and $\mathrm{PM}_{2.5}$ & $\begin{array}{l}\text { Apply the percent of mass in the } \mathrm{PM}_{10} \text { APS size distribution to the } \\
\text { TSP mass concentration sample to estimate the } \mathrm{PM}_{10} \text { in the TSP } \\
\text { sample. Apply the percent of mass in the } \mathrm{PM}_{2.5} \text { APS size distribution } \\
\text { to the TSP mass concentration sample to estimate the } \mathrm{PM}_{2.5} \text { in the } \\
\text { TSP sample. }\end{array}$ \\
\hline $\begin{array}{l}\text { Number Concentration (count) } \\
0.01-0.4 \mu \mathrm{m}\end{array}$ & Total number reported by the SMPS for particles $0.01-0.4 \mu \mathrm{m}$. \\
\hline $\begin{array}{l}\text { Deposited Fraction (\%) } \\
\text { determined by mass-based } \\
\text { particle size distribution }\end{array}$ & $\begin{array}{l}\text { APS mass-based particle size distributions for particles } 0.5-20 \mu \mathrm{m} \\
\text { was used to estimate deposition using modeling. }\end{array}$ \\
\hline $\begin{array}{l}\text { Deposited Fraction (\%) } \\
\text { determined by number-based } \\
\text { particle size distribution }\end{array}$ & $\begin{array}{l}\text { SMPS number-based particle size distributions for particles } 0.01-0.4 \\
\mu \mathrm{m} \text { was used to estimate deposition using modeling. }\end{array}$ \\
\hline Elemental analysis of PM & $\begin{array}{l}\text { SEM-EDX analysis of PM collected on 37mm PTFE coated filters } \\
(\mathrm{PM}>1 \mu \mathrm{m}) \text {. }\end{array}$ \\
\hline Environmental dry deposition & Flux measures and ICP-MS analysis of dry deposited PM. \\
\hline
\end{tabular}

The two MTM areas included in this study were located in Boone County and Raleigh County, WV. Raleigh County had 13 surface mines (5.7\% of total state surface mines) and 18 underground mines (8\%) in 2011 and contributed 6.5\% of coal to total coal production in West Virginia. In 2011, July and the months of September through December were the lowest coal production months. The tonnage produced ranged from 500,000 to 1,000,000 during the year. Boone County had 31 surface mines (13.5\% of total state surface mines) and 68 underground mines (24.3\%) in 2011 and contributed the highest percent (15\%) to the total coal production in the state. The months of October through December were the lowest coal production months in Boone County (WV MHS\&T, 2012). It is estimated that majority of the coal mined at the surface mining sites was done by MTM production methods as MTM contributed to $66 \%$ of the coal produced by surface mining methods (WV MHS\&T, 2012). The non-mining county under study, Pocahontas County, was located in eastern West Virginia and had no coal mining.

Three specific aims are presented to address the current gaps in knowledge on PM characterization at MTM areas of southern West Virginia. The studies corresponding to the three aims use primary data analysis of quantitative and semi-quantitative data. The aim of the first study addressed in Chapters 2 and 3 was to determine particle size distribution and 
concentration to calculate deposited lung dose at MTM and non-mining sites. Two sub-aims of this project were conducted to 1) evaluate the variability in particle size distribution and concentration measurements within sampling areas and 2) examine seasonal variability in particle size distribution and concentration within and between MTM and non-mining areas. Measures of penetration and measures of respiratory deposition based on size distributions were compared for their ability to distinguish between the MTM and non-mining areas. The research hypotheses were 1) mass and number concentrations were greater at MTM areas and highest during the summer season and 2) MTM areas have elevated estimates of respiratory dose compared to non-mining areas. Results showed the MTM areas had significantly higher number concentrations and deposited number concentrations than the non-mining area.

The specific aim of the second study, described in Chapter 4, was to identify the most abundant elements contributing to collected TSP samples at MTM and non-mining sites using individual particle analysis. Chemical compositions of PM samples from a scanning electron microscope combined with an Energy Dispersive X-ray Spectrometer were compared across seasons and between MTM and non-MTM sites. The research hypotheses were 1) the elemental crustal and anthropogenic element concentrations were higher at the MTM sites relative to the non-mining site and 2) MTM summer samples contained elevated concentrations of elements relative to the MTM samples from other seasons during the year. MTM sites contained elevated concentrations of crustal elements, but only small amounts of anthropogenic elements were detected using this method of particle analysis. Significant differences between elemental concentrations by season were not present.

The study in Chapter 5 aimed to quantify environmental dry deposition for inorganic materials at mining and non-mining sites. Environmental dry deposition of total suspended particles was investigated to determine contributions of contaminates to the environment from coal-related activities and also represent surface contamination. The research hypotheses were 1) mining sites contain elevated concentrations of inorganic materials relative to non-mining sites and 2) trace element concentrations were elevated among mining summer samples relative to other seasons. Mining sites had elevated flux estimates and elevated concentrations of both crustal and anthropogenic inorganic materials. 


\section{References}

Anderson ZJ, Wahlin P, Raaschou-Nielsen O, Ketzel M, Scheike T, Loft S. Size distribution and total number concentration of ultrafine and accumulation mode particles and hospital admissinos in children and the elderly in Copenhagen, Denmark. Occup Envion Med. 2008;65:458-466.

ARC (Appalchain Regional Commission). Appalachian Regional Comission Homepage. 2009. Available at: http://www.arc.gov. Accessed 9 July 2012.

Ahern MM, Hendryx M, Conley J, Fedorko E, Ducatman A, Zullig KJ. The association between mountaintop mining and birth defects among live births in central Appalachia, 19962003. Environ Res. 2011;111(6):838-846.

Ayers H, Boyer J, Feeney P et al. Appalachian coalfield delegration position paper on sustainable energy. In: Proceedings of the United Nations Commission on Sustainable Development 15th Session, 30 April-11 May 2007, New York. 2007. Available at: http://www.datacenter.org/reports/csdpositionpaper.pdf. Accessed 20 December 2011.

Bateson TF, Schwartz J. Children's response to air pollutants. Journal of Toxicology and Environmental Health Part A. 2008;71(3): 238-243.

Beeson WL, Abbey DE, Knutsen SF. Long-term concentrations of ambient air pollutants and incident lung cancer in California adults: results from the AHSMOG study. Adventist Health Study on Smog.Environ Health Perspect. 1998;106(12): 813-822.

Behringer B, Friedell G. Appalachia: where place matters in health. Prev Chronic Dis. 2006;3(4):A113.

Chapman RS, Watkinson WP, Dreher KL, Costa DL. Ambient particulate matter and respiratory and cardiovascular illness in adults: particle-borne transition metals and the heart-lung axis. Environ Toxicol Pharmacol. 1997;4(3-4):331-338.

Chen Y, Yang Q, Krewski D, Shi Y, Burnett RT, McGrail K. Influence of relatively low level of particulate air pollution on hospitalization for COPD in elderly people. Inhal Toxicol. 2004;16(1):21-25.

Dockery DW. Epidemiologic evidence of cardiovascular effects of particulate air pollution. Environ Health Perspect. 2001;109 Suppl 4:483-486.

Dockery DW, Pope CA 3rd, Xu X, et al. An association between air pollution and mortality in six U.S. cities. N Eng J Med. 1993;329(24):1753-1759.

Dominici F, Peng RD, Bell ML et al. Fine particulate air pollution and hospital admission for cardiovascular and respiratory diseases. JAMA. 2006;295(10):1127-1134. 
Donaldson K, Stone V, Clouter A, Renwick L, MacNee W. Ultrafine particles. Occup Environ Med. 2001;58:211-216.

Esch L, Hendryx M. Chronic cardiovascular disease mortality in mountaintop mining areas of central Appalachian states. J Rural Health. 2011;27(4):350-357.

Gauderman WJ, Avol E, Gilliland F et al. The effect of air pollution on lung development from 10 to 18 years of age. $N$ Eng J Med. 2004;351(11):1057-1067.

Geredien R. Post-Mountaintop Removal Reclamation of Mountain Summits for Economic Development in Appalachia. New York: Natural Resources Defense Council. 2009. Available: http://tinyurl.com/3rv4kco. Accessed 31 October 2011.

Halverson J, Ma L, Harner E. An analysis of disparities in health status and access to care in the Appalachian region. The Appalachian Regional Commission. 2004. Available: http://www.arc.gov/assets/research_reports/AnalysisofHealthDisparitiesIntroductionExec utiveSummary.pdf. Accessed 15 February 2011.

HEI (Health Effects Institute). Diesel emissions and lung cancer: Epidemiology and Quantitative Risk Assessment, Special Report of the Institute’s Diesel Epidemiology Expert Panel, June 1999. 1999.

Hendryx M. Poverty and mortality disparities in central Appalachia:mountaintop mining and environmental justice. Journal of Health Disparities Research and Practice. 2011;4(3): 44-53.

Hendryx M. Mortality from heart, respiratory, and kidney disease in coal mining areas of Appalachia. Int Arch Occup Environ Health. 2009;82:243-249.

Hendryx M, Ahern MM. Relations between health indicators and residential proximity to coal mining in West Virginia. Am J Public Health. 2008;98(4):669-671.

Hendryx M, Pomeroy J, Balistreri M. Air quality in mining and non mining areas of West Virginia, April to June 2008. Sludge Safety. 6 January. 2009. Available at: http://www.sludgesafety.org/health/Air_Quality_April-June_2008.pdf. Accessed 21 October 2011.

Hendryx M, Wolfe L, Luo J, Webb B. Self-reported cancer rates in two rural areas of West Virginia with and without mountaintop coal mining. J Community Health. 2011;37(2):320-327.

Hendryx M, Zullig KJ. Higher coronary heart disease and heart attack morbidity in Appalachian coal mining regions. Prev Med. 2009;49:5.

Hinds WC. Aerosol Technology: Properties, Behavior, and Measurement of Airborne Particles. Vol 2. New York: John Wiley \& Sons, Inc.; 1999. 
Hitt NP, Hendryx MS. Ecological integrity of streams related to human cancer mortality rates. EcoHealth. 2010;7(1):91-104.

KET (Kentucky Educational Television). 27 Coal-Mining States. 2005.Available at:http://www.ket.org/trips/coal/agsmm/agsmmwhere.html. Accessed 14 August 2012.

Kirk E, Maggard R. Long-term downstream impacts of surface mining and valley fill construction to benthic macroinvertebrate and water quality. In: Proceedings of the fourth National Meeting of the American Society of Mining and Reclamation, 18-24 April 2004, Lexington, KY, 1095-1120. 2004. Available at: http://www.asmr.us/Publications/Conference \%20Proceedings/2004/1095Kirk\%20WV.pdf. Accessed 12 May 2012.

Kolker A, Engle M, Orem W et al. Atmospheric particulate matter in proximity to mountaintop coal mines. In: Proceedings of the VM Goldschmidt Conference, June 24-29, 2012. 2012. Montreal.

Knuckles TL, Stapleton PA, Minarchick VC et al. Air pollution particulate matter collected from an Appalachian mountaintop mining site induces microvascular dysfunction. Microcirculation. 2013;20(2):158-169.

Lin M, Chen Y, Burnett RT, Villeneuve PJ, Krewski D. The influence of ambient coarse particulate matter on asthma hospitalization in children: case-crossover and time-series analyses. Environ Health Perspect. 2002;110(6):575-581.

Lin M, Chen Y, Burnett RT, Villeneuve PJ, Krewski D. Effect of short-term exposure to gaseous pollution on asthma hospitalisation in children: a bi-directional case-crossover analysis. $J$ Epidemiol Community Health, 2003;57(1):50-55.

Lin M, Chen Y, Villeneuve PJ et al. Gaseous air pollutants and asthma hospitalization of children with low household income in Vancouver, British Columbia, Canada. Am J Epidemiol. 2004;159(3):294-303.

Lindberg TT, Bernhardt ES, Bier R, Helton AM, Merola RB, et al. Cumulative impacts of mountaintop mining on an Appalachian watershed. PNAS. 2011;108(52):20929-20934.

Lippmann M, Yeates D, Albert R. Deposition, retention, and clearance of inhaled particles. $\mathrm{Br} J$ Ind Med. 1980;37(4):337-362.

Mastin JP. Environmental cardiovascular disease. Cardiovasc Toxicol. 2005;5(2):91-94.

Mazzarella G, Ferraraccio F, Prati MV, et al. Effects of diesel exhaust particles on human lung epithelial cells: an in vitro study. Respiratory Medicine. 2007;101(6):1155-1162. 
McQuaid, J. Mountaintop Mining Legacy: Destroying Appalachian Streams. Yale Environment 360. 2009.Available:

http://e360.yale.edu/feature/mountaintop_mining_legacy_destroying_appalachian_stream s/2172/. Accessed 13 March 2012.

MSHA (Mine Safety and Health Administration). Effects of Blasting on Air Quality. Arlington, VA: U.S. Department of Labor. 2010. Available at: http://www.msha.gov/illness prevention/healthtopica/blasting.htm. Accessed 31 October 2011.

Nurkiewicz TR, Porter DW, Barger M, et al.Systemic microvascular dysfunciton and inflammation after pulmonary particulate matter exposure. Environ Health Perspect. 2006;114(3):412-419.

Oberdörster G, Sharp Z, Elder AP, Gelein R, Kreyling W, Cox C. Translocation of ultrafine particles to the brain. Inhal Toxicol. 2004;16:437-445.

Peters A, Dockery DW, Muller JE, Mittleman MA. Increased particulate air pollution and the triggering of myocardial infarction. Circulation. 2001;103(23):2810-2815.

Pond G, Passmore M, Borsuk F, Reynolds L, Rose C. Downstream effects of mountaintop coal mining: comparing biological conditions using family-and genus-level macroinvertebrate bioassessment tools. Journal of North American Benthological Society. 2008;27(3):717737.

Pope CA 3rd, Dockery DW. Health effects of fine particulate air pollution:lines that connect. $J$ Air \& Waste Manage Assoc. 2006;56:709-742.

Pope CA III, Burnett RT, Thurston GD et al. Cardiovascular mortality and long-term exposure to particulate air pollution: epidemiological evidence of general pathophysiological pathways of disease. Circulation. 2004;109:71-77.

Pope CA 3rd, Burnett RT, Thun MJ et al. Lung cancer, cardiopulmonary mortality, and longterm exposure to fine particulate air pollution. JAMA. 2002;287(9):1132-1141.

Schwartz J. What are people dying of on high air pollution days? Environ Research. 1994; 64(1):26-35.

Sioutas C, Delfino RJ, Singh M. Exposure assessment for atmospheric ultrafine particles (UFPs) and implications in epidemiologic research. Environ Health Perspect. 2005;113:947-955.

Sorensen M, Daneshvar B, Hansen M et al. Personal PM2.5 exposure markers of oxidative stress in blood. Environ Health Perspect. 2003;111(2):161-166.

Stearns R. Mountaintop Removal Mining. Furman Confluence. 2010. Available at: https://confluence.furman.edu:8443/display/GGY230F10/Surface Mining2. Accessed 9 June 2012. 
Tamagawa E, Bai N, Morimoto K et al. Particulate matter exposure induces persistent lung inflammation and endothelial dysfunction. Am J Physiol Lung Cell Mol Physiol. 2008;295:L79-L85.

U.S. EIA (Energy Information Administration). Coal Production and Number of Mines by State and Mine Type, 2008-2007. 2009. Available at: http://www.eia.doe.gov/cneaf/coal/page/acr/table1.html. Accessed June 9, 2010.

U.S. EPA (Environmental Protection Agency). EPA Issues Comprehensive Guidance to protect Appalachian communities from harmful environmental impacts of mountaintop mining. 2010. Available at: http://yosemite.epa.gov/opa/admpress.nsf/e77fdd4f5afd88a3852576b3005a604f /4145c96189a17239852576f8005867bd!OpenDocument. Accessed 8 August 2011.

U.S. EPA (Environmental Protection Agency). Particulate Matter (PM). 2012. Available at: http://www.epa.gov/pm/index.html. Accessed 19 December 2011.

Wilson WE, Suh HH. Fine and coarse particles:concentration relationships relevant to epidemiological studies. J Air \& Waste Manage Assoc. 1997;47:1238-1249.

Wood LE. Trends in national and regional economic distress:1960-2000.The Appalachian Regional Commission. 2005. Available at: http://www.arc.gov/assets/research reports/TrendsinNationalandRegionalEconomicDistr ess1960to2000.pdf. Accessed 11 February 2011.

WV MHS\&T (West Virginia Office of Miners’ Health Safety and Training).2011 Calendar Year Statistical Report. 2012. Available: http://www.wvminesafety.org/2011statisticalreport.htm. Accessed 22 September 2012.

Xia T, Li N, Nel AE. Potential health impacts of nanoparticles. Annu Rev Public Health.2008;20:137-150.

Yang Q, Chen Y, Shi Y, Burnett RT, McGrail KM, Krewski D. Association between ozone and respiratory admissions among children and the elderly in Vancouver, Canada. Inhal Toxicol. 2003;15(13):1297-1308.

Zullig KJ, Hendryx M. Health-related quality of life among central Appalachian residents in mountaintop mining counties. Am J Public Health. 2011;101(5):848-853. 


\section{Chapter 2}

Particle Size Distribution and Concentration in West Virginia Areas with Health Disparities 


\subsection{Introduction}

Atmospheric particulate matter (PM) comes directly from natural and anthropogenic sources and indirectly from chemical reactions converting atmospheric PM into secondary PM (Hinds, 1999). Exposure to increased PM mass is associated with excess respiratory and cardiovascular morbidity and mortality (Pope \& Dockery, 2006). PM is typically monitored with $\mathrm{PM}_{10}$ and $\mathrm{PM}_{2.5}$ mass-based, size-classified measures of exposure (U.S. EPA, 2012). PM 10 and $\mathrm{PM}_{2.5}$ measure respiratory exposure or penetration and quantify the capability of a particle to reach the lungs but not necessarily deposit in the lungs. Particle respiratory deposition (dose) is distinct from exposure because it refers to the proportion of particles that collide with and adhere to internal lung surfaces. Respiratory deposition occurs through a variety of mechanisms and is dependent on respiratory tract characteristics and particle size and shape (Lippmann et al., 1980). Dose is critical to quantify when examining a dose-response relationship because the deposited particles will generate a pathophysiological response. Particles deposit in the lung alveoli or penetrate lung epithelial cells to enter the vasculature and stimulate inflammation and oxidative stress leading to microvascular dysfunction and cardiovascular effects (Hogg \& van Eeden, 2009). However, many dose-response epidemiological studies associating PM and health indirectly measure $\mathrm{PM}$ dose with $\mathrm{PM}_{10}$ and $\mathrm{PM}_{2.5}$ mass exposure measures.

Particle size distributions that include ultrafine particles (UFPs) are stronger indicators of dose compared to mass-based, partially size-classified $\mathrm{PM}_{10}$ and $\mathrm{PM}_{2.5}$ measures (Anderson et al., 2008; Donaldson et al., 2001). UFP have a greater surface area per unit mass and higher number concentration and alveolar deposition efficiency than larger particles resulting in greater inflammation capabilities (Donaldson et al., 2001; Kim \& Jaques, 2004; Oberdorster et al., 2005; Sioutas et al., 2005). As a result, contaminants carried on the surface of UFP are delivered to the body at a higher dose increasing health risk. Delivery of equal mass of UFP and larger PM results in more bronchoalveolar inflammation with UFP than with larger PM generating increased inflammatory effects (Donaldson et al., 2001).

This study utilized mass-based and number-based particle size distributions to calculate deposited lung dose in two residential areas of rural West Virginia known to have relatively higher and lower disease rates. Coal mining, including mountaintop mining (MTM), is prominent in the higher disease rate area and no mining occurs in the lower disease rate area. (The MTM method uses explosives and excavation equipment to remove vegetation, rock, and 
dirt from mountaintops to expose coal seams (U.S. EPA, 2010).) Prior studies have characterized health outcome differences between higher disease rate MTM areas and lower disease rate non-mining areas. Age-adjusted total mortality rates in MTM areas are significantly greater compared to non-mining areas in central Appalachian states (Hendryx, 2011). Residents of MTM areas had an increased prevalence ratio for congenital anomaly births (1.26, 95\% CI=1.21-1.32) compared to other Appalachian coal mining areas (Ahern et al., 2011). Ageadjusted chronic cardiovascular rates were greater in MTM Appalachian counties compared to non-mining Appalachian counties $(\beta=24.7, \mathrm{SE}=9.3, \mathrm{p}<0.009)$ (Esch \& Hendryx, 2011). Those living in MTM areas under study were two times as likely to report having cancer compared to those living in a non-mining areas (Hendryx et al., 2011).

\subsection{Methods}

\subsubsection{Sampling Sites}

Sampling was conducted at nine sites within three rural residential areas of West Virginia during June 2011. Six sites were located in the higher disease rate area and were spaced throughout valleys in two adjacent counties (Raleigh County and Boone County) where active MTM and other types of coal mining activity (rail and truck transportation, underground mines, and processing facilities), were prominent. During the sampling period, some of the sites had more active MTM activity than others as evident by visual and audible excavation equipment operations, explosive blasting, and falling rock and gravel. Three non-mining sites were located in eastern West Virginia in Pocahontas County where disease rates were lower and the majority of the county is federal or state owned land (WV Department of Tourism, 2006). Figure 5 illustrates the locations of the sampling sites within each area.

The sampling sites labelled A, B, and C (Figure 5) were located in Raleigh County in southern WV. Raleigh County had 13 surface mines (5.7\% of total state surface mines) and 23 underground mines (8\% of total state underground mines) in 2011 and contributed 6.5\% to total coal production in West Virginia that year. Sites A and B were located about one mile apart within the same valley. These sites were located off a main, two-lane road with heavier traffic, including coal trucks. At the time of sampling, site A was farthest from active mining, but 


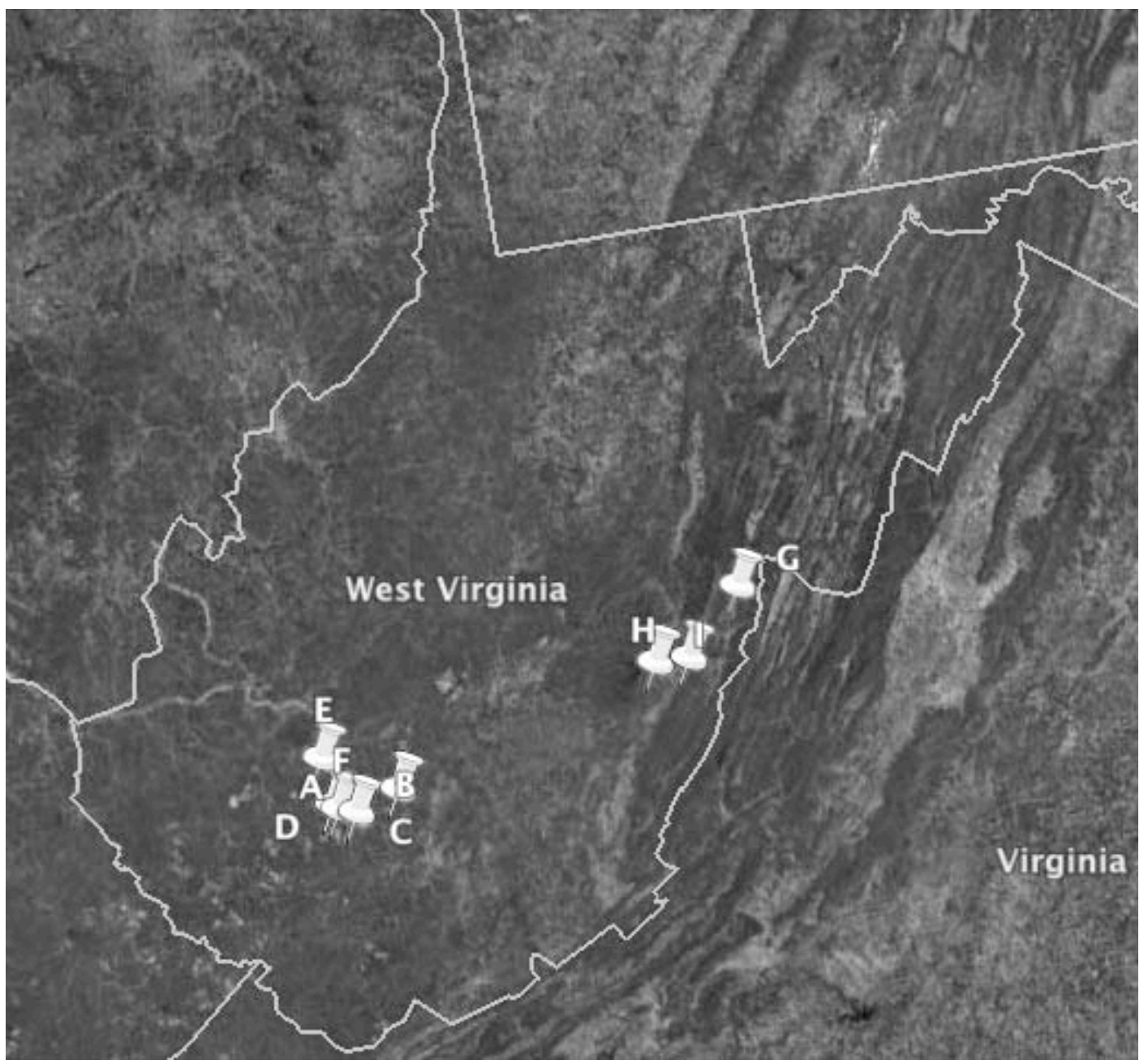

Figure 5 Sampling site locations. Sites A, B, and C in Raleigh County, Sites D, E, and F in Boone County, and Sites G, H, and I in Pocahontas County.

MTM sites were directly to the northwest and southwest and a smaller site to the northeast. Site C was about 23 miles away from sites A and B in an adjacent valley in Raleigh County. A large MTM site extended to the east of Site C, which was located in an area with about ten other residential homes a greater distance off the main state road compared to sites A and B. This site was estimated to be closest of all MTM sites to an active MTM area during the sampling period based on gravel falling onto the roof of a home, observations of heavy equipment activity, and reports from residents of blasting occurring during the sampling period.

Sampling sites D, E, and F were located in Boone County, WV, an adjacent county to Raleigh. In 2011, Boone County had 31 surface mines (13.5\% of total state surface mines) and 68 underground mines (24.3\%) and contributed the highest percent of all counties (15\%) to the total state coal production. Sites D and F were in the same valley approximately 2 miles apart. 
Site $\mathrm{F}$ was located in the yard of a residence in a less inhabited part of the valley where traffic was very calm and was southeast of Site D. A large MTM site was located east, above the valley, and mining activity also occurred on the mountaintops to the west of the valley. Site E was in a valley about 23 miles to the north in Seth-Prenter, WV. Traffic on the nearby road was similar to that seen in sites A and B, and a MTM site was west of Site E.

Sites G, H, and I were located in Pocahontas County, WV. The northern most sampling site of the non-mining area was Site G, which was at the library in Green Bank, WV away from the main residential area of the town and next to a school. Site H was in the yard of a resident living approximately 1.5 miles east of Marlinton (population 1,204) in a residential area. Site I was in an open location surrounded by agricultural fields and working farms about 0.3 miles from the downtown of Hillsboro (population 243).

Table 2 Summary of site characteristics.

\begin{tabular}{|c|c|c|c|c|c|}
\hline Site & Town & Latitude & Longitude & $\begin{array}{l}\text { Elevation } \\
\text { (m) }\end{array}$ & $\begin{array}{c}\text { Distance to } \\
\text { State Road* } \\
\text { (m) }\end{array}$ \\
\hline A & Naoma & 3753’0.4” N & $81^{\circ} 32^{\prime} 2.5^{\prime \prime} \mathrm{W}$ & 303 & 150 \\
\hline B & Naoma & $37^{\circ} 53^{\prime} 27^{\prime \prime} \mathrm{N}$ & $81^{\circ} 31^{\prime} 55^{\prime \prime} \mathrm{W}$ & 288 & 20 \\
\hline $\mathrm{C}$ & Artie & $37^{\circ} 56^{\prime} 43^{\prime \prime} \mathrm{N}$ & $81^{\circ} 20^{\prime} 46^{\prime \prime} \mathrm{W}$ & 436 & 1,859 \\
\hline $\mathrm{D}$ & Twilight & $37^{\circ} 55^{\prime} 31^{\prime \prime} \mathrm{N}$ & $81^{\circ} 37^{\prime} 25^{\prime \prime} \mathrm{W}$ & 333 & 143 \\
\hline $\mathrm{E}$ & Seth-Prenter & $38^{\circ} 05^{\prime} 5^{\prime \prime} \mathrm{N}$ & $81^{\circ} 38^{\prime} 30^{\prime \prime} \mathrm{W}$ & 224 & 50 \\
\hline $\mathrm{F}$ & Lindytown & $37^{\circ} 54^{\prime} 36^{\prime \prime} \mathrm{N}$ & 81³6’8” W & 354 & 100 \\
\hline G & Green Bank & $38^{\circ} 25^{\prime} 27^{\prime \prime} \mathrm{N}$ & $79^{\circ} 49^{\prime} 43^{\prime \prime} \mathrm{W}$ & 821 & 125 \\
\hline $\mathrm{H}$ & Marlinton & $38^{\circ} 13^{\prime} 4^{\prime \prime} \mathrm{N}$ & $80^{\circ} 4^{\prime} 37^{\prime \prime} \mathrm{W}$ & 707 & 450 \\
\hline I & Hillsboro & $38^{\circ} 8^{\prime} 17^{\prime \prime} \mathrm{N}$ & 80¹3’2” W & 704 & 110 \\
\hline
\end{tabular}

*Distance from State Road refers to the distance from the site to the nearest main road.

\subsubsection{Instrumentation}

Brief sampling for mass concentration, particle size distribution, and number concentration were performed at each site. Total suspended particle (TSP) mass concentration measurements $\left(\mathrm{mg} / \mathrm{m}^{3}\right)$ were obtained at each site for a continuous period of 25-32 hours using two different mass concentration sampling techniques. The first technique involved collecting 
particles on polytetrafluoroethylene (PTFE) coated glass fiber filters (37mm diameter 5.0 $\mu \mathrm{m}$ pore-size, SKC Inc, Eighty Four, PA) for gravimetric measurement. A PTFE filter was placed in a two-piece plastic filter cassette on top of a support pad, to prevent filter fibers from rupturing. Cassette pieces were sealed together with tape to eliminate particles from leaking into the cassette or bypassing the filter. The sealed cassette was connected to low volume vacuum pump (Model 1531-1078-G288x, Gast Manufacturing Inc., Benton Harbor, MI).

TSP mass was calculated gravimetrically from the change in pre- and post-experiment filter weight, volume of air passing through the filter, and sampling time. Each filter was equilibrated for 24 hours at constant relative temperature and humidity before pre-weighing. The change in filter weight was calculated by dividing the difference in the pre- and post-experiment filter weight by the average volume of air during sampling. The volume of air sampled was calculated by averaging the sampling period start and end pump flow rates (overall average flow rate of $22.7 \mathrm{~L} / \mathrm{min}$ ). The average sampling time was approximately 29 hours. Field blanks were prepared in the same manner to check the precision of the weighing method resulting in an average error of $0.00075 \mathrm{mg}$.

The second mass measurement was taken with a DustTrak II DRX Aerosol Monitor 8530 (TSI, Shoreview, MN) to record the near real-time mass concentration per minute and was run simultaneously with the PTFE filter. The DustTrak served to check the accuracy of the TSP gravimetric mass concentration measurements. The DustTrak is reported to overestimate filterbased samplers by a factor of three, which was consistent with our filter to DustTrak ratio of 0.25-0.41 (Chung et al., 2001).

Particle size distributions were determined with two near-real time instruments to obtain size distributions for two particle size ranges. The Aerodynamic Particle Sizer (APS) (TSI, Shoreview, MN) measured size-classified, mass concentrations for 52 size categories based on the aerodynamic diameter of particles 0.5-20 $\mu \mathrm{m}$. The Scanning Mobility Particle Sizer (SMPS) included both an Electrostatic Classifier (EC) and Condensation Particle Counter (CPC) to size particles 0.01-0.4 $\mu \mathrm{m}$ into 105 size categories based on particle number. The EC sized and separated particles based on their electrical mobility before they were counted in the CPC since particles $<0.5 \mu \mathrm{m}$ are best measured with the thermodynamic equivalent diameter. Total number concentration for particles 0.01-0.4 $\mu \mathrm{m}$ was also determined with the SMPS. The SMPS was 
equipped with an X-ray aerosol neutralizer as opposed to krypton neutralizer making it suitable for fieldwork.

The APS and SMPS were transported to each site three times during the 25-32 hour sampling period. The instruments were run on two separate occasions during the daytime and one time at night. At each site visit, the APS recorded mass-based size distributions for two, tenminute sampling sessions and the SMPS recorded number-based size distributions for three to eight, two minute 15 second sessions.

Quality control checks were performed prior to and after taking the APS and SMPS equipment into the field to ensure accurate measurements. Methods to ensure quality of data included operating the SMPS used for this field study alongside a SMPS unit that was kept in a laboratory setting. No difference was observed between the two SMPS units when running them side-by-side before and after the field sampling.

Currently, the EPA does not have a State and Local Air Monitoring Station set up in the Pocahontas area to conduct $\mathrm{PM}_{10}$ and $\mathrm{PM}_{2.5}$ ambient air monitoring (WV DEP, 2012). A PM 2.5 monitor is operating in Raleigh County but it is located in the county's major population centre and distant from MTM activity. Therefore, we obtained our own estimates of $\mathrm{PM}_{10}$ and $\mathrm{PM}_{2.5}$ at each site visit using gravimetric measurements and APS size distributions.

\subsubsection{Respiratory Deposition Calculations}

Mass-based and number-based size distributions were used to estimate deposited respiratory dose to adult humans. Total respiratory deposition was calculated with a mathematical model based on the International Commission on Radiation Protection standards and formulas from Stahlhofen et al. (1989) that was fit to the particle size distributions. The model was developed with human exposure data to calculate total (nasal, extrathoracic region, tracheobronchial region, and alveolar region) deposition efficiency values based on particle size distributions accounting for regional respiratory parameters (Stahlhofen et al., 1989). The arithmetic mass-based size distributions from the APS and number-based particle size distributions from the SMPS were converted to lognormal distributions for empirical purposes. The fraction of PM in a particle size range was multiplied by the deposition fraction for each region to yield a regional deposited dose for that particular size range (Stahlhofen et al., 1989). Deposition in a region is affected by deposition in the preceding regions and total deposition is 
deduced by accounting for deposition in all regions. After integrating the geometric means and standard deviations for all lung regions, total lung was determined for 50\% oral and 50\% nasal breathing with the parameters: $Q$ (volumetric flow rate) $=116.7 \mathrm{~cm}^{3} / \mathrm{sec}, \mathrm{V}=500 \mathrm{~cm}^{3}, \mathrm{FRC}=3,300$ $\mathrm{cm}^{3}, \mathrm{f}=7$ breaths per minute, and a standard particle density of 1 . The deposited percent measurement is unique because it converts a size distribution with multiple means and standard deviations (due to a polydisperse sample) to a single number, which has utility for comparing size distributions across sites.

The equations presented are simplified from Stahlhofen et al (1989) by Hind (1999).

$\mathrm{d}_{\mathrm{p}}=$ particle diameter

$\mathrm{IF}=$ inhalable fraction, where:

$\mathrm{IF}=1-0.5\left[1-\left(1 /\left(1+0.00075 d_{p}^{2.8}\right)\right)\right]$

The deposition fraction for the head airways $\mathrm{DF}_{\mathrm{H}}$ is:

$\mathrm{DF}_{\mathrm{H}}=\mathrm{IF}\left[1 /\left(1+\exp \left(6.84+1.183 \ln \mathrm{d}_{\mathrm{p}}\right)\right)+1 /\left(1+\exp \left(0.924-1.885 \ln \mathrm{d}_{\mathrm{p}}\right)\right)\right]$

The deposition fraction for the tracheobronchial region $\mathrm{DF}_{\mathrm{TB}}$ is:

$\mathrm{DF}_{\mathrm{TB}}=\left(0.00352 / \mathrm{d}_{\mathrm{p}}\right)\left[\exp \left(-0.234\left(\ln \mathrm{d}_{\mathrm{p}}+3.4\right)^{2}\right)+63.9 \exp \left(-0.819\left(\ln \mathrm{d}_{\mathrm{p}}-1.61\right)^{2}\right)\right]$

The deposition fraction for the alveolar region $\mathrm{DF}_{\mathrm{A}}$ is:

$D_{A}=\left(0.0155 / d_{p}\right)\left[\exp \left(-0.416\left(\ln d_{p}+2.84\right)^{2}\right)+19.11 \exp \left(-0.482\left(\ln d_{p}-1.362\right)^{2}\right)\right]$

The total deposition, DF is the sum of all regions depositions or:

$\mathrm{DF}=\mathrm{IF}\left[0.0587+\left(0.911 /\left(1+\exp \left(4.77+1.485 \ln \mathrm{d}_{\mathrm{p}}\right)\right)\right)+(0.943 /(1+\exp (0.508-2.58\right.$ $\left.\left.\left.\ln \mathrm{d}_{\mathrm{p}}\right)\right)\right)$ ]

Two respiratory dose estimates were determined for each site during each sampling period. One estimate was calculated for PM 0.5-20 $\mu \mathrm{m}$ using the APS provided mass-based particle size distributions. The second estimate was calculated for PM 0.01-0.4 $\mu \mathrm{m}$ using the SMPS provided number-based particle size distributions. Dose estimates are presented separately for the 0.5-20 $\mu \mathrm{m}$ and 0.01-0.4 $\mu \mathrm{m}$ size distributions. Multiple particle size distribution readings were collected at each site during each sampling period, so the reported respiratory deposition for a site was calculated by first obtaining a dose for each day and night reading at a site and then finding the arithmetic mean of all site doses. Results were consistent with respiratory deposition measures calculated by fitting a deposition function to the site's overall average size distribution calculated by averaging all individual site size distribution 
readings.

\subsubsection{Analysis}

Summaries of parameters were calculated for each site. Site concentrations were compared with two-sample standardized t-tests. T-tests and the Bonferroni adjusted p-values were reported for multiple comparisons. T-tests for unequal variance were used in some instances. The deposited mass and number is the product of a site's deposition fraction applied to the total mass or particle number for that specific site.

\subsection{Results}

\subsubsection{Meteorology}

Meteorological conditions were reported for each sampling area during the sampling dates due to their influence on particle number (Table 3). Greater average wind speeds were observed around the open non-mining area, with periodic gusts at the MTM areas in Raleigh and Boone Counties. The predominant wind direction during sampling was from the northwest and wind gusts were stronger during the afternoon. There were light gusts of wind throughout the sampling period at the MTM areas from the northwest. Air temperature was lower in Pocahontas County, which was at a higher elevation than the MTM areas. The observed relative humidity during this period fell within the normal monthly range for all counties (NOAA, 2012).

Table 3 Daily meteorological conditions.

\begin{tabular}{cccccc}
\hline County & $\begin{array}{c}\text { Date } \\
\mathbf{2 0 1 1}\end{array}$ & $\begin{array}{c}\text { Average Wind } \\
\text { Speed mph } \\
\text { (max speed) }\end{array}$ & $\begin{array}{c}\text { Average Wind } \\
\text { Direction }\end{array}$ & $\begin{array}{c}\text { Average } \\
\text { Temperature }\end{array}$ & $\begin{array}{c}\text { Relative } \\
\text { Humidity }\end{array}$ \\
\hline Raleigh & 6 June & $<1(4)$ & $\mathrm{NW}$ & $78^{\circ} \mathrm{F}$ & $77 \%$ \\
& 7 June & $<1(12)$ & $\mathrm{NNW}$ & $74^{\circ} \mathrm{F}$ & $77 \%$ \\
Boone & 8 June & $<1(6)$ & $\mathrm{NNW}$ & $78^{\circ} \mathrm{F}$ & $80 \%$ \\
& 9 June & $<1(7)$ & $\mathrm{NW}$ & $80^{\circ} \mathrm{F}$ & $82 \%$ \\
\hline \multirow{2}{*}{ Pocahontas } & 10 June & $7(20)$ & $\mathrm{NWN}$ & $69^{\circ} \mathrm{F}$ & $75 \%$ \\
& 11 June & $6(13)$ & $\mathrm{W}$ & $70^{\circ} \mathrm{F}$ & $79 \%$ \\
\hline
\end{tabular}

\subsubsection{Concentration Comparisons}

TSP, $\mathrm{PM}_{10}$, andPM $\mathrm{M}_{2.5}$ and mass concentration for combined sites within each area (county) and individual sampling sites are presented in Table 4. The average $\mathrm{PM}_{10}$ mass concentration was significantly greater at the Boone area and combined MTM area compared to the Pocahontas non-mining area. $\mathrm{PM}_{10}$ differed significantly as a function of site at the 
Pocahontas area, $F(2,9)=25.56, p=0.0002$. Post-hoc Tukey's HSD tests showed that Site H had significantly lower $\mathrm{PM}_{10}$ than the other two sites at the 0.05 level of significance. There was no difference in TSP mass concentration and $\mathrm{PM}_{2.5}$ between the MTM sites both individually and combined compared to the non-mining area.

The combined MTM areas had significantly greater number concentration of particles 0.01-0.4 $\mu \mathrm{m}$ compared to the non-mining area (Table 5). The number concentration was higher in all individual MTM sites compared to the average number concentration at the Pocahontas area, except at Site D. Within the Raleigh area, Site C had a significantly higher number concentration than the area mean. Number concentration differed significantly as a function of site at the Raleigh area with site $\mathrm{C}$ having a significantly higher number concentration than the other two sites, $\mathrm{F}(2,10)=17.40, \mathrm{p}=0.0006$. Post-hoc Tukey's HSD tests showed that Site H had significantly lower $\mathrm{PM}_{10}$ than the other two sites at the 0.05 level of significance. After applying the respiratory deposition percent to the count of particles 0.01-0.4 $\mu \mathrm{m}$, the deposited count concentration was significantly greater at the Raleigh area and at the Combined MTM area compared to the Pocahontas area. There was a difference within the Raleigh area sites for deposited number $F(2,10)=16.48$, $\mathrm{p}=0.0007$, as Site $\mathrm{C}$ was significantly higher than Sites A and $\mathrm{B}$ at $\mathrm{p}=0.05$, but the Raleigh sites were not significantly different from the Raleigh mean. Site I was significantly greater than the non-mining area mean but was not different from the deposited count at other Pocahontas sites.

The average respiratory deposition percent for PM0.01-0.4 $\mu \mathrm{m}$ varied by area and was higher in Raleigh (33.0\%-37.9\%) compared to Boone (26.3-28.7\%) and Pocahontas (29.2\%31.6\%) counties, but this difference was not statistically significant. Deposited percent differed significantly as a function of site at Boone area, $F(2,8)=11.29, \mathrm{p}=0.0047$, and Pocahontas area, $\mathrm{F}(2,21)=7.60, \mathrm{p}=0.0033$. Site $\mathrm{D}$ had a significantly higher respiratory deposition than the other two sites in the Boone area, and Site I also had a higher deposition percent than the other two non-mining sites in Pocahontas county at the 0.05 level of significance. The average respiratory deposition coefficients and modes for particles 0.01-0.4 $\mu \mathrm{m}$ are described in Table 6.

Table 4 Concentration for TSP, $\mathrm{PM}_{10}$, and PM 2.5 mass (average, 95\% CI) June 2011. 


\begin{tabular}{|c|c|c|c|}
\hline Area & TSP Mass $\mu \mathrm{g} / \mathrm{m}^{3}$ & $\begin{array}{l}\mathrm{PM}_{10} \\
\mu \mathrm{g} / \mathbf{m}^{3}\end{array}$ & $\begin{array}{l}\mathbf{P M}_{2.5} \\
\mu \mathrm{g} / \mathbf{m}^{3}\end{array}$ \\
\hline Raleigh & $\begin{array}{c}22.6\left(\begin{array}{c}(17.3,27.9) \\
n=3\end{array}\right. \\
\text { (a) }\end{array}$ & $\begin{array}{c}8.1(6.3,9.9) \\
n=3\end{array}$ & $\begin{array}{c}3.6(3.1,4.2) \\
n=3\end{array}$ \\
\hline $\begin{array}{l}\text { A } \\
B \\
C\end{array}$ & $\begin{array}{l}27.7 \\
21.6 \\
18.6\end{array}$ & $\begin{array}{c}9.4(7.7-11.1) \\
8.6(7.7-9.6) \\
6.2(5.4-7.0)\end{array}$ & $\begin{array}{l}4.0(3.3,4.7) \\
4.1(3.3,5.0) \\
2.8(2.2,3.3)\end{array}$ \\
\hline Boone & $\begin{array}{c}25.3(25.1,25.6) \\
n=2\end{array}$ & $\begin{array}{c}8.7(8.2,9.2)^{*} \\
n=2\end{array}$ & $\begin{array}{c}4.4(4.1,4.8) \\
n=2\end{array}$ \\
\hline $\mathrm{D}$ & 25.5 & $9.1(8.7,9.6)$ & $4.7(4.1,5.2)$ \\
\hline $\mathrm{E}$ & 25.2 & $8.2(7.7,8.7)$ & $4.2(3.9,4.6)$ \\
\hline $\mathrm{F}$ & -- & -- & -- \\
\hline $\begin{array}{l}\text { Combined } \\
\text { MTM Areas }\end{array}$ & $\begin{array}{c}23.7(20.1,26.7) \\
n=5\end{array}$ & $\begin{array}{c}8.3(7.0,9.6)^{*} \\
n=5\end{array}$ & $\begin{array}{c}4.0(3.3,4.7) \\
n=5\end{array}$ \\
\hline Pocahontas & $\begin{array}{c}14.2(10.4,17.9) \\
n=3\end{array}$ & $\begin{array}{c}5.3(4.8,5.8) \dagger \\
n=3\end{array}$ & $\begin{array}{c}3.5(3.1,4.5) \\
n=3\end{array}$ \\
\hline G & 16.0 & $6.2(5.8,6.6)$ & $4.1(3.4,4.7)$ \\
\hline $\mathrm{H}$ & 10.3 & $3.8(3.3,4.3)$ & $2.7(2.1,3.3)$ \\
\hline I & 16.1 & $5.4(5.2,5.6)$ & $3.4(3.0,3.9)$ \\
\hline
\end{tabular}

$*$ MTM site or area significantly different from Pocahontas Area mean at $\alpha=0.05$ after Bonferroni adjustment.

$\dagger$ Significant difference between sites within the area (ANOVA) at $\alpha=0.05$ after Bonferroni adjustment.

Table 5 Count, Deposited Respiratory Count, and Respiratory Deposition Percent (average, 95\% confidence interval) for PM0.01-0.4 $\mu \mathrm{m}$. 


\begin{tabular}{|c|c|c|c|}
\hline Area & $\begin{array}{l}\text { Count } \\
\# / \mathbf{c m}^{3}\end{array}$ & $\begin{array}{c}\text { Deposited Respiratory } \\
\text { Count } \\
\# / \mathrm{cm}^{3} \\
\end{array}$ & $\begin{array}{c}\text { Respiratory } \\
\text { Deposition \% }\end{array}$ \\
\hline Raleigh & 415,347 & 148,546 & 35.13 \\
\hline $\mathrm{n}=12$ & $(331,876-498,818) \dagger$ & $(111,406-185,687) * \dagger$ & (33.22-37.04) \\
\hline A & $\begin{array}{c}314,714 \\
(310742-318686) *\end{array}$ & $\begin{array}{c}103,891 \\
(100 \text { (1) }\end{array}$ & 33.02 \\
\hline B & $\begin{array}{c}387,595 \\
(333,267-441,922)^{*}\end{array}$ & $\begin{array}{c}130,251 \\
(120,801,139,701)^{*}\end{array}$ & $\begin{array}{c}\text { 33.86 } \\
(31.41-36.30)\end{array}$ \\
\hline $\mathrm{C}$ & $\begin{array}{c}601,125 \\
(504,104-698,146) *+\end{array}$ & $\begin{array}{c}228,615 \\
(181,176,276,055)^{*}\end{array}$ & $\begin{array}{c}37.83 \\
(34.67-40.99)\end{array}$ \\
\hline $\begin{array}{c}\text { Boone } \\
n=12\end{array}$ & 367,251 & 99,400 & 27.03 \\
\hline$n=12$ & $(318,756-686,007)$ & $(85,726-185,125)$ & $(25.82-30.57) \dagger$ \\
\hline $\mathrm{D}$ & $\begin{array}{c}389,660 \\
(286,753-492,568)\end{array}$ & $\begin{array}{c}112,082 \\
(79,638,144,525)\end{array}$ & $\begin{array}{c}28.68 \\
(27.52-29.84)\end{array}$ \\
\hline E & $\begin{array}{c}391,729 \\
(303,655-479,804)^{*}\end{array}$ & $\begin{array}{c}103,020 \\
(82,714-123,326)\end{array}$ & $\begin{array}{c}26.34 \\
(25.89-26.79)\end{array}$ \\
\hline $\mathrm{F}$ & $\begin{array}{c}304,044 \\
(298,448-309,639)^{*}\end{array}$ & $\begin{array}{c}80,684 \\
(76,954-84,414)\end{array}$ & $\begin{array}{c}26.53 \\
(25.79-27.27) \ddagger\end{array}$ \\
\hline $\begin{array}{c}\text { Combined MTM } \\
\text { Areas } \\
n=12\end{array}$ & $\begin{array}{c}410,609 \\
(359,673-461,546)^{*}\end{array}$ & $\begin{array}{c}132,210 \\
(108,702-155,718)^{*}\end{array}$ & $\begin{array}{c}31.42 \\
(29.39-33.45)\end{array}$ \\
\hline $\begin{array}{c}\text { Pocahontas } \\
n=24\end{array}$ & $\begin{array}{c}260,580 \\
(226,760-294,400)\end{array}$ & $\begin{array}{c}78,498 \\
(67,525-89,471)\end{array}$ & $\begin{array}{c}29.90 \\
(29.29-30.52) \dagger\end{array}$ \\
\hline G & $\begin{array}{c}236,952 \\
(191,414-282,491)\end{array}$ & $\begin{array}{c}69,946 \\
(56,001,83,891)\end{array}$ & $\begin{array}{c}29.43 \\
(28.89-29.98)\end{array}$ \\
\hline $\mathrm{H}$ & $\begin{array}{c}247,457 \\
(183,361-311,553)\end{array}$ & $\begin{array}{c}72,117 \\
(53,826-90,407)\end{array}$ & $\begin{array}{c}29.24 \\
(28.73-29.76)\end{array}$ \\
\hline I & $\begin{array}{c}315,705 \\
(260,635-370,775)\end{array}$ & $\begin{array}{c}100,897 \\
(80,178,121,615)^{*}\end{array}$ & $\begin{array}{c}31.60 \\
(29.94-33.25)\end{array}$ \\
\hline
\end{tabular}

$*$ MTM site or area significantly different from non-mining area average at $\alpha=0.05$ after Bonferroni adjustment.

$\uparrow$ Significant difference between sites within the area (ANOVA) at $\alpha=0.05$ after Bonferroni adjustment.

$\ddagger$ Site different from the area mean at $\alpha=0.05$ after Bonferroni adjustment.

Table 6 Respriatory deposition coefficients and geometric means for particles 0.01-0.4 $\mu \mathrm{m}$.

\begin{tabular}{|c|c|c|c|c|c|c|}
\hline & Coefficient 1 & Coefficient 2 & Coefficient 3 & Mode 1 & Mode 2 & Mode 3 \\
\hline MTM & 0.13 & 0.8 & 0.23 & 0.03 & 0.13 & 0.17 \\
Non-mining & 0.35 & 0.43 & 0.33 & 0.07 & 0.10 & 0.19 \\
\hline
\end{tabular}

\subsection{Discussion and Conclusions}


Despite statistically significant differences in $\mathrm{PM}_{10}$ mass concentration between the MTM and non-mining areas (Table 4), $\mathrm{PM}_{10}$ in both areas were substantially less than the EPA limit of $100 \mu \mathrm{g} / \mathrm{m}^{3}$. The medical significance of this small differential $\left(\sim 3.0 \mu \mathrm{g} / \mathrm{m}^{3}\right)$ is, therefore, questionable. A higher $\mathrm{PM}_{10}$ mass concentration indicated greater coarse particle mass, which is unlikely to account for the differences in disease rates between the two areas. Chemical constituents and increased concentration of smaller particles (UFPs) are more plausible explanations for the difference in health outcomes than $\mathrm{PM}_{10}$ or $\mathrm{PM}_{2.5}$ mass. The greater (though still relatively low) $\mathrm{PM}_{10}$ mass concentration at the individual and combined MTM sites indicated more localized dust in the MTM air during sampling. A difference in $\mathrm{PM}_{2.5}$ was not observed due to the similar concentrations of $\mathrm{PM}_{2.5}$ that may have relocated to the sampling sites from other locations to the east or northeast and remained in the atmosphere.

The combined MTM areas had significantly higher $\mathrm{PM}_{10}$ mass concentrations, number concentrations, and deposited number concentrations than the non-mining area. TSP, $\mathrm{PM}_{2.5}$, and deposition percent were not significantly different between the MTM and non-mining areas. The mass concentration, number concentration, and deposited number parameters collected in this study have not previously been examined at these particular areas of higher and lower disease rates.

Number-based particle size distributions to determine deposited dose concentration were examined in this study because dose has been suggested to be a superior indicator of certain kinds of inflammatory disease compared to $\mathrm{PM}_{10}$ and $\mathrm{PM}_{2.5}$ mass concentration (Anderson et al., 2008; Donaldson et al., 2001). For example, in a study of pulmonary deposition, Wang et al. determined that over $70 \%$ of the total number of particles deposited in the bronchioles and alveoli, while only 22\% of the total mass penetrated to the alveoli (Wang et al., 2002). In addition, ambient PM, collected from MTM areas in West Virginia, alters normal microvascular function after being intratracheally instilled in rats (Knuckles et al., 2013).

The current study showed that mining in the region resulted in significantly higher particle counts at most MTM sites. Sampling sites in closer proximity to mining sites, particularly to more active mining sites, had higher particle counts. All sites in Raleigh and Boone areas were near active MTM operations, although it was evident during sampling that some were more active than others. Site $\mathrm{C}$ was the most active mining site due to reported blasting activity during the morning of the second day of sampling as well as falling gravel and 
rocks coming down the hillside. Site C was significantly greater than the other Raleigh sites for particle number.

Deposited number, which was calculated based on particle size and regional deposition parameters, indicated significantly elevated dose at theMTM area and at some individual MTM sampling sites. Measurement of the deposited percent is unique because it converts a multimodal size distribution with multiple means and standard deviations to a single number which has utility for comparing size distributions across sites. There was no significant difference in respiratory deposition rates across the MTM and non-mining area, but the number of particles from these sources was greater at the MTM sites compared to the non-mining sites, leading to the higher dose estimates.

The particle number concentrations in all three areas were higher than other reported number concentrations throughout the country and world. A study monitoring number concentrations in urban areas around Los Angeles with similar sizing equipment showed daytime summer number concentrations (for the month of August 2009) ranging from 17,000-40,000 particles/cm ${ }^{3}$ (Hudda et al., 2010). Anderson et al. (2008) measured number concentration of particles 6-700 nm in size in Copenhagen, Denmark to associate number concentration with hospital admissions for cardiovascular disease and respiratory conditions in the elderly and children. The average number concentration from May 2001 to December 2004 in that study was 8,116 particles $/ \mathrm{cm}^{3}$.

In comparison, the present study showed number concentrations to be 35-75 times greater than those in Copenhagen $\left(410,000\right.$ particles $/ \mathrm{cm}^{3}$ at the MTM area compared to 8,100 particles $/ \mathrm{cm}^{3}$ in Copenhagen) (Anderson et al., 2008). If health reactions at the West Virginia areas sampled were similar to those in Copenhagen, paediatric asthma hospital admissions and cardiovascular disease and respiratory disease hospital admissions in the elderly should also be a problem in these mining and non-mining areas of West Virginia.

Variability in concentration existed within sampling areas and potential sources of variability included: fluctuations in the dust size distributions affecting the calculated deposited fraction across sampling areas, differences in weather patterns, and the amount of mining activity during the sampling period. While there are sources of PM that were not identified in this study and may contribute to a substantially elevated background particle number concentration, local sources seem to exceed that contribution and account for significant differences between the 
MTM and non-mining areas. For example, Site C had the highest particle number (601,125 particle $/ \mathrm{cm}^{3}$ ) and was located away from heavy traffic closer to a MTM site. Site G, with proximity to heavier traffic routes, had the lowest average particle count of 236,952particles/cm .

The limitations of the study included calculations of respiratory deposition based on a standard breathing pattern that did not account for changes and fluctuations in oral and nasal breathing. Sampling equipment was selected for ease of use in the field. Limitations with sampling equipment included damage to a filter during sampling resulting in the exclusion of one higher disease rate site from the study. The filter cassettes underestimated TSP mass concentration, but were a more practical and feasible method for obtaining TSP samples at multiple sites compared to other methods, such as a hi-volume sampler. The TSP mass concentration measure was an underestimate and seemed to be a better estimate of $\mathrm{PM}_{10}$ due to the entry efficiency of the $35 \mathrm{~mm}$ filter for particles $25 \mu \mathrm{m}$.

Another limitation of this study is that particle size and concentration data were collected for a brief period during one summer month and were collected in limited areas. Changes in PM across seasons and at different times within the summer season are planned for future evaluations. Obtaining concentrations from areas at a variety of methodical distances from MTM sites should also be considered since current literature suggests that the impacts of air quality are localized to the immediate area of a mining site (U.S EPA, 2000). The MTM and non-mining sites were dispersed throughout the respective areas to obtain samples representative of the variability within the area. Furthermore, although data were collected from an area with significantly more documented health problems where MTM was occurring, particles were not necessarily from a MTM source, and no biological assessments were made of PM exposure in humans.

This study indicates that accounting for the fraction of the particulate that deposits in the lung, thus directly contributing to dose, is a more sensitive indicator of epidemiological disease patterns than mass measures such as $\mathrm{PM}_{2.5}$. $\mathrm{PM}_{10}$, although different statistically between the MTM and non-mining areas, was unlikely to result in medically significant results for the higher disease rate area. The study also shows that measuring the deposited fraction of dose is now technically feasible for both mass-based and number-based particle size distributions. The levels of particle number concentrations at the higher disease rate area were almost 50 times larger than those associated with increased disease risk in major urban areas. Increased risks of respiratory 
and cardiovascular disease have been associated with measures of particle number concentration at levels much lower than were seen in this study.

\section{References}


Ahern MM, Hendryx M, Conley J, Fedorko E, Ducatman A, Zullig KJ. The association between mountaintop mining and birth defects among live births in central Appalachia, 19962003. Environ Res. 2011;111(6):838-846.

Anderson ZJ, Wahlin P, Raaschou-Nielsen O, Ketzel M, Scheike T, Loft S. Size distribution and total number concentration of ultrafine and accumulation mode particles and hospital admissinos in children and the elderly in Copenhagen, Denmark. Occup Envion Med. 2008;65:458-466.

Chung A, Chung DPY, Kleeman MJ, et al. Comparison of real-time instruments used to monitor airborne particulate matter.J. Air Waste Manage. Assoc. 2001; 51:109-120.

Donaldson K, Stone V, Clouter A, Renwick L, MacNee W. Ultrafine particles. Occup Environ Med. 2001;58:211-216.

Esch L, Hendryx M. Chronic cardiovascular disease mortality in mountaintop mining areas of central Appalachian states. J Rural Health. 2011;27(4):350-357.

Hendryx M. Poverty and mortality disparities in central Appalachia:mountaintop mining and environmental justice. Journal of Health Disparities Research and Practice. 2011;4(3): 44-53.

Hendryx M, Wolfe L, Luo J, Webb B. Self-reported cancer rates in two rural areas of West Virginia with and without mountaintop coal mining. J Community Health. 2011;37(2):320-327.

Hinds WC. Aerosol Technology: Properties, Behavior, and Measurement of Airborne Particles. Vol 2. New York: John Wiley \& Sons, Inc.; 1999.

Hogg JC, van Eeden S. Pulmonary and systemic response to atmospheric pollution. Respirology. 2009;14;3:336-346.

Hudda N, Cheung K, Moore KF, Sioutas C. Inter-community variability in total particle number concentrations in the eastern Los Angeles air basin. Atmos Chem Phys. 2010;10:1138511399.

Kim CS, Jaques PA. Analysis of total respiratory deposition of inhaled ultrafine particles in adult subjects at various breathing patterns.Aerosol Sci. Technol. 2004;38(6):525-540.

Knuckles TL, Stapleton PA, Minarchick VC et al. Air pollution particulate matter collected from an Appalachian mountaintop mining site induces microvascular dysfunction. Microcirculation. 2013;20(2):158-169.

Lippmann M, Yeates D, Albert R. Deposition, retention, and clearance of inhaled particles. $\mathrm{Br} J$ Ind Med. 1980;37(4):337-362. 
National Oceanic and Atmospheric Administration (NOAA). Average Relative Humidity (\%).National Climatic Data Center. 2008. Available at:

http://www.ncdc.noaa.gov/oa/climate/online/ccd/avgrh.html. Accessed 20 August, 2012.

Oberdorster G, E. Oberdorster E, Oberdorster J. Nanotoxicology: an emerging discipline evolving from studies of ultrafine particles.Environ. Health Perspect. 2005;113(7):823839.

Pope CA 3rd, Dockery DW. Health effects of fine particulate air pollution:lines that connect. $J$ Air \& Waste Manage Assoc. 2006;56:709-742.

Sioutas C, Delfino RJ, Singh M. Exposure assessment for atmospheric ultrafine particles (UFPs) and implications in epidemiologic research. Environ Health Perspect. 2005;113:947-955.

Stahlhofen W, Rudolf G, James AC. Intercomparison of experimental regional aerosol deposition. J Aerosol Med. 1989;2(3):285-308.

U.S. EPA (Environmental Protection Agency).Mid-Atlantic Mountaintop Mining. 2011. Available at: http://www.epa.gov/Region3/mtntop/. Accessed March 14, 2010.

U.S. EPA (Environmental Protection Agency). Mountaintop Mining/Valley Fill Environmental Impact Statement. 2000. Available at: http://wvgazette.com/static/series/mining/reports/EIS/Executive\%20Summary.pdf. Accessed 12 April 2012.

U.S. EPA (Environmental Protection Agency). Particulate Matter (PM). 2012. Available at: http://www.epa.gov/pm/index.html. Accessed 19 December 2011.

Wang G, Huang L, Gao S, Wang L. Measurements of PM10 and PM2.5 in urban area of Nanjing, China and the assessment of pulmonary deposition of particle mass. Chemosphere. 2002;48:689-695.

WV DEP (West Virginia Department of Enviornmental Protection). Air Monitoring. 2012 Available at: http://www.dep.wv.gov/daq/airmonitoring/Pages/default.aspx. Accessed 15 November 2012.

WVDoT (West Virginia Department of Tourism). Pocahontas County. 2006. Available at: http://www.pocahontascountywv. com/files/quick_county_facts.pdf. Accessed 2 November 22011. 


\section{Chapter 3}

Atmospheric Particulate Matter Concentration Measurements in West Virginia Coal Mining and Non-Mining Areas Over a Year Period 


\subsection{Introduction}

Exposure to increased atmposheric particulate matter (PM) is reported to be associated with excess hospital admissions, morbidity, and mortality for respiratory and cardiovascular health outcomes (Dockery et al., 1993; Dockery, 2001; Dominici et al., 2006; Peters et al., 2001; Pope \& Dockery, 2006; Schwartz, 1994). Health effects manifest from pathophysiological inflammatory responses to particles depositing in the lung alveoli or infiltrating lung epithelial cells to enter the vasculature (Costa \& Dreher, 1997; Hogg \& van Eeden, 2009). Current $\mathrm{PM}_{10}$ and $\mathrm{PM}_{2.5}$ standards monitor PM with partially size-classified, mass-based particle measures. However, increasing evidence supports the use of number-based particle size distributions to study the health effects of PM (Hudda et al., 2010). Particle number parameters are more inclusive of ultrafine particles (UFPs), particles with a diameter less than $0.1 \mu \mathrm{m}$, as compared to partially size classified mass concentration measures. UFPs penetrate through the epithelial cell lining and induce inflammatory response and oxidative stress resulting in health outcomes, yet UFPs contribute little to $\mathrm{PM}_{10}$ and $\mathrm{PM}_{2.5}$ mass concentration. The small size, large number concentration, and greater surface area per unit mass of UFPs stimulates respiratory and systemic response (Donaldson et al. 2001; Hinds, 1999; Sioutas, 2005).

People who live in southern West Virginia where coal mining is prominent have increased health problems compared to people in non-mining areas. Residents of coal mining areas have significantly higher mortality from chronic heart, respiratory, and kidney diseases, and elevated morbidity from chronic cardiopulmonary, cardiovascular, and kidney diseases (Hendryx, 2009; Hendryx \& Ahern, 2008; Hendryx \& Zullig, 2009).Recent investigations of health outcomes in coal mining areas indicated areas practicing mountaintop mining (MTM) methods have elevated health outcomes compared to areas with other forms of coal mining or no mining. For example, age-adjusted chronic cardiovascular rates were greater in MTM Appalachian counties compared to non-mining Appalachian counties $(\beta=24.7, \mathrm{SE}=9.3, \mathrm{p}<0.009)$ (Esch \& Hendryx, 2011). Those living in MTM areas under study were two times as likely to report having cancer compared to those living in non-mining areas (Hendryx et al., 2011).

The MTM method involves removing large amounts of vegetation, rock, and dirt from mountain peaks and ridges with explosives and excavation equipment. The underlying coal seams are exposed and the spoil, composed of crushed shale, coal debris, sandstone, and other materials, is removed and deposited in nearby valleys (U.S. EPA, 2011). During the mining 
processes, particulate matter is generated from explosive blasting to loosen spoil, heavy equipment operations, diesel exhaust, dragline operations, feeder breakers that crush coal, and wind erosion of coal storage piles (Ghose \& Majee, 2007). Particles from MTM mix with background primary and secondary aerosols from combustion, traffic, industrial activities, and power plants. The potential health risks from exposure to PM around MTM areas is unknown, but previous research has determined significantly greater dose and elevated number concentration in residential communities proximate to MTM from brief PM sampling (Chapter 2). The purpose of this study was to determine particle size distribution, mass concentration, and number concentration to calculate deposited lung dose in MTM and non-mining areas across seasons. The ability of the particle measures to distinguish a difference between the two areas was also examined.

\subsection{Methods}

\subsubsection{Sampling}

Ambient PM sampling was conducted from June 2011 to May2012 at three rural residential areas to obtain seasonal PM measures. Two MTM sampling sites were located in narrow valleys surrounded by mountains in two adjacent counties (Raleigh County and Boone County) where MTM was prominent, along with other coal mining activities (underground mining and coal processing facilities). The MTM sites were matched to a site in an area without any mining activity in Pocahontas County, located in eastern West Virginia (Figure 6).

In June 2011, sampling was conducted at nine sites (three per rural area), and one site from each area was selected for continued sampling in this study. During the brief sampling episodes, it was evident that the MTM operations were constantly moving and we could not predict which site would remain proximal to active mining for future sampling. Therefore, the site most representative of the area was selected for extended sampling through May 2012 (See Appendix B). The three selected sites are summarized in Table 7. A sample of residents surveyed from the MTM area and non-mining area indicated a similar percent of residents were female, current or former smokers, and smokeless tobacco users in the two areas (Hendryx et al., 2011). Previous research on the health status of residents living around these sites indicated increased health problems among residents in the MTM area compared to the non-mining area (Hendryx et al., 2011). Residents surveyed at the MTM areas were significantly more likely to 
have poorer health outcomes and report an occupational history as a coal miner. In addition, mining area residents had resided in the area longer $(M=45.1, S D=23.0)$ as compared to those surveyed in the non-mining area $(M=39.8, S D=24.3)$ (Hendryx et al., 2011).

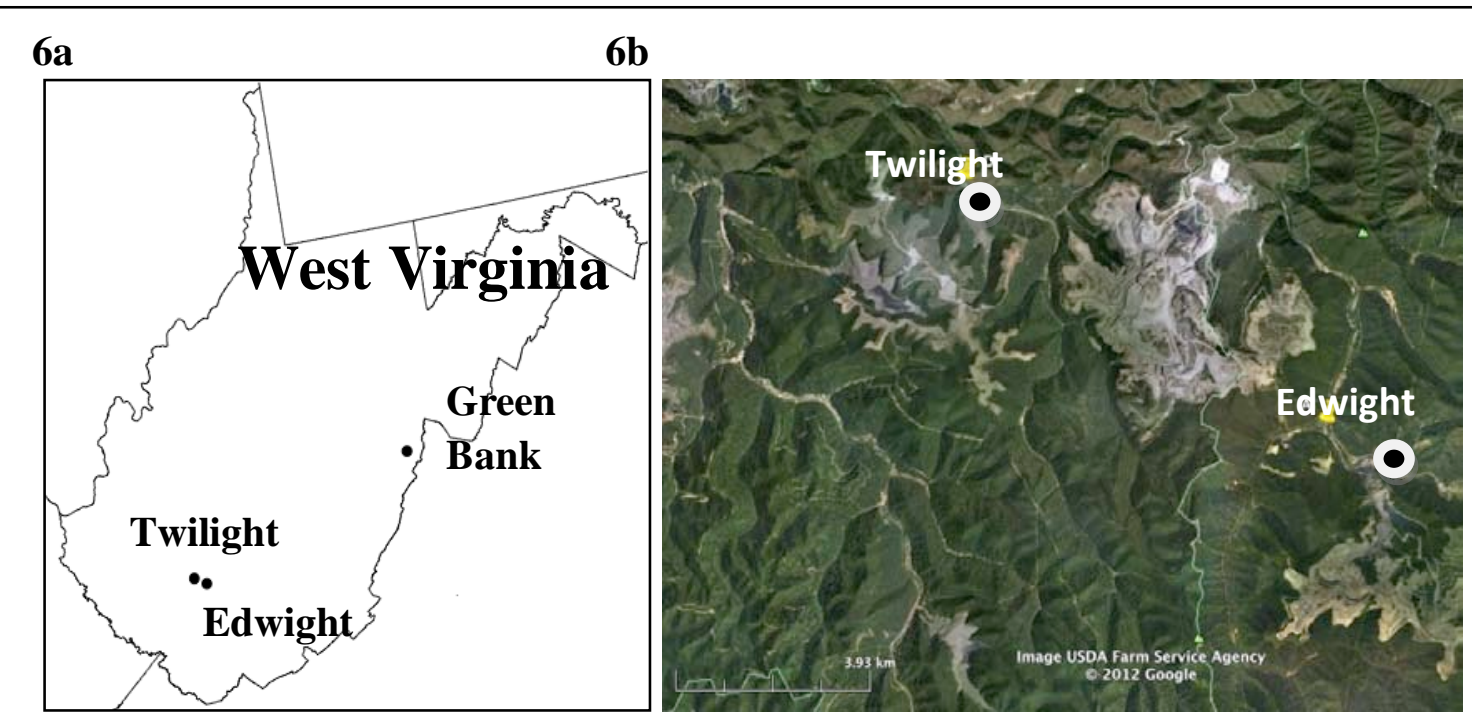

Figure 6a) Locations of the MTM sampling sites in southern West Virginia (Edwight, Raleigh County and Twilight, Boone County) and the non-mining site in eastern West Virginia (Green Bank, Pocahontas County).

6b) MTM activity surrounding the Edwight and Twilight sampling sites.

Table 7 Summary of site characteristics.

\begin{tabular}{|c|c|c|c|c|}
\hline Town & Latitude & Longitude & Elevation (m) & $\begin{array}{c}* \text { Distance to } \\
\text { State Road (m) }\end{array}$ \\
\hline Edwight & $37^{\circ} 53^{\prime} 0.4^{\prime \prime} \mathrm{N}$ & $81^{\circ} 32^{\prime} 2.5^{\prime \prime} \mathrm{W}$ & 303 & 160 \\
\hline Twilight & $37^{\circ} 55^{\prime} 31^{\prime \prime} \mathrm{N}$ & $81^{\circ} 37^{\prime} 25^{\prime \prime} \mathrm{W}$ & 333 & 143 \\
\hline Green Bank & $38^{\circ} 25^{\prime} 27^{\prime \prime} \mathrm{N}$ & $79^{\circ} 49^{\prime} 43^{\prime \prime} \mathrm{N}$ & 821 & 125 \\
\hline
\end{tabular}

*Distance to State Road refers to the distance from the site to the nearest main road.

\subsubsection{Sampling Sites}

Edwight, Raleigh County: Edwight is an unincorporated area approximately 8 miles south of the town of Whitesville, WV and 30 miles northeast of the county seat, Beckley, WV. Raleigh County ranks among the lowest $25 \%$ of all 55 counties in West Virginia by overall county health ranking, which is determined based on mortality rate of those less than 75 years old, self reported fair or poor health, self reported physical and mental health, and rate of low birth weight infants (University of Wisconsin Population Health Institute, 2012). Raleigh County had 13 surface mines (5.7\% of total state surface mines) and 23 underground mines (8\% 
of total state underground mines) in 2011 and contributed 6.5\% production to the state's total coal production. Throughout 2011, the state produced a range of 500,000 to 1,000,000 tons of coal per month, and July and September-December were the lowest coal production months in Raleigh County (WV MHS\&T, 2012).

The Edwight sampling site was located in a valley along the Coal River in a resident's yard about 160 meters off state road WV 3. The site was surrounded by MTM activity, including an expansive MTM site directly to the northwest and south and a smaller MTM site about three miles northeast. Residences in the sampling area were scattered around the site and not centrally located.

Twilight, Boone County: Twilight is an unincorporated area with a population of 90 people (U.S. Census Bureau, 2011). Twilight is located approximately 20 miles from the county seat of Madison, WV, which houses about 3,000 people. Boone County ranks in the lowest 10\% of all counties in West Virginia by health outcome and has higher than state average premature deaths (University of Wisconsin Population Health Institute, 2012). In 2011, Boone County had 31 surface mines (13.5\% of total state surface mines) and 68 underground mines (24.3\% of total state underground mines) and contributed the greatest percent (15\%) to the state's total coal production. October, November, and December were the lowest coal production months in Boone County.

The sampling site was located about 143 meters off county highway 26 on a dead end road. This site was in a Twilight resident's yard and at a slight elevation from the main road. An expansive MTM site stretched from the southwest to the southeast of the valley where this site was located.

Green Bank, Pocahontas County: Green Bank has a population of 143 people and is in a county where approximately60\% of the land is federal or state owned and no coal mining is present (U.S. Census Bureau, 2011; WV DOT, 2006). Pocahontas County ranks in the lowest $40 \%$ of all counties in West Virginia by health outcome, however, the surrounding counties have high health rankings (University Of Wisconsin Population Health Institute, 2012). The Green Bank site was in the parking lot of a rural library, approximately 125 meters of state road 28/92. Visits to this site were predominately on weekends when the library was closed or at times when there was minimal, if any vehicle traffic in the parking lot. This site was also unique from the 
MTM sites because it was located in an open area rather than in a contained valley with the topography reflecting different wind speeds and air movement patterns, including inversions.

\subsubsection{Instrumentation}

Mass concentration, mass-based and number-based particle size distributions, and number concentration samples were obtained over an annual sampling period from each site. Total suspended particle (TSP) mass concentration was measured gravimetrically with a polytetrafluoroethylene (PTFE) coated glass fiber filter (37mm diameter $5.0 \mu \mathrm{m}$ pore-size, SKC Inc, Eighty Four, PA) connected to low volume vacuum pump (Model 1531-1078-G288x, Gast Manufacturing Inc., Benton Harbor, MI). A low volume vacuum pump was permanently placed at each site to collected TSP samples for approximately three to six weeks (average time of 29 days) before exchanging the used filter for a clean filter.

A PTFE filter was placed in two-piece plastic filter cassettes on top of a support pad to prevent filter fibers from rupturing. Cassette pieces were sealed together with tape to eliminate particles from leaking into the cassette or bypassing the filter. Each filter was equilibrated for 24 hours at constant relative temperature and humidity before pre-weighing. TSP mass was calculated gravimetrically from the change in pre- and post-experiment filter weight, volume of air passing through the filter, and sampling time. The difference between the pre- and postexperiment filter weight was divided by the average volume of air passing through the filter. The air volume was calculated by averaging the sampling period start and end pump flow rates (overall average flow rate of $17.4 \mathrm{~L} / \mathrm{min}$ ) during the sampling period.

An Aerodynamic Particle Sizer (APS, Model 3321, TSI, Inc., Shoreview, MN) measured mass-based size distribution related to a particle's aerodynamic properties for PM with an aerodynamic diameter of 0.5-20 $\mu \mathrm{m}$. The APS operates with a time-of-flight technique that accelerates particles through a line of two laser beams to obtain a particle's velocity and determine its aerodynamic diameter. Aerodynamic diameter is a standardized measure of the diameter of a one unit density sphere with the same settling velocity as the particle being measured. Aerodynamic mass frequencies for 52 size categories were collected with the APS. The APS operates on the theory that smaller particles have a greater velocity than larger particles and sizes PM accordingly based on aerodynamic diameter. Particles $>15 \mu \mathrm{m}$ settle out of the air and were generally excluded from sizing while particles with an aerodynamic diameter 0.37-0.5 
$\mu \mathrm{m}$ were grouped into one size range because their velocities were too high to distinguish their exact size.

Number-based particle size distributions were determined with a Scanning Mobility Particle Sizer (SMPS) for particle 0.01-0.4 $\mu \mathrm{m}$. The SMPS includes an Electrostatic Classifier (EC) (Model 3080, DMA, Model 3081, TSI, Inc., Shoreview, MN) and Condensation Particle Counter (CPC) (Model 3788, TSI, Inc., Shoreview, MN) to size particles into 105 size categories by particle number based on thermodynmic equivalent diameter. The EC sizes and separates polydisperse aerosol based on electrical mobility, which is related to particle size, into a specific size range of monodisperse aerosol. Particles in a particular range of mobility move to the CPC to be counted. The CPC operates using condensation to grow particles for optical counting. The sheath to aerosol sample flow ratio was set at a 10 to 1 ratio. Number concentration of particles 0.01-0.4 $\mu \mathrm{m}$ was also determined with the SMPS.

The APS and SMPS were transported to each site every three to six weeks. At each site visit, the APS recorded mass-based size distributions for two, ten-minute sampling sessions and the SMPS recorded number-based size distributions for three to eight, two minute 15 second sessions. Meteorological conditions, including average daily wind direction and speed, maximum daily wind speed, average temperature, and relative humidity, were also recorded during each visit. Currently, the EPA does not have a State and Local Air Monitoring Station set up in Pocahontas County to conduct $\mathrm{PM}_{10}$ and $\mathrm{PM}_{2.5}$ ambient air monitoring (WV DEP, 2012). A PM 2.5 monitor was operating in Raleigh County but it was located in the county's major population centre and distant from MTM activity. Therefore, we obtained estimates of $\mathrm{PM}_{10}$ and $\mathrm{PM}_{2.5}$ at each site visit using gravimetric measurements and APS size distributions.

\subsubsection{Respiratory Deposition}

Size distributions were used to estimate deposited respiratory dose to adult humans. Total respiratory deposition was calculated with a mathematical model developed from experimental data to determine regional deposition efficiency values in four areas of the respiratory tract (nose, extrathoracic region, tracheobronchial region, and alveolar region) (Stahlhofen et al., 1989). The efficiency values of Stahlhofen et al. (1989) accounted for particle size and regional respiratory parameters when calculating particle deposition efficiency. 
The arithmetic mass-based particle size distributions from the APS and number-based particle size distributions from the SMPS were converted to lognormal distributions for empirical purposes. The product of the fraction of PM in a specific particle size range and the respiratory deposition fraction for that size range determined the percent deposition for a given size range of particles (Stahlhofen et al., 1989). After determining respiratory deposition for all size ranges, the regional geometric means and standard deviations were integrated to estimate total lung deposition for 50\% oral and 50\% nasal breathing with the parameters: Q (volumetric flow rate) $=116.7 \mathrm{~cm}^{3} / \mathrm{sec}, \mathrm{V}=500 \mathrm{~cm}^{3}, \mathrm{FRC}=3,300 \mathrm{~cm}^{3}$, and $\mathrm{f}=7$ breaths per minute. The deposited percent measurement is unique because it converts a size distribution with multiple means and standard deviations (due to a polydisperse sample) to a single number, which has utility for comparing size distributions across sites.

Two respiratory dose estimates were determined for each site during each sampling period. One estimate was calculated for PM 0.5-20 $\mu \mathrm{m}$ using the APS provided mass-based particle size distributions (Figure 7) shows the mass-based particle size distribution with the overlaid deposition curves. The coefficients, geometric mean, and geometric standard deviation of the deposition curves that fit the lognormal distribution to the arithmetic particle size distribution are shown in Figure 7. The second estimate was calculated for PM 0.01-0.4 $\mu \mathrm{m}$ using the SMPS provided number-based particle size distributions (Figure 8). Dose estimates are presented separately for the mass-based size distributions for PM0.5-20 $\mu \mathrm{m}$ and numberbased size distributions for PM0.01-0.4 $\mu \mathrm{m}$. Multiple particle size distributions were obtained at each site visit, so a dose was first obtained for each size distribution from a site and then the overall dose was calculated by averaging all doses at that site. Results were consistent with respiratory deposition measures calculated by fitting a deposition curve to the site's overall average size distribution. 


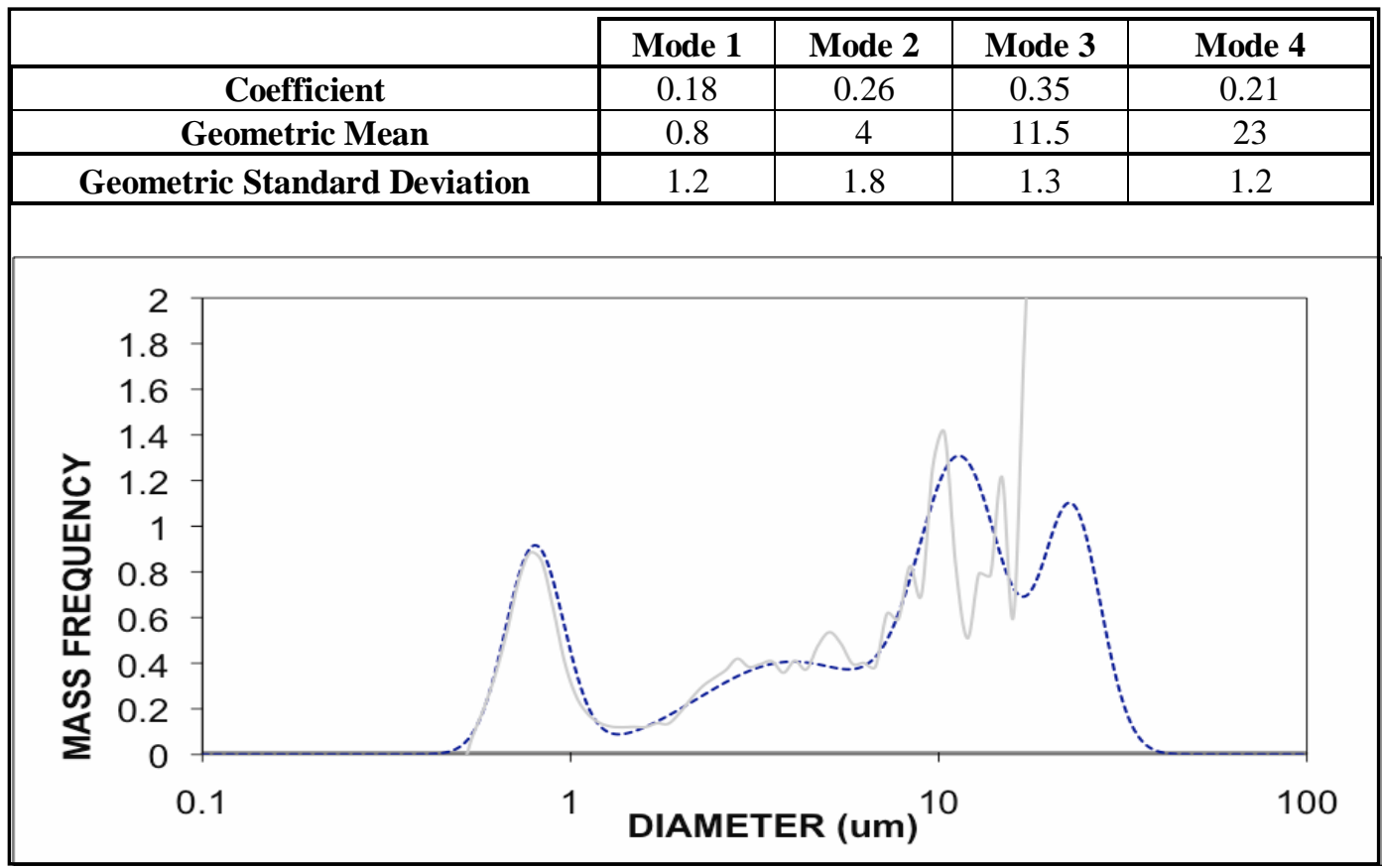

Figure 7 MTM site mass-based size distribution deposition curve by aerodynamic diameter.

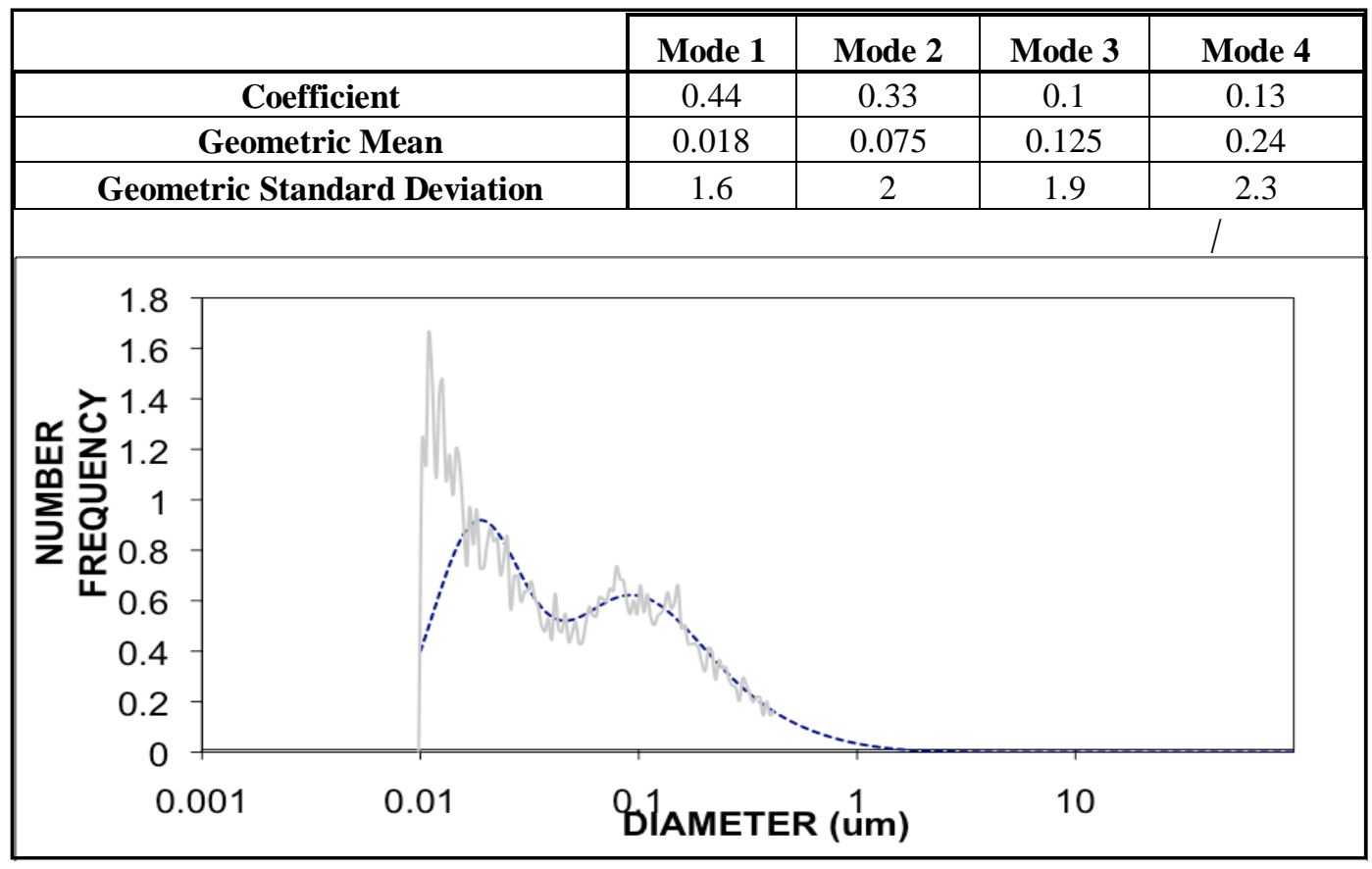

Figure 8 MTM site number-based size distribution deposition curve by thermodynamic (mobility) diameter. 


\subsubsection{Analysis}

Data were reviewed for irregularities associated with electronic equipment errors. SMPS readings with $<1,000$ particles $/ \mathrm{cm}^{3}$ were excluded assuming electronic errors. Wilcoxon signedrank tests were carried out between MTM and non-mining particle parameters. This method of analysis was selected due to small sample sizes and non-normal distributions of the particle variables. Median values were compared between the MTM and non-mining sites by season and month. Seasonal labels were assigned to groups of months and were not specific to the actual astronomical season dates. Seasonal labels included: summer (June, July, August), fall (September, October, November), winter (December, January, February), and spring (March, April, May).

\subsection{Results}

\subsubsection{Meteorology}

Weather patterns influence particle concentration, in particular, number concentration of ultrafine PM. Table 8 presents an overview of the meteorological conditions at sampling sites along with the instruments used and filter exchange details for each sampling occurrence. Stronger winds were recorded throughout the year around the non-mining Green Bank site compared to the MTM sites, Edwight and Twilight. Light winds were present at the MTM sites during July, November, and April sampling, but occasional wind gusts were more characteristic of the MTM sites during the remainder of the year. Temperatures fluctuated with the seasons and the air temperature was generally lower at Green Bank, where elevation was higher. The observed relative humidity fell within the normal monthly range, except in January and February 2012 at Edwight and Twilight when the humidity was above the normal monthly range. Humidity was also higher than normal at Green Bank in March and May 2012, but lower than normal in April 2012(NOAA, 2008). 
Table 8 Daily meteorological conditions and summary data of measurements taken during each site visit.

\begin{tabular}{|c|c|c|c|c|c|c|}
\hline Site & $\begin{array}{c}\text { Date of Site } \\
\text { Visit }\end{array}$ & $\begin{array}{l}\text { Average } \\
\text { Wind } \\
\text { Direction }\end{array}$ & $\begin{array}{c}\text { Average } \\
\text { Wind Speed } \\
\text { mph (max } \\
\text { wind speed) }\end{array}$ & $\begin{array}{l}\text { Average } \\
\text { Temp. } \\
{ }^{\circ} \mathbf{F}\end{array}$ & $\begin{array}{l}\text { Humidity } \\
\text { (\%) }\end{array}$ & $\begin{array}{c}\text { Measurements } \\
\text { Conducted During Site } \\
\text { Visit.* }\end{array}$ \\
\hline Edwight & 6 June 2011 & NW & $0(4)$ & 78 & 77 & TSP start, APS, SMPS \\
\hline Edwight & 7 June 2011 & NNW & $0(12)$ & 74 & 77 & TSP end, APS, SMPS \\
\hline Twilight & 8 June 2011 & NNW & $0(6)$ & 78 & 80 & TSP start, APS, SMPS \\
\hline Twilight & 9 June 2011 & NW & $0(7)$ & 80 & 82 & TSP end, APS, SMPS \\
\hline Green Bank & 10 June 2011 & NWN & $7(20)$ & 69 & 75 & TSP start, APS, SMPS \\
\hline Green Bank & 11 June 2011 & $\mathrm{~W}$ & $6(13)$ & 70 & 79 & TSP end, APS, SMPS \\
\hline Edwight, Twilight & 11 July 2011 & NNW & $1(7)$ & 82 & 71 & TSP start, APS, SMPS \\
\hline Green Bank & 11 July 2011 & SW & $9(22)$ & 75 & 80 & TSP start, APS, SMPS \\
\hline Edwight, Twilight & 5 Aug. 2011 & SE & $0(6)$ & 78 & 80 & TSP replace, APS, SMPS \\
\hline Green Bank & 5 Aug. 2011 & SSE & $13(17)$ & 70 & 93 & TSP replace, APS, SMPS \\
\hline Edwight, Twilight & 12 Sept. 2011 & $\mathrm{~N}$ & $0(6)$ & 66 & 86 & TSP replace, APS, SMPS \\
\hline Green Bank & 11 Sept. 2011 & $\mathrm{~W}$ & $6(14)$ & 63 & 71 & APS, SMPS \\
\hline Edwight, Twilight & 8 Oct. 2011 & ESE & $0(5)$ & 60 & 80 & TSP replace \\
\hline Green Bank & 8 Oct. 2011 & ESE & $5(8)$ & 56 & 81 & TSP start \\
\hline Edwight, Twilight & 26 Oct. 2011 & NW & $0(7)$ & 55 & 77 & TSP replace, APS, SMPS \\
\hline Green Bank & 25 Oct. 2011 & WNW & $12(21)$ & 50 & 65 & TSP end, APS, SMPS \\
\hline Edwight, Twilight & 14 Nov. 2011 & SW & $1(9)$ & 63 & 65 & TSP start, APS, SMPS \\
\hline Green Bank & 14 Nov. 2011 & WSW & $16(26)$ & 56 & 68 & TSP start, APS, SMPS \\
\hline Edwight, Twilight & 4 Dec. 2011 & SSE & $0(5)$ & 47 & 73 & TSP replace, APS, SMPS \\
\hline Green Bank & 4 Dec. 2011 & $\mathrm{~S}$ & $9(15)$ & 40 & 72 & TSP replace, APS, SMPS \\
\hline Edwight, Twilight & 16 Jan. 2012 & SW & $0(5)$ & 37 & 82 & TSP replace \\
\hline Green Bank & 16 Jan. 2012 & SSW & $9(18)$ & 27 & 72 & TSP replace \\
\hline Edwight, Twilight & 19 Feb 2012 & SE & $0(5)$ & 38 & 87 & TSP replace, APS, SMPS \\
\hline Green Bank & 2 Mar. 2012 & SSE & $11(16)$ & 38 & 100 & TSP end. \\
\hline Edwight & 3 April 2012 & NNW & $1(7)$ & 60 & 68 & $\begin{array}{l}\text { TSP replace, APS, SMPS } \\
\text { No power at site B }\end{array}$ \\
\hline Green Bank & 3 April 2012 & $\mathrm{~W}$ & $7(12)$ & 57 & 30 & APS, SMPS. \\
\hline Edwight & 7 May 2012 & $\mathrm{~N}$ & - & 71 & 79 & $\begin{array}{l}\text { TSP end, APS, SMPS } \\
\text { No power at site B }\end{array}$ \\
\hline Green Bank & 6 May 2012 & SE & $4(12)$ & 62 & 97 & APS, SMPS \\
\hline
\end{tabular}

*TSP start indicates a new filter put on the vacuum pump; TSP replace indicates replacing the used filter with a new filter; TSP end indicates removing the used filter and not replacing it with a new filter.

\subsubsection{Seasonal and Monthly Variation}

Sites were divided into two subgroups with the Edwight and Twilight sites belonging to the groups characterized as MTM. The Green Bank site was the non-mining site. Table 9 shows the median TSP, $\mathrm{PM}_{10}$, and $\mathrm{PM}_{2.5}$ mass concentrations across seasons at the MTM and non-mining sites. A Wilcoxon signed-rank test indicated no significant effect of mining activity for TSP, $\mathrm{PM}_{10}$, and $\mathrm{PM}_{2.5}$ mass concentration when compared for all four seasons. TSP and $\mathrm{PM}_{2.5}$ mass concentrations were lowest during the winter season in both the MTM and nonmining sites, and $\mathrm{PM}_{10}$ was greater during the spring and summer. Table $\mathbf{1 0}$ shows mass 
concentration at the MTM and non-mining sites by month in order to identify any differences between the areas that were covered up by seasonal groupings. A Wilcoxon signed-rank test showed a significant effect of mining activity for $\mathrm{PM}_{10}$ mass concentration during June $(Z=2.8$, $p=0.0172)$ and July $(Z=4.0, p=0.0008)$. $\quad \mathrm{PM}_{2.5}$ mass concentration was significantly greater at the MTM site $(M d n=1.8)$ than at the non-MTM site $(M d n=0.54)$ during July $(Z=4.0, p=0.0008)$.

Table 9 Comparison of MTM and non-mining sites for TSP, $\mathrm{PM}_{10}$, and $\mathrm{PM}_{2.5}$ mass by season.

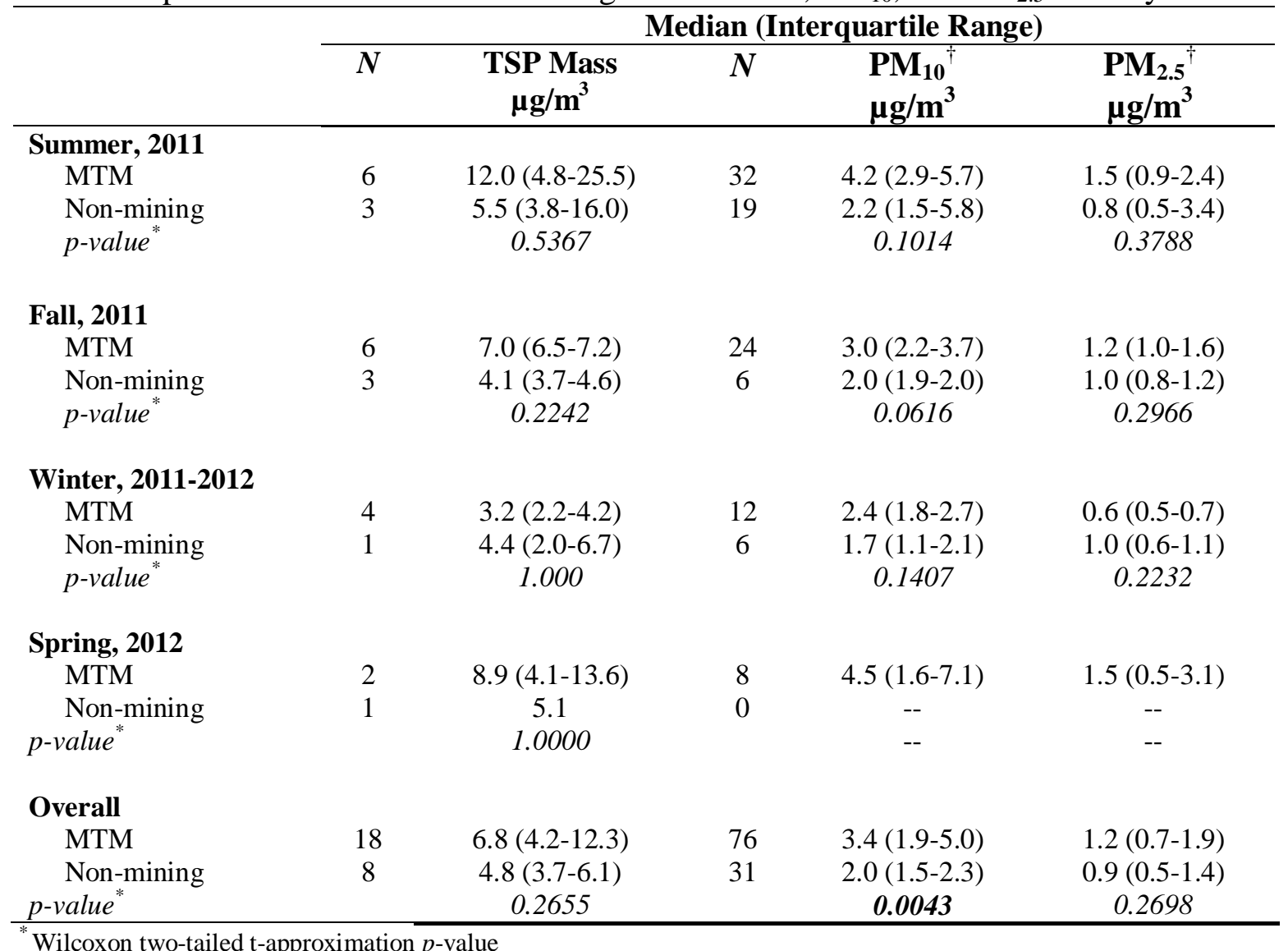


Table 10 Comparison of MTM and non-mining sites for TSP, $\mathrm{PM}_{10}, \mathrm{PM}_{2.5}$ mass by month.

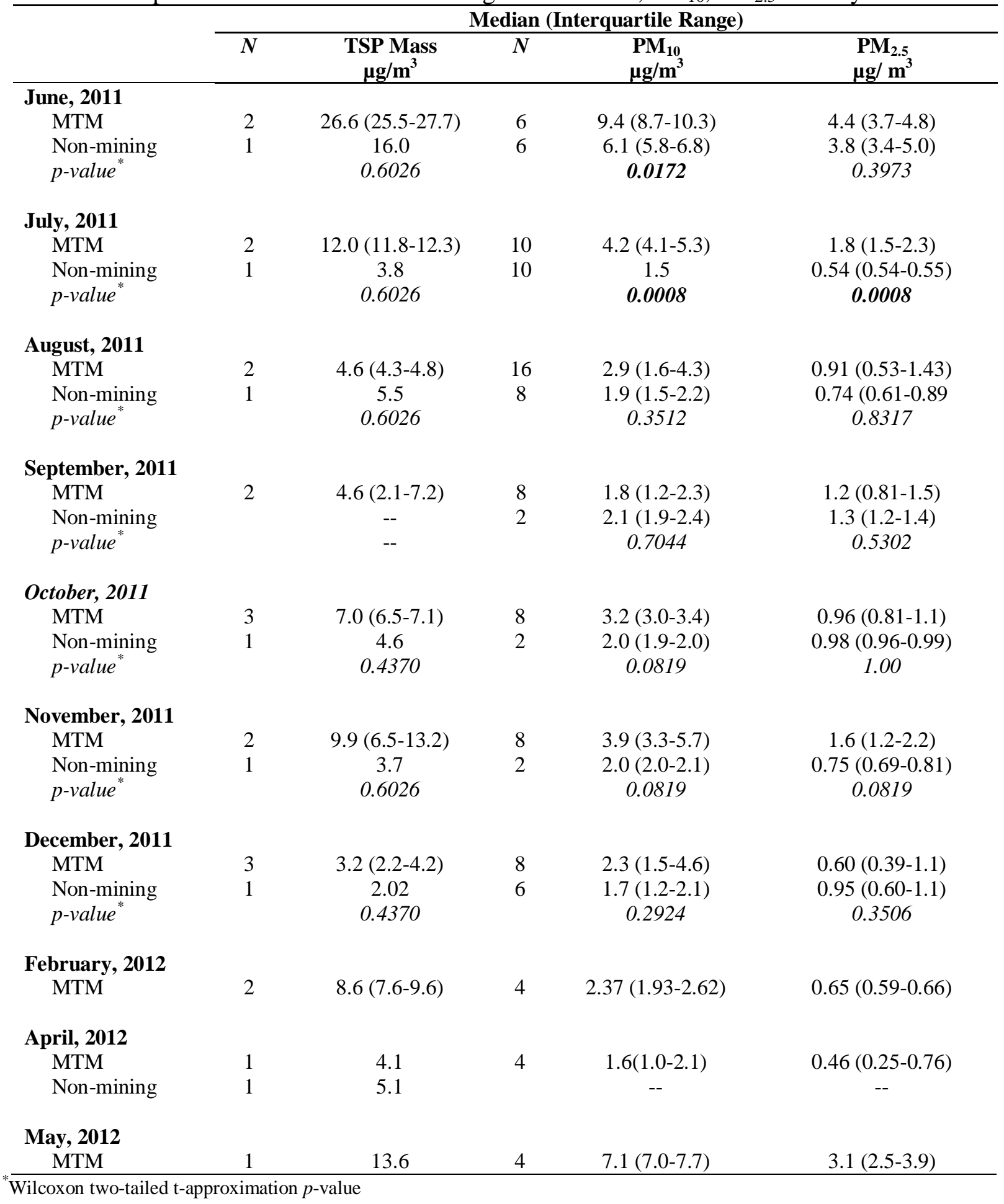

Table 11 shows the median respiratory deposition percent and deposited mass concentration for particles 0.5-20 $\mu \mathrm{m}$ across seasons at the MTM and non-mining sites. The sized-mass distributions provided by the APS were used to estimate lung deposition, and the deposition 
percent was applied to the TSP mass to obtain deposited mass concentrations. Wilcoxon signedrank tests indicated significant effect of mining activity for deposition percent $(Z=-4.3$, $p=0.0001)$ and deposited mass concentration $(Z=-2.5, p=0.0158)$ during the summer. Table 12 indicates the average coefficients and geometric means for the respiratory deposition calculations

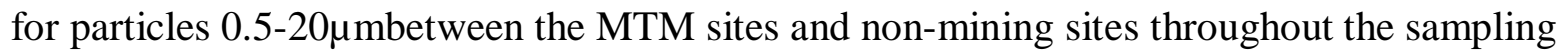
period. Table 13 shows median deposition percent and deposited mass concentration for particles $0.5-20 \mu \mathrm{m}$ at the MTM and non-mining sites by month. There was a significant effect of mining activity for deposition percent during July $(Z=-3.0, p=0.0095)$ and for deposited mass concentration for June $(Z=2.8, p=0.0172)$ and July $(Z=4.0, p=0.0095)$.

Table 11 Comparison of MTM and non-mining sites for deposition percent and mass dose by season for particles $0.5-20 \mu \mathrm{m}$.

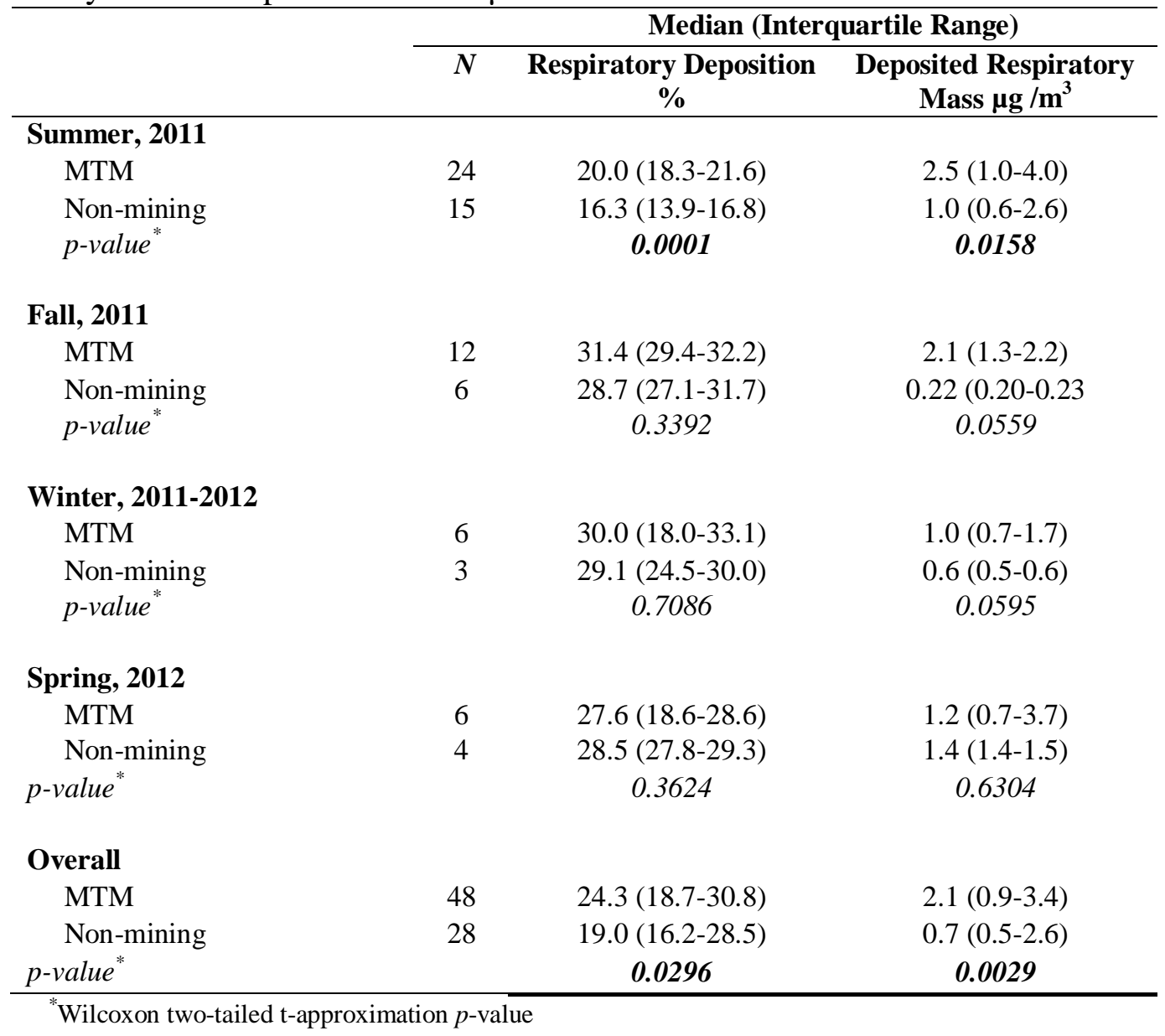


Table 12 Respriatory deposition coefficients and geometric means for particles $0.5-20 \mu \mathrm{m}$.

\begin{tabular}{|l|c|c|c|c|c|c|c|c|}
\hline & Coefficient 1 & Coefficient 2 & Coefficient 3 & Coefficient 4 & Mode 1 & Mode 2 & Mode 3 & Mode 4 \\
\hline MTM & 0.14 & 0.33 & 0.24 & 0.30 & 1.2 & 4.9 & 11.6 & 23.1 \\
\hline Non-mining & 0.21 & 0.29 & 0.21 & 0.30 & 0.9 & 3.8 & 10.2 & 23.0 \\
\hline
\end{tabular}

Table 13 Comparison of MTM and non-mining sites for respiratory deposition percent and deposited respiratory mass by month for particles $0.5-20 \mu \mathrm{m}$.

\begin{tabular}{|c|c|c|c|}
\hline & \multicolumn{3}{|c|}{ Median (Interquartile Range) } \\
\hline & $N$ & $\begin{array}{c}\text { Respiratory } \\
\text { Deposition \% } \\
\end{array}$ & $\begin{array}{c}\text { Deposited Respiratory Mass } \\
\mathrm{\mu g} / \mathrm{m}^{3}\end{array}$ \\
\hline \multicolumn{4}{|l|}{ June, 2011} \\
\hline MTM & 6 & $18.1(16.9-18.9)$ & $4.6(4.3-5.2)$ \\
\hline Non-mining & 6 & $16.4(16.3-16.6)$ & $2.6(2.6-2.7)$ \\
\hline$p$-value & & 0.0927 & 0.0172 \\
\hline \multicolumn{4}{|l|}{ July, 2011} \\
\hline MTM & 10 & $22.7(19.2-25.8)$ & $2.8(2.4-3.2)$ \\
\hline Non-mining & 5 & $13.9(13.9-15.4)$ & $0.5(0.5-0.6)$ \\
\hline$p$-value ${ }^{*}$ & & 0.0095 & 0.0095 \\
\hline \multicolumn{4}{|l|}{ August, 2011} \\
\hline MTM & 8 & $19.9(18.1-21.2)$ & $0.9(0.8-1.0)$ \\
\hline Non-mining & 4 & $16.3(13.4-19.0)$ & $0.9(0.7-1.0)$ \\
\hline$p$-value & & 0.1349 & 0.9339 \\
\hline \multicolumn{4}{|c|}{ September, 2011} \\
\hline MTM & 4 & $28.9(27.9-30.0)$ & $1.3(0.6-2.0)$ \\
\hline Non-mining & 2 & $27.0(26.8-27.1)$ & -- \\
\hline$p$-value & & 0.2994 & \\
\hline \multicolumn{4}{|l|}{ October, 2011} \\
\hline MTM & 4 & $31.6(31.4-31.9)$ & $2.2(2.1-2.2)$ \\
\hline Non-mining & 2 & $28.7(27.9-29.6)$ & -- \\
\hline$p$-value & & 0.1661 & \\
\hline \multicolumn{4}{|l|}{ November, 2011} \\
\hline MTM & 4 & $32.4(31.1-32.8)$ & $2.8(1.3-4.3)$ \\
\hline Non-mining & 2 & $33.5(31.7-35.3)$ & $0.21(0.20-0.22$ \\
\hline$p$-value & & 0.8261 & 0.1661 \\
\hline \multicolumn{4}{|l|}{ December, 2011} \\
\hline MTM & 4 & $31.8(30.0-34.8)$ & $0.7(0.6-1.0)$ \\
\hline Non-mining & 3 & $29.1(24.5-29.8)$ & $0.6(0.5-0.6)$ \\
\hline p-value & & 0.0814 & 0.0998 \\
\hline \multicolumn{4}{|l|}{ February, 2012} \\
\hline MTM & 2 & $17.2(16.5-18.0)$ & $1.8(1.7-1.9)$ \\
\hline \multicolumn{4}{|l|}{ April, 2012} \\
\hline MTM & 4 & $23.4(17.4-28.7)$ & $1.0(0.7-1.2)$ \\
\hline Non-mining & 2 & $28.5(28.0-29.1)$ & $1.4(1.4-1.5)$ \\
\hline$p$-value & & 0.6434 & 0.0603 \\
\hline \multicolumn{4}{|l|}{ May, 2012} \\
\hline MTM & 2 & $27.7(26.9-28.6)$ & $3.8(3.7-3.9)$ \\
\hline Non-mining & 2 & $28.6(27.7-30.0)$ & -- \\
\hline$p$-value ${ }^{*}$ & & 0.4386 & \\
\hline
\end{tabular}


Table 14 shows the respiratory deposition percent, number concentration, and deposited number concentration at the MTM and non-mining sites by season for particles 0.01-0.4 $\mu \mathrm{m}$. At all sites, deposition percent was lowest in the summer. Deposition percent was significantly greater at the MTM site during summer and fall. Table 15 indicates the average coefficients and geometric means for the respiratory deposition calculations for particles 0.01-0.4 $\mu \mathrm{m}$ between the MTM sites and non-mining sites throughout the sampling period.

Monthly comparisons indicated a significantly greater deposition percent at the MTM areas in August $(Z=-2.6, p=0.0171)$ and October $(Z=-2.5, p=0.0105)$ (Table 16). The remaining months and seasons had similar deposition percents indicating similar particle distributions. However, number concentration and deposited concentration were significantly greater at MTM sites during June, October, and December. At all sites, the median particle count was highest during the winter season and also high in summer. Deposited number was elevated in the winter and spring months. Overall, the MTM areas had a significantly greater respiratory deposition percent, particle count, and deposited particle count when collapsing all measurements across seasons to compare the mining areas. 
Table 14 Comparison of MTM and non-mining sites for respiratory deposition percent, particle count, and deposited respiratory count by season for particles 0.01-0.4 $\mu \mathrm{m}$.

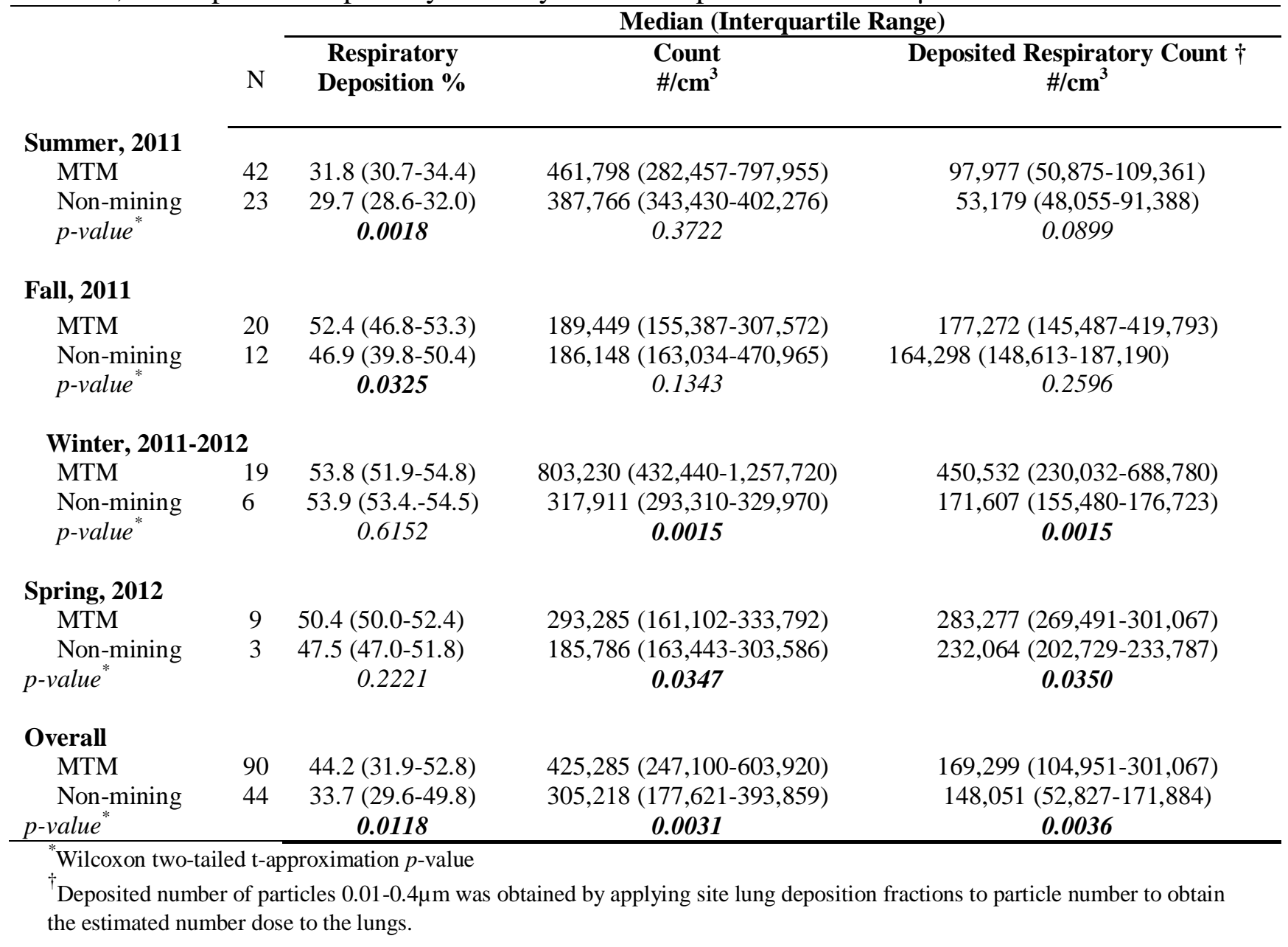

Table 15 Respriatory deposition coefficients and geometric means for particles 0.01-0.4 $\mu \mathrm{m}$.

\begin{tabular}{|c|ccccccccccc|}
\hline & Coefficient 1 & Coefficient 2 & Coefficient 3 & Coefficient 4 & Mode 1 & Mode 2 & Mode 3 & Mode 4 \\
\hline $\begin{array}{c}\text { MTM } \\
\text { Non-mining }\end{array}$ & 0.25 & 0.39 & 0.23 & 0.13 & 0.02 & 0.05 & 0.09 & 0.37 \\
& 0.26 & 0.29 & 0.29 & 0.13 & 0.02 & 0.05 & 0.12 & 0.34 \\
\hline
\end{tabular}


Table 16 Comparison of MTM and non-mining sites for respiratory deposition percent, particle count, and deposited respiratory countby monthfor particles 0.01-0.4 $\mu \mathrm{m}$.

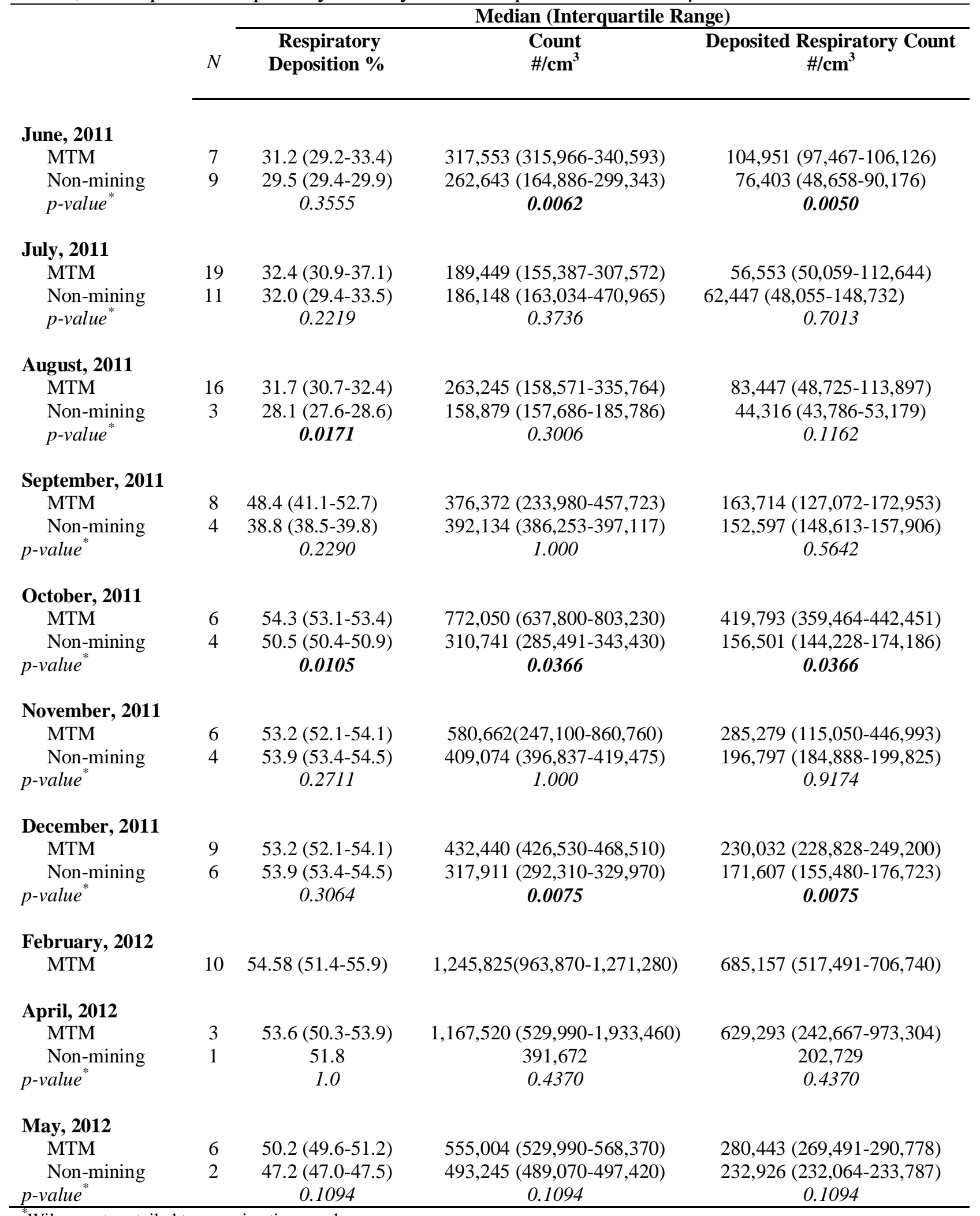

Wilcoxon two-tailed t-approximation $p$-value 


\subsection{Discussion and Conclusions}

This study applied repeated sampling to examine changes in PM at MTM and nonmining sites over an extended time period to build on previous, brief PM sampling data. Extended sampling determined seasonal behavior of mass concentration, number concentration, and deposited lung dose during sampling period at a small number of sites in West Virginia. The maximum PM mass concentrations were found during the summer and the minimum mass concentrations were in the winter. However, statistically significant differences in mass concentration between the MTM and non-mining sites were infrequent and only present during summer months (Table 17). Respiratory deposition percent values were similar across the seasons, except during the summer when the deposition percent was low. The lower respiratory deposition percents in the summer indicate fewer particles in the smaller size ranges during this time. PM growth by absorption and condensation, as well as larger, aged PM, during the summer months would result in a smaller deposition percent. Also, a PM source may have been absent or at an increased distance during the summer months. The respiratory deposition values account for particle size and the relatively comparable values for the remainder of the year indicate consistent PM sources at both sites. However, the number concentration and deposited number concentrations around the MTM area were greater than the non-mining site during the study period denoting increased number of particles from the sources.

Table 17 Summary of significant (+) and non-significant (-) results between MTM and nonmining sites by season.

\begin{tabular}{|c|c|c|c|c|c|c|c|c|}
\hline $\begin{array}{l}\text { ○=Significant } \\
\bullet=\text { Nonsignificant }\end{array}$ & $\begin{array}{c}\text { TSP } \\
\text { Mass } \\
\mu \mathrm{g} / \mathrm{m}^{3}\end{array}$ & $\begin{array}{l}\mathrm{PM}_{10} \\
\mu \mathrm{g} / \mathrm{m}^{3}\end{array}$ & $\begin{array}{l}\mathrm{PM}_{2.5} \\
\mu \mathrm{g} / \mathrm{m}^{3}\end{array}$ & $\begin{array}{c}\text { Respiratory } \\
\text { Deposition } \\
\% \\
\text { PM } 0.5-20\end{array}$ & $\begin{array}{c}\text { Deposited } \\
\text { Respiratory } \\
\text { mass } \\
\text { PM } 0.5-20\end{array}$ & $\begin{array}{c}\text { Respiratory } \\
\text { Deposition } \\
\% \\
\text { PM0.01-.4 }\end{array}$ & $\begin{array}{c}\text { Count } \\
\# / \mathbf{c m}^{3} \\
\text { PM0.01- } \\
.4\end{array}$ & $\begin{array}{c}\text { Deposited } \\
\text { Respiratory } \\
\text { Count } \\
\# / \mathbf{c m}^{3} \\
\text { PM0.01-.4 }\end{array}$ \\
\hline $\begin{array}{l}\text { Summer, } 2011 \\
\text { MTM vs. Non-mining }\end{array}$ & - & - & - & + & + & + & - & - \\
\hline $\begin{array}{l}\text { Fall, } 2011 \\
\text { MTM vs. Non-mining }\end{array}$ & - & - & - & - & - & + & - & - \\
\hline $\begin{array}{l}\text { Winter, 2011-2012 } \\
\text { MTM vs. Non-mining }\end{array}$ & - & - & - & - & - & - & + & + \\
\hline $\begin{array}{l}\text { Spring, } 2012 \\
\text { MTM vs. Non-mining }\end{array}$ & - & - & - & - & - & - & + & + \\
\hline $\begin{array}{l}\text { Overall } \\
\text { MTM vs. Non-mining }\end{array}$ & - & + & - & + & + & + & + & + \\
\hline
\end{tabular}


Multiple modes represented by the particle size distributions indicate multiple particle sources; however, the equipment in this study did not directly identify source. Size distributions of PM specified a peak around 0.02-0.03 $\mu \mathrm{m}$ suggesting the presence of secondary PM manufactured through photochemical reactions converting oxides of nitrogen and sulfur from emission gases to particulates. These secondary particles may be the result of primary PM emissions from coal-fired power plants located northwest and south of the sampling areas in Cincinnati, OH, Columbus, OH, Lexington, KY and the Ohio River Valley area which travel across state boundaries. Health damages from coal-fired power plant emissions occur among populations living both near coal-fired power plants and at a distance (Levy \& Sengler, 2002; MacIntosh et al., 2003).

A peak in the size distributions around 0.05-0.07 $\mu \mathrm{m}$ consists of coagulated soot and accumulation mode particles (Wilson and Suh, 1997). Particles in the larger coarse mode are likely mechanically generated or secondary long-range transported particles. At MTM sites, these coarse particles also include dirt from overburden removal and coal dust primarily composed of crustal elements (Kolker et al. 2012).

Number concentrations at the Green Bank site were lower relative to the MTM sites but were still observed in high concentrations compared to other locations including Los Angeles and Copenhagen, Denmark (Anderson et al., 2008; Hudda et al., 2010). Primary particles, along with photochemically produced PM from urban areas, were transported to the sampling areas and may explain elevated number concentrations at both areas (Hudda et al., 2010). Another explanation for the relatively lower Green Bank number concentrations was the meteorological effect on the transport and dispersion of PM in the atmosphere. Despite the relatively consistent area sources, meteorological conditions influence particle number concentrations across seasons and between sites. Increased airflow, as was present in Green Bank, aided particle transport to the area, yet it also improved dispersion of particles in the atmosphere. The topography of the southern West Virginia mining areas confines airflow in the valleys and shields circulation patterns in the valleys. Air flows up the valley slopes during the daytime as a result of solar heating, but at night the wind reverses coming back down valley slopes trapping contaminants. Inversions of warm air over cooler air may suppress vertical mixing of PM, thereby increasing particle number. However, inversion occurrences were not recorded in this study. Increased relative humidity on some sampling days contributed to growth of PM through condensation. 
Atmospheric processing also changed PM size, shape, composition, and weight through coagulation, absorption, and evaporation.

Mining activity is a possible justification for the greater particle number concentrations in the vicinity of the MTM sites and seasonal differences in particle parameters. In addition, fossil fuel combustion sources, including motor vehicles, diesel engines, and heavy-duty equipment around MTM sampling sites, are major sources of organic compounds and secondary PM (Hilderman et al., 1991). The June 2011 sampling included more sampling sites than in the current study and indicated significantly higher $\mathrm{PM}_{10}$ mass concentrations, number concentrations, and deposited number concentrations at the MTM sites compared to the nonmining site. Both the June 2011 study and this study demonstrate infrequent statistically significant mass concentration differences between the MTM and non-mining sites, but the slight mass concentration differences were not toxicologically significant. Elevated particle number concentrations and particle size distributions leading to an increased particle dose, along with chemical constituents of PM, are a more plausible explanation for health outcome differences between the two areas than particle mass.

A limitation of this study involves shortcomings of the sampling equipment. The rural locations of the sampling sites, as well as limited equipment resources, prevented us from obtaining flow calibration measures of the low-volume pumps during sampling except at pump start and stop times. The differences between start and stop flow measurements indicated that flow decreased during the three to six week sampling period and linear declines in flow were assumed. In some instances (September 2011 and May 2012), the low-volume pumps stopped altogether and no mass concentration was recorded because the pump shut-off time and end flow were unknown. In addition, the filters became overloaded and encrusted with impacted particles making them less efficient at collecting PM and underestimating TSP mass concentration. However, the filter cassettes were a more practical and feasible method for obtaining TSP samples at multiple sites during this annual period compared to other methods, such as a hivolume sampler.

Measurements were carried out with the same instrumentation to obtain comparable data between sites. While the location of the sites was selected based on a number of considerations, the number of measurements at each site was not consistent for the annual sampling period. The findings from this study are based on measurements from three sites with a small number of 
observations each month and season, limiting statistical power. Further examination of the magnitude of PM concentrations needs to be conducted with additional sites, specifically MTM sites. 


\section{References}

Ahern MM, Hendryx M, Conley J, Fedorko E, Ducatman A, Zullig KJ. The association between mountaintop mining and birth defects among live births in central Appalachia, 19962003. Environ Res. 2011;111(6):838-846.

Anderson ZJ, Wahlin P, Raaschou-Nielsen O, Ketzel M, Scheike T, Loft S. Size distribution and total number concentration of ultrafine and accumulation mode particles and hospital admissinos in children and the elderly in Copenhagen, Denmark. Occup Envion Med. 2008;65:458-466.

Costa DL, Dreher KL. Bioavailable transition metals in particulate matter mediate cardiopulmonary injury in healthy and compromised animal models. Environ Health Perspect. 1997;105(5):1053-1060.

Dockery DW. Epidemiologic evidence of cardiovascular effects of particulate air pollution. Environ Health Perspect. 2001;109 Suppl 4:483-486.

Dockery DW, Pope CA 3rd, Xu X, et al. An association between air pollution and mortality in six U.S. cities. N Eng J Med. 1993;329(24):1753-1759.

Dominici F, Peng RD, Bell ML et al. Fine particulate air pollution and hospital admission for cardiovascular and respiratory diseases. JAMA. 2006;295(10):1127-1134.

Donaldson K, Stone V, Clouter A, Renwick L, MacNee W. Ultrafine particles. Occup Environ Med. 2001;58:211-216.

Esch L, Hendryx M. Chronic cardiovascular disease mortality in mountaintop mining areas of central Appalachian states. J Rural Health. 2011;27(4):350-357.

Ghose MK, Majee SR. Characteristics of hazardous airborne dust around an Indian surface coal mining area. Environ Monit Assess. 2007;130(1-3):17-25.

Hendryx M. Mortality from heart, respiratory, and kidney disease in coal mining areas of Appalachia. Int Arch Occup Environ Health. 2009;82:243-249.

Hendryx M. Poverty and mortality disparities in central Appalachia:mountaintop mining and environmental justice. Journal of Health Disparities Research and Practice. 2011;4(3): 44-53.

Hendryx M, Ahern MM. Relations between health indicators and residential proximity to coal mining in West Virginia. Am J Public Health. 2008;98(4):669-671.

Hendryx M, Wolfe L, Luo J, Webb B. Self-reported cancer rates in two rural areas of West Virginia with and without mountaintop coal mining. J Community Health. 2011;37(2):320-327. 
Hendryx M, Zullig KJ. Higher coronary heart disease and heart attack morbidity in Appalachian coal mining regions. Prev Med. 2009;49:5.

Hinds WC. Aerosol Technology: Properties, Behavior, and Measurement of Airborne Particles. Vol 2. New York: John Wiley \& Sons, Inc.;1999.

Hogg JC, van Eeden S. Pulmonary and systemic response to atmospheric pollution. Respirology. 2009;14(3):336-346.

Hudda N, Cheung K, Moore KF, Sioutas C. Inter-community variability in total particle number concentrations in the eastern Los Angeles air basin. Atmos Chem Phys. 2010;10:1138511399.

Levy JI, Spengler JD. Modeling the benefits of power plant emissions controls in Massachusetts. J Air \& Waste Manage Assoc. 2002;52:5-18.

MacIntosh DL, Levy JI, Spengler JD. Testimony before the Wisconsin Public Service Commission: Matter of a Pollution Control Construction Permit, Case No. IH-04-03. 2003.

McCawley MA, Kent MS, Berakis MT. 2001. Ultrafine beryllium number concentration as a possible metric for chronic beryllium disease risk. App Occup Environ Hyg. 2001;16(5): 631-638.

National Oceanic and Atmospheric Administration (NOAA). Average Relative Humidity (\%).National Climatic Data Center. 2008. Available at: http://www.ncdc.noaa.gov/oa/climate/online/ccd/avgrh.html. Accessed 20 August, 2012.

Peters A, Dockery DW, Muller JE, Mittleman MA. Increased particulate air pollution and the triggering of myocardial infarction. Circulation. 2001;103(23):2810-2815.

Pope CA 3rd, Dockery DW. Health effects of fine particulate air pollution:lines that connect. $J$ Air \& Waste Manage Assoc. 2006;56:709-742.

Pope CA 3rd, Burnett RT, Thun MJ et al. Lung cancer, cardiopulmonary mortality, and longterm exposure to fine particulate air pollution. JAMA. 2002;287(9):1132-1141.

Pond G, Passmore M, Borsuk F, Reynolds L, Rose C. Downstream effects of mountaintop coal mining: comparing biological conditions using family-and genus-level macroinvertebrate bioassessment tools. Journal of North American Benthological Society. 2008;27(3):717737.

Schwartz J. What are people dying of on high air pollution days? Environ Research. 1994; 64(1):26-35. 
Sioutas C, Delfino RJ, Singh M. Exposure assessment for atmospheric ultrafine particles (UFPs) and implications in epidemiologic research. Environ Health Perspect. 2005;113:947-955.

Stahlhofen W, Rudolf G, James AC. Intercomparison of experimental regional aerosol deposition. J Aerosol Med. 1989;2(3):285-308.

University of Wisconsin Population Health Institute, (2012).County health rankings 2012.2012. Available at: http://www.countyhealthrankings.org/\#app/west-virginia/2012. Accessed 7 October 2012.

U.S. Census Bureau. American FactFinder. 2011. Available at: http://factfinder2.census.gov/faces/nav/jsf/pages/index.xhtml. Accessed 11 August 2012.

U.S. EPA (Environmental Protection Agency).Mid-Atlantic Mountaintop Mining. Available at: http://www.epa.gov/Region3/mtntop/. 2011. Accessed March 14, 2010.

WVDoT (West Virginia Department of Tourism). Pocahontas County. 2006. Available at: http://www.pocahontascountywv. com/files/quick_county_facts.pdf. Accessed 2 November 22011.

WV MHS\&T (West Virginia Office of Miners' Health Safety and Training).2011 Calendar Year Statistical Report. 2012. Available: http://www.wvminesafety.org/2011statisticalreport.htm. Accessed 22 September 2012.

Zullig KJ, Hendryx M. Health-related quality of life among central Appalachian residents in mountaintop mining counties. Am J Public Health. 2011;101(5):848-853. 
Chapter 4

Elemental Composition and Concentration of Atmospheric Particulate Matter in West Virginia Mountaintop Mining Areas 


\subsection{Introduction}

Particulate matter (PM) is a combination of solid particles and liquid droplets of various sizes, shapes, and compositions suspended in the air. Primary pollutants originate directly from natural and anthropogenic sources. Secondary pollutants originate indirectly from chemical and thermal reactions converting existing atmospheric PM and gases into secondary PM (Hinds, 1999). Natural and anthropogenic particle origins, as well as time in the atmosphere, reflect particle composition, morphology, and size.

Oxidant gases, organic compounds, and transition metals absorb or condense onto air particles during their lifetime in the atmosphere and influence composition and pathophysiological response in the respiratory system (Moreno, 2004; Oberdorster, 2001). Particles depositing in the lungs or infiltrating lung epithelial cells stimulate oxidative stress and inflammatory response (Costa \& Dreher, 1997; Hogg \& van Eeden, 2009). Toxic elements, as components of PM, increase inflammatory response and oxidative stress resulting in an augmented potential for health effects (Wilson et al., 2002). Partially size-classified, mass-based PM concentrations $\left(\mathrm{PM}_{10}\right.$ and $\left.\mathrm{PM}_{2.5}\right)$ from a central monitor are frequently used to measure $\mathrm{PM}$ exposure in dose-response population studies, however, particle elemental composition helps classify PM and assess PM-related health impacts (Ghio \& Devin, 2000; Schwartz \& Meas, 2000).

The health-effects from PM exposures of the same mass but different compositions are distinct. For example, exposure to PM from an active Utah Valley steel mill resulted in greater pulmonary inflammatory effects and injury compared to exposure to an equal PM mass collected during a 13-month inactive period when the mill closed. Although epidemiological evidence indicated that reduced PM mass during the closing was associated with a decrease in morbidity and mortality, chemical properties and morphology of particles, along with particle size, may be better indicators of health effects than particle mass (Adamson et al., 2000; Ghio \& Devin, 2000; Richards, 1997). The change in particle composition during the mill closing (including decreases in $\mathrm{Fe}, \mathrm{Cu}, \mathrm{Zn}, \mathrm{Pb}, \mathrm{Ni}$, and $\mathrm{V}$ ) suggests particle composition is indicative of adverse health effects (Ghio \& Devin, 2000).

An active coalmine generates PM from a variety of activities including, but not limited to, coal mining, cleaning, and transportation (Finkelman \& Gross 1999). The PM around coal mines contains elements found in coal (C, H, Al, Fe, Mg, Ca, $\mathrm{Na}, \mathrm{K}, \mathrm{S}$, and trace elements of 
metals including As, Be, Cd, Co, Cr, Hg, Mn, Ni, Pb, Sb, Se, and U; Finkelman \& Gross 1999; Mastin 2005; Menke et al. 2006). Mountaintop mining (MTM) is a form of surface coal mining that uses explosives and excavation methods to remove vegetation, rock, and other crustal materials from the surface of mountaintops to expose the coal seams beneath. Coal is extracted using surface mining techniques, and debris removed from the mountain surface is deposited in nearby valleys (U.S. EPA, 2011). MTM is common in some Appalachian states, including West Virginia (U.S EPA, 2011). Due to the use of heavy equipment, fossil fuel combustion sources, erosion, and resuspension of PM by the wind at MTM sites, it is expected that PM around MTM sites is different in comparison to PM around non-MTM sites (U.S. EPA, 2011).

Preliminary analyses of high-volume PM samplers at MTM and non-mining areas during brief 24-hour sampling periods indicated higher proportions of crustal elements (elements more abundant in the earth's crust) in the MTM areas sampled (Kolker et al., 2012). Geochemical window wipe PM samples reported heavier anthropogenic enrichment at the non-mining sites indicating dilution by crustal materials at sites in close proximity to MTM operations. Organics sampled from windows of residents in MTM areas were dominated by low molecular weight alkylated compounds suggesting derivation from coal rather than coal combustion (Kolker et al., 2012). These preliminary studies from brief sampling periods used bulk analysis techniques (ICP-MS and GS-MS) to report air contaminants during a limited time period in June, August, and December 2011.

Individual particle composition data are still needed for PM from MTM areas. Obtaining individual particle composition data is important to describe the characteristics of the diverse particles from a sample since bulk analysis does not account for particle heterogeneity. Chemical characterization of individual particles also offers the opportunity to specify potential PM sources. The purposes of this study were to use individual particle analysis to analyze TSP collected on filters to 1) identify the most abundant individual elements and 2) classify particle compounds of PM around MTM and non-MTM sites.

\subsection{Methods}

\subsubsection{Sampling Sites}


Total suspended particle (TSP) samples from three rural residential sites in West Virginia were collected over multiple time periods during a one-year time span. The Edwight and Twilight sites were situated in two adjacent counties (Boone County and Raleigh County) where MTM is prominent, along with other types of coal mining activity (underground mines, processing facilities). These sites were matched to a non-mining site (Green Bank) in eastern West Virginia where no recent mining activity has occurred and about $60 \%$ of the land is federal or state owned (WV DOT, 2006) (Figure 9).

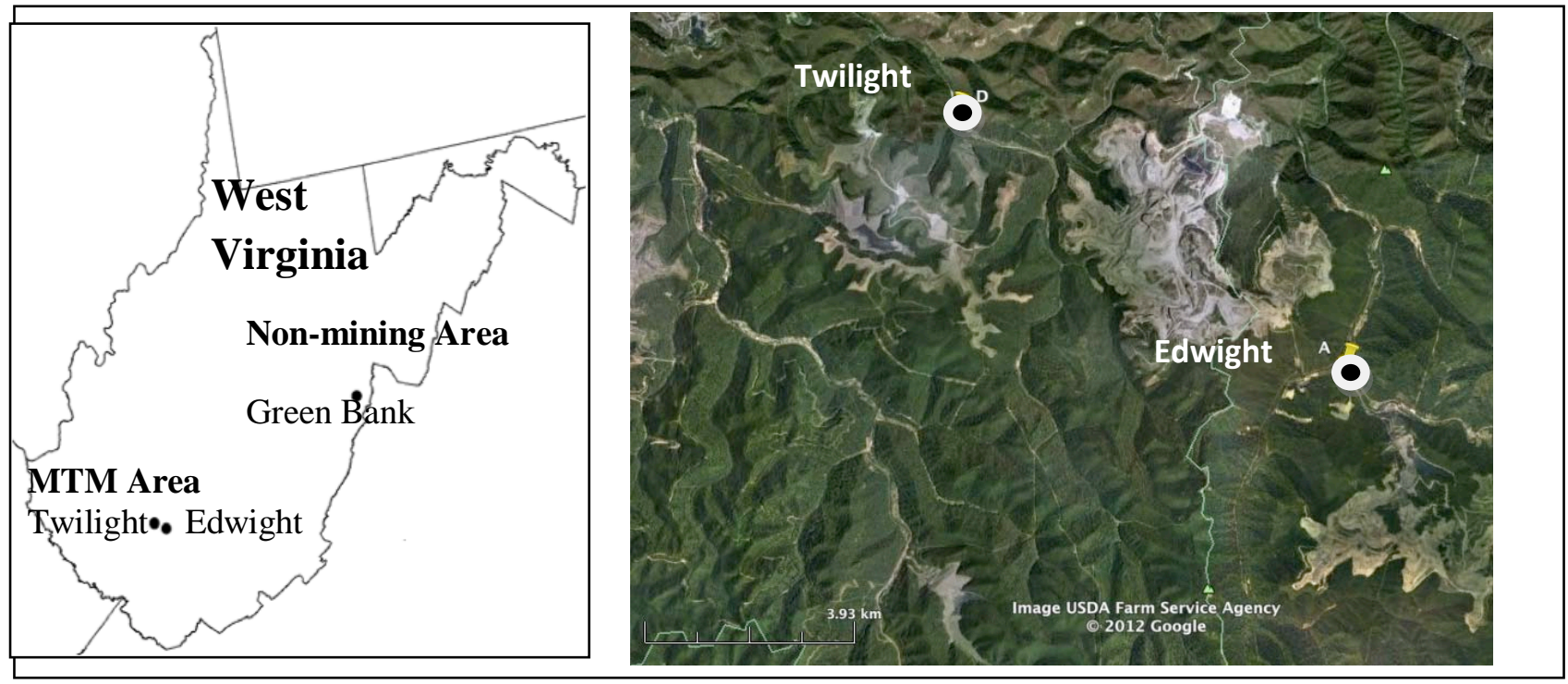

Figure 9 Locations of the MTM sampling sites in southern West Virginia and the non-mining sampling site in eastern West Virginia.

\subsubsection{Sampling collection}

A low-volume vacuum pump (Model 1531-1078-G288x, Gast Manufacturing Inc., Benton Harbor, MI) was set up at each of the three sites. Each pump was connected to a TSP filter and run for a three to six week period to collect PM on the filter. The filters were collected from each site every three to six weeks to prevent filter overload, and new filters replaced the loaded filters to obtain consecutive PM samples from each site during the period of June, 2011 to May, 2012 (Table 18).

TSPs were collected on a PTFE coated glass fiber filter (37mm diameter, 5.0 $\mu \mathrm{m}$ diameter pore-size, SKC Inc, Eighty Four, PA) placed in a two-piece plastic filter cassette connected to the low-volume vacuum pump. The low-volume pumps were in water-resistant boxes to protect them from water and the elements. Each filter was equilibrated for 24 hours at constant relative 
temperature and placed in the filter cassette on top of a support pad to prevent filter fibers from rupturing. Cassette pieces were sealed together with tape to eliminate particles from leaking into the cassette or bypassing the filter.

\subsubsection{Individual Particle Analysis}

A JEOL JSM-7600F scanning electron microscope (SEM) (JEOL, LTD., Tokyo, Japan) was combined with an Energy Dispersive X-ray Spectrometer (EDX) (Oxford Inca, Oxford Instruments, Oxfordshire, UK) for individual air particle composition analysis. In preparation for SEM-EDX analysis, a small sample (approximately $2 \mathrm{~cm}^{2}$ ) of the filter was cut and mounted on a brass specimen stub (comprised of copper and zinc) with double-sided adhesive copper tape. Approximately 4-5 samples were cut from each filter, and 20-25 individual particles were randomly chosen from multiple fields of view from each filter sample for analysis. A total of 100 particles per filter were analyzed using the SEM-EDX software's Spot \& ID EDX Analysis Mode.

Table 18 PM collection dates for MTM sites and Non-mining site from June, 2011-May, 2012 with number of particles analyzed in parenthesis (n).

\begin{tabular}{c|c|c|c}
\hline \multirow{2}{*}{ Season } & \multicolumn{2}{|c|}{ MTM Sites (n) } & Non-mining Site (n) \\
\hline Summer 2011 & June 6-7 (97) & Twilight & Green Bank \\
& July 11-Aug. 5 (96) & July 11-Aug. 5 (104) & July 11-Aug. 5 (153) \\
& Aug. 5-Sept. 11 (100) & Aug. 5-Sept. 11 (100) & Aug. 5-Sept. 11 (100) \\
Fall 2011 & Oct. 8-26 (100) & Oct. 8-26 (100) & Oct. 8-26 (100) \\
& Nov. 14-Dec. 4 (99) & Nov. 14-Dec. 4 (100) & Nov. 14-Dec. 4 (100) \\
Winter 2012 & Jan. 16-Feb. 19 (101) & Jan. 16-Feb. 19 (100) & Jan. 16-Mar. 2 (100) \\
Spring 2012 & Feb. 19-Apr. 3 (101) & Feb. 19-Apr. 3 (100) & - \\
& Apr. 3- May 7 (100) & - & Apr. 3- May 7 (100) \\
\hline
\end{tabular}

The EDX analysis technique acquires the peak intensities of X-rays emitted from each spot on a particle to determine chemical composition using the INCA Energy software program. Focusing an electron beam on the particle causes secondary electrons to be emitted, converted to an electric signal, and be detected by an X-ray detector. The converted X-ray energy corresponds to a specific element, which is thereby identified. In this study, the SEM-EDX 
performed semi-quantitative elemental analysis on samples by acquiring the X-ray spectrum emitted from a particle site and reporting the element concentration in atomic weight. In addition, we used a direct method to measure particle diameter and observed morphological characteristics for each analyzed particle.

Since the elements of the particle were unknown, the accelerating voltage was set to $20 \mathrm{kV}$ in order to receive sufficient X-rays to detect most elements. The working distance between the lower piece of the objective lens and the electron plane was set to $15 \mathrm{~mm}$ and live time was set to 100 seconds for X-ray acquisition on the uncoated samples. Many accumulation mode particles were present as constituents of other particles with chemicals reflecting their atmospheric history. The microscope magnification was set to 2000-3500x to analyze particles with a horizontal or vertical diameter 0.5 to $20 \mu \mathrm{m}$ due to magnification limitations of the SEM.

Elements with weight percents less than $1 \%$ were not specified because they were below the EDX detection limit (Martinez et al. 2008). An analysis of a blank PTFE coated glass fiber filter revealed large amounts of carbon $(M=221,790$ ppm, SD=112,182) and fluorine $(\mathrm{M}=873,967 \mathrm{ppm}, \mathrm{SD}=173,607)$ in the filter (Figure 10). As a result, carbon and fluorine were not determined in the SEM-EDX analysis due to their concentration on the PTFE filter, and oxygen was not determined due to its presence in the main specimen chamber. A quant optimization was performed on the copper stub before each set of analysis, and copper and zinc were removed due to their presence on the brass specimen stub. Corrected relative weight percentages were presented rather than absolute weight percentages, and elements were normalized to $100 \%$ to correct for contribution of filter and brass stub materials.

\subsubsection{Analysis}

The Edwight and Twilight site particles were combined to create the MTM group for the purpose of this analysis. Elemental frequencies and concentrations were examined for each season using seasonal groupings determined by meteorological and elemental similarities between months, not the actual astronomical season. For example, June 2011 was grouped as a summer season because the elemental concentrations looked more like July 2011 than April 2012 (Spring) for Edwight and Green Bank and were similar to both July 2011 and April 2012 for Twilight. The SEM-EDX individual particle analysis determined bulk elemental concentration of each particle. The proportions of particles with a particular element were 
quantified to determine the most abundant elements by frequency. To determine if the proportion of particles with a given element was significantly different between MTM and nonmining sites, a Pearson chi-square was conducted (Fisher's exact methods were used when the frequency per cell was less than five). Wilcoxon signed-rank tests were carried out between MTM and non-mining sites to compare median weight values for each site by season. Exact methods were used due to numerous ties in the rank scores. Median values for the most prominent elements were compared between the MTM and non-mining sites by season. Particles were composed of either a single element or multiple elements that made up a compound. The elemental concentration of each particle was also examined, along with particle morphologies, in order to characterize compounds and minerals including aluminosilicates, silicates, sulfates, calcium, iron, and fly ash.

11a

11b

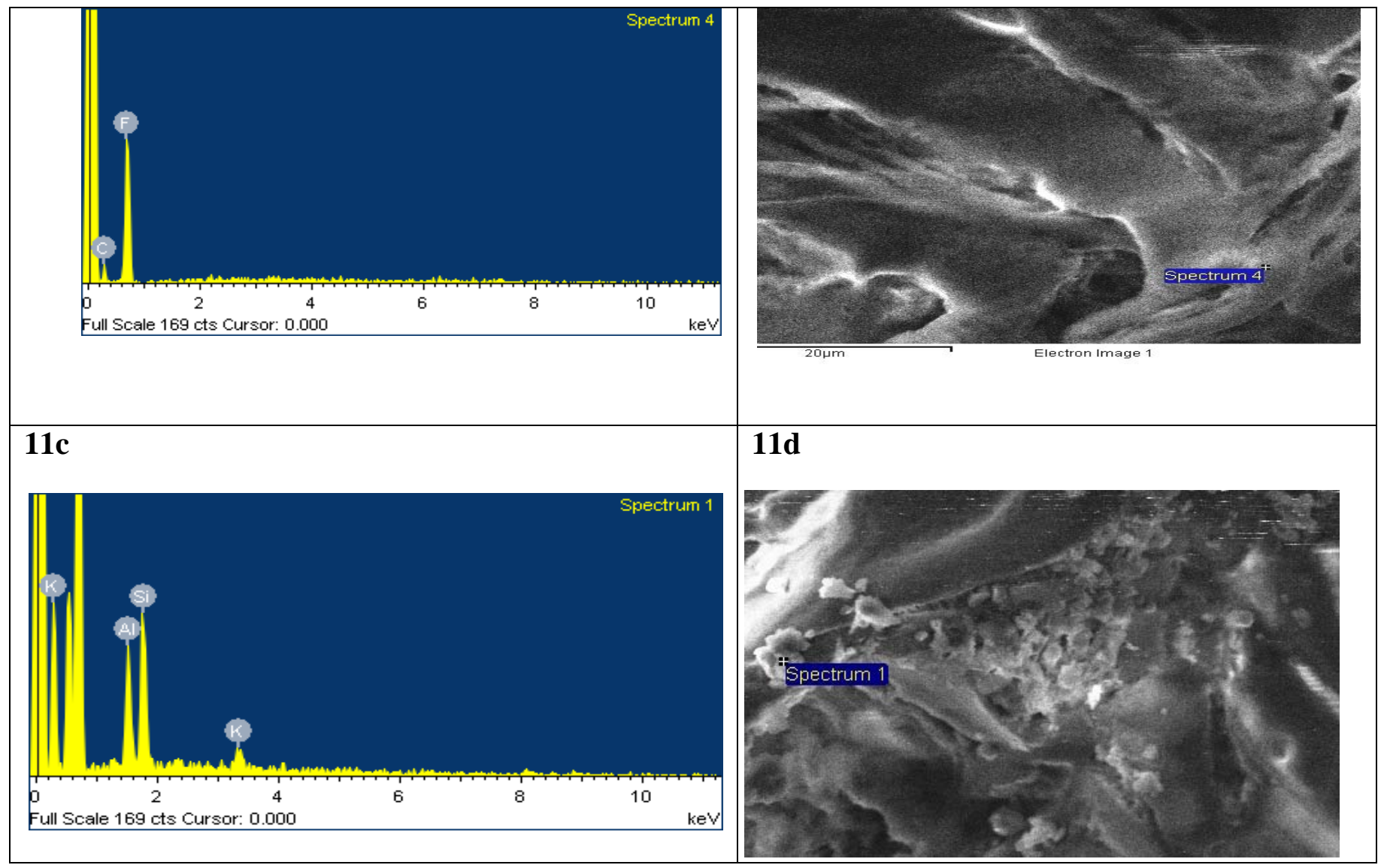

Figure 11 (a) SEM-EDX Inca Energy analysis of a blank; (b) Blank filter corresponding to SEM-EDX Inca Energy analysis in (11a); (c) SEM-EDX Inca Energy analysis of particle from Edwight WV, June, 2011; (d) TSP sample corresponding to the individual particle analysis in (11c). 


\subsection{Results}

\subsubsection{Elemental Analysis}

A total of 23 elements were identified on the analyzed TSP samples by the SEM-EDX analysis, and nine of those elements (Mg, Al, Si, S, K, Ca, Fe, Na, and Mo) were in all seasonal samples. The average proportion of particles with a specified element was calculated for each seasonal sample (Figure 12). The presented results are semi-quantitative and describe changes in element abundance. $\mathrm{Al}, \mathrm{Si}, \mathrm{S}$, and $\mathrm{K}$ were the most abundant and were present in approximately $30 \%$ or more of the particles from all seasonal samples.

A chi-square test of independence was performed to examine the relationship between the proportion of particles with a specific element and mining activity. The relations between PM elemental proportion distributions and mining area were inconsistent in their direction of effect based on season. $\mathrm{Mg}, \chi^{2}(1, \mathrm{~N}=949)=10.11, \mathrm{p}=.0015$, and $\mathrm{Fe}, \chi^{2}(1, \mathrm{~N}=949)=45.31, \mathrm{p}=<.0001$, were more likely to be present in PM from MTM summer samples compared to non-mining site summer samples. However, $\mathrm{Mg}, \chi^{2}(1, \mathrm{~N}=599)=8.6, \mathrm{p}=.0033$, and $\mathrm{Fe}, \chi^{2}(1, \mathrm{~N}=599)=12.58$, $\mathrm{p}<.0004$, were significantly lower at MTM fall samples and spring samples (Mg, $\chi^{2} \quad(1$, $\mathrm{N}=400)=3.87, \mathrm{p}=.0492$ and $\left.\mathrm{Fe}, \chi^{2}(1, \mathrm{~N}=400)=4.73, \mathrm{p}=.0297\right)$ compared to the non-mining site. There was a significant relationship between Si at MTM sites in summer, $\chi^{2}(1, N=949)=183.50$, $\mathrm{p}<.0001$, and spring, $\chi^{2}(1, \mathrm{~N}=400)=5.14, \mathrm{p}=.0234$, compared to the non-mining site. S was more likely to be present in non-mining sites during summer, $\chi^{2}(1, \mathrm{~N}=949)=67.33, \mathrm{p}<.0001$, and winter, $\chi^{2}(1, N=301)=9.93, p=.0016$, but was significantly more likely to be in MTM sites PM during spring, $\chi^{2}(1, \mathrm{~N}=400)=16.85$, $\mathrm{p}<.0001$. MTM was associated with greater Ca in PM during summer, $\chi^{2}(1, \mathrm{~N}=949)=18.28, \mathrm{p}<.0001$, while non-mining was associated with Ca during the other three seasons $\left(\mathrm{p}^{<.05}\right)$. Na was greater at the non-mining site during summer, $\chi^{2}(1$, $\mathrm{N}=949)=57.09, \mathrm{p}<.0001$, and spring, $\chi^{2}(1, \mathrm{~N}=400)=1.39, \mathrm{p}=.0239$. Figure 12e indicated Al, $\chi^{2}$ $(1, \mathrm{~N}=2,249)=75.36, \mathrm{p}<.0001, \mathrm{Si}, \chi^{2}(1, \mathrm{~N}=2,249)=15.38, \mathrm{p}<.0001, \mathrm{~K}, \chi^{2}(1, \mathrm{~N}=2,249)=16.64, \mathrm{p}$ $<.0001$, and $\mathrm{Br}, \chi^{2}(1, \mathrm{~N}=2,249)=8.22, \mathrm{p}=.0041$, were significantly associated with MTM areas when removing the seasonal effect. Around the non-mining site, $\mathrm{S}, \chi^{2}(1, \mathrm{~N}=2,249)=53.18, \mathrm{p}$ $<.0001, \mathrm{Ca}, \chi^{2}(1, \mathrm{~N}=2,249)=28.24, \mathrm{p}<.0001, \mathrm{Na}, \chi^{2}(1, \mathrm{~N}=2,249)=41.71, \mathrm{p}<.0001$, and $\mathrm{Cl}, \chi^{2}$ $(1, N=2,24953)=15.04, \mathrm{p}<.0001$ were more likely to be present in the PM when collapsing the analysis across seasons. 
12a. Summer

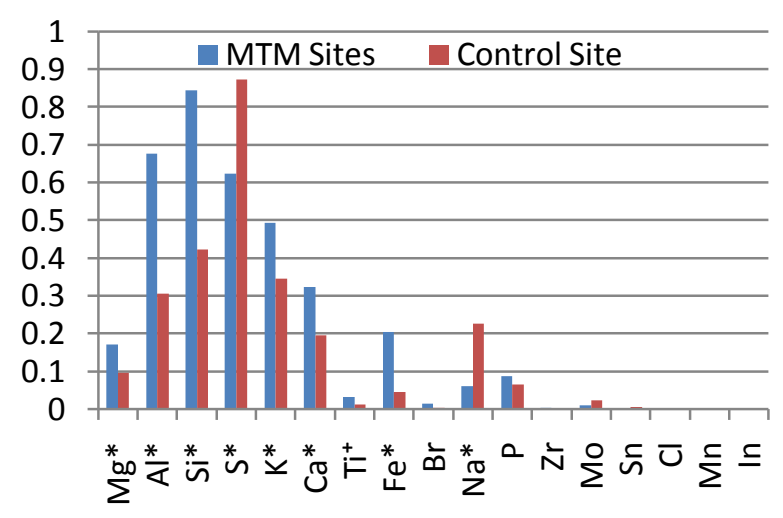

\section{2c. Winter}

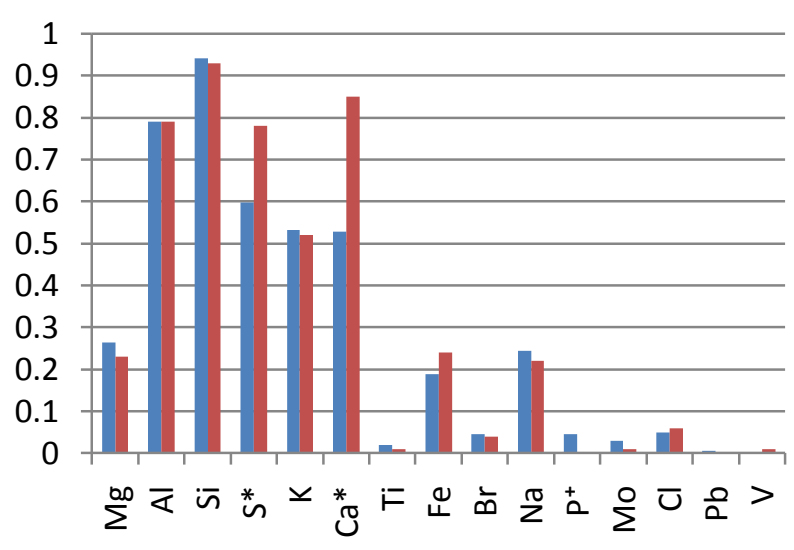

12d. Spring 12b. Fall

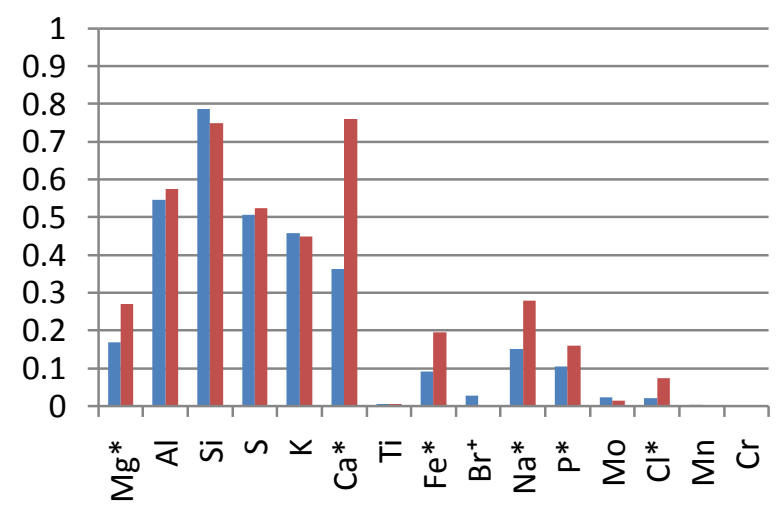

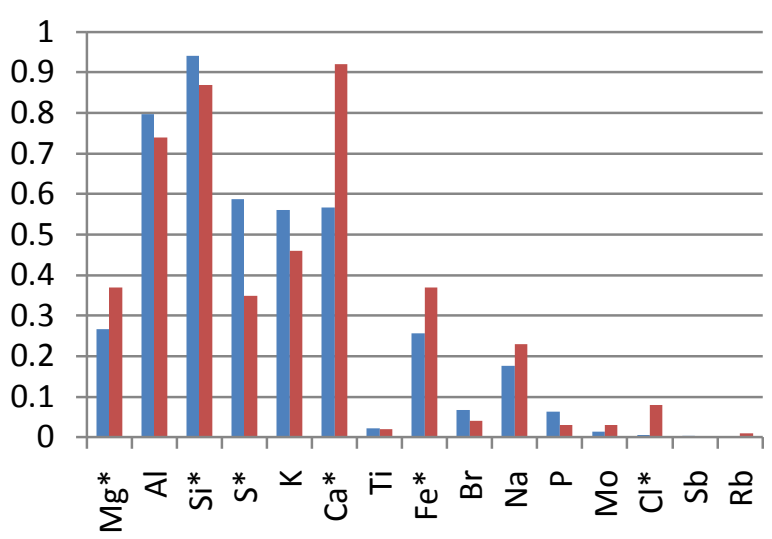

\section{2e. Overall Comparison}

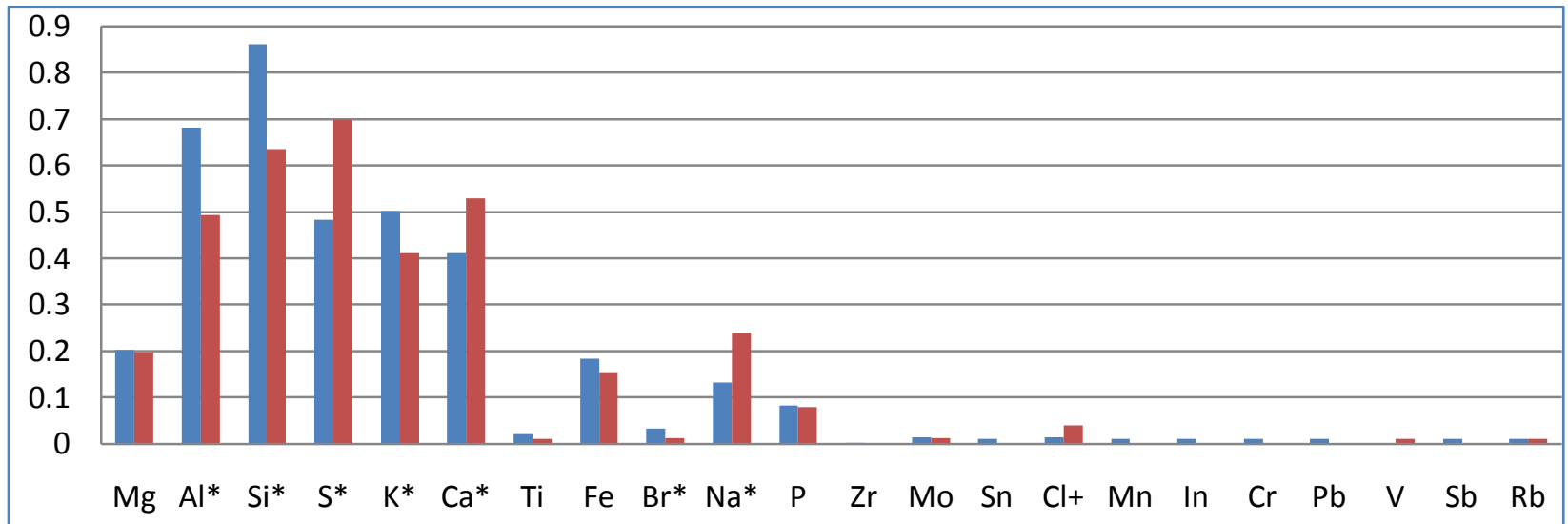

*Seasonal difference significant at $p<0.05$ corresponding to Pearson chi-square $\dagger$ Seasonal difference significant at $p<0.05$ corresponding to Fisher's exact test

Figure 12 Proportion of particles with the presence of an element by season and site. 
Table 19 reports the median weight percents of elements for both the MTM and nonmining sites. A Wilcoxon signed-rank test showed a significant effect of mining activity for all elements during the summer. An analysis of the direction of effect indicated significantly greater median weight percents at the MTM sites for all elements except S, which was greater at the non-mining sites. During the fall season, the non-mining site had a greater median weight concentration of $\mathrm{Mg}(Z=3.2, \mathrm{p}=.0015)$ and $\mathrm{Ca}(Z=10.1, \mathrm{p}<.0001)$, whereas there was no difference between the two sites in S weight. As winter moved in, there was no difference between the two areas in $\mathrm{Mg}, \mathrm{K}, \mathrm{Fe}$, and Na weight. In winter, $\mathrm{Al}(Z=-2.2, \mathrm{p}=.0290)$ and $\mathrm{Si}(Z=-$ 2.8, $\mathrm{p}=.0046)$ were significantly greater at the MTM sites while $\mathrm{S}(Z=3.7, \mathrm{p}=.0002)$ and Ca $(Z=5.6, \mathrm{p}<.0001)$ were significantly greater at the non-mining site. In spring, $\mathrm{Al}(Z=-3.3$, $\mathrm{p}=.0012)$ and $\mathrm{Si}(\mathrm{Z}=-4.4, \mathrm{p}<0001)$ remained statistically greater at the MTM sites, and $\mathrm{S}$ was also present in higher concentrations. $\mathrm{Mg}(Z=2.0, \mathrm{p}=.0416)$ and $\mathrm{Ca}(Z=8.0, \mathrm{p}<.0001)$ had elevated weight concentrations at the non-mining site compared to the MTM site.

\subsubsection{Element Groups}

Particles were categorized by elemental composition into specific particle groups (Table 20). Particle morphological characteristics from the SEM helped determine irregular mineral particles and fly ash. The average proportion was calculated for each seasonal sample (Figure 13). Discrepancies were present in the particle compounds between mining and non-mining sites. During the summer season (Figure 13a), the proportions of particles with compounds AlSi, $\chi^{2}(1, \mathrm{~N}=940)=62.5, \mathrm{p}<.0001, \mathrm{Si}, \chi^{2} \quad(1, \mathrm{~N}=940)=18.8, \mathrm{p}<.0001$, and Fe, $\chi^{2}$ (1, $\mathrm{N}=940)=4.8, \mathrm{p}=.0387$, were significantly greater at the MTM site compared to the non-mining site. At the non-mining site, $\mathrm{S}, \chi^{2}(1, \mathrm{~N}=940)=98.2, \mathrm{p}<.0001$, and $\mathrm{S}$ with $\mathrm{K}$ and $\mathrm{Na}, \chi^{2}(1$, $\mathrm{N}=940)=58.7, \mathrm{p}<.0001$, were present in greater proportions than at the MTM site for the summer. During the fall, the MTM site had higher AlSi, $\chi^{2}(1, \mathrm{~N}=597)=19.4, \mathrm{p}<.0001, \mathrm{Si}, \chi^{2}(1$, $\mathrm{N}=597)=10.7, \mathrm{p}<.0001$, and $\mathrm{K}, \chi^{2}(1, \mathrm{~N}=597)=6.1 \mathrm{p}=.0109$, compared to the non-mining site. However, at the non-mining site during the fall, $\mathrm{Ca}, \chi^{2}(1, \mathrm{~N}=597)=48.2, \mathrm{p}<.0001, \mathrm{CaS}, \chi^{2}(1$, $\mathrm{N}=597)=5.0, \mathrm{p}=.0257$, and $\mathrm{Na}, \chi^{2}(1, \mathrm{~N}=597)=6.1, \mathrm{p}=.0361$ were present in greater proportions than at the MTM site. 
Table 19 Median weight percent concentration (Interquartile range) of elements measured in MTM and non-mining sites PM by season.

\begin{tabular}{|c|c|c|c|c|c|c|c|c|c|}
\hline & & \multicolumn{8}{|c|}{$\begin{array}{c}\text { Median (Interquartile Range) } \\
\text { Mean }\end{array}$} \\
\hline & $\mathbf{N}$ & Mg & Al & Si & $\mathrm{S}$ & $\mathbf{K}$ & $\mathbf{C a}$ & Fe & $\mathrm{Na}$ \\
\hline \multicolumn{10}{|l|}{ Summer 2011} \\
\hline MTM & 596 & $\begin{array}{c}0(0-0) \\
1.0\end{array}$ & $\begin{array}{c}10.9(0-21.3) \\
12.4\end{array}$ & $\begin{array}{c}42.3(16.9-59.9) \\
42.4\end{array}$ & $\begin{array}{c}9.3(0-37.6) \\
23.2\end{array}$ & $\begin{array}{c}0(0-9.4) \\
5.9\end{array}$ & $\begin{array}{c}0(0-5.7) \\
8.2\end{array}$ & $\begin{array}{c}0(0-0) \\
2.9\end{array}$ & $\begin{array}{c}0(0-0) \\
0.8\end{array}$ \\
\hline Non-mining & 353 & $\begin{array}{c}0(0-0) \\
1.0\end{array}$ & $\begin{array}{c}0(0-6.7) \\
5.2\end{array}$ & $\begin{array}{c}0(0-28.1) \\
16.4\end{array}$ & $\begin{array}{c}52.5(31.3-100) \\
57.1\end{array}$ & $\begin{array}{l}0(0-9.8) \\
6.5\end{array}$ & $\begin{array}{l}0(0-0) \\
5.2\end{array}$ & $\begin{array}{c}0(0-0) \\
0.6\end{array}$ & $\begin{array}{c}0(0-0) \\
4.6\end{array}$ \\
\hline p-value* & & 0.0080 & $<0.0001$ & $<0.0001$ & $<0.0001$ & 0.0219 & 0.0002 & $<0.0001$ & $<0.0001$ \\
\hline \multicolumn{10}{|l|}{ Fall 2011} \\
\hline MTM & 400 & $\begin{array}{c}0(0-0) \\
1.4 \\
\end{array}$ & $\begin{array}{c}4.8(0-19.0) \\
9.8\end{array}$ & $\begin{array}{c}42.3(6.6-64.1) \\
41.1 \\
\end{array}$ & $\begin{array}{c}3.4(0-38.1) \\
22.4\end{array}$ & $\begin{array}{c}0(0-10.3) \\
6.8 \\
\end{array}$ & $\begin{array}{c}0(0-13.3) \\
11.0 \\
\end{array}$ & $\begin{array}{c}0(0-0) \\
1.6\end{array}$ & $\begin{array}{c}0(0-0) \\
1.8\end{array}$ \\
\hline Non-mining & 200 & $\begin{array}{l}0(0-2.9) \\
2.2\end{array}$ & $\begin{array}{l}4.0(0-11.6) \\
6.6\end{array}$ & $\begin{array}{c}18.4(1.0-37.6) \\
23.9\end{array}$ & $\begin{array}{l}3.8(0-28.2) \\
26.4\end{array}$ & $\begin{array}{l}0(0-5.5) \\
3.2\end{array}$ & $\begin{array}{l}21.6(3.6-56.5) \\
32.3\end{array}$ & $\begin{array}{c}0(0-0) \\
3.9\end{array}$ & $\begin{array}{c}0(0-3.7) \\
4.7\end{array}$ \\
\hline$p$-value* & & 0.0015 & 0.0341 & $<0.0001$ & 0.5023 & 0.0114 & $<0.0001$ & 0.0003 & 0.0001 \\
\hline \multicolumn{10}{|c|}{ Winter 2011-2012 } \\
\hline MTM & 201 & $0(0-1.8)$ & $10.5(3.7-18.7)$ & $43.9(27.3-62.1)$ & $6.1(0-22.3)$ & $2.5(0-7.4)$ & $4.1(0-7.4)$ & $0(0-0)$ & $0(0-0)$ \\
\hline Non-mining & 100 & $0(0-0)$ & $7.5(2.4-15.6)$ & $35.6(14.2-52.4)$ & $15.8(5.0-34.3)$ & $2.0(0-5.3)$ & $18.8(6.3-41.5)$ & $0(0-0)$ & $0(0-0)$ \\
\hline p-value* & & 0.5292 & 0.0290 & 0.0046 & 0.0002 & 0.2182 & $<0.0001$ & 0.3717 & 0.6577 \\
\hline \multicolumn{10}{|l|}{ Spring 2012} \\
\hline MTM & 300 & $0(0-1.5)$ & $11.9(4.1-22.1)$ & $46.1(22.2-60.9)$ & $6.3(0-22.9)$ & $3.2(0-8.0)$ & $3.4(0-19.1)$ & $0(0-2.5)$ & $0(0-0)$ \\
\hline Non-mining & 100 & $0(0-2.7)$ & $6.6(0-15.8)$ & $25.5(9.2-51.9)$ & $0(0-5.0)$ & $0(0-6.6)$ & $33.8(6.5-72.7)$ & $0(0-3.5)$ & $0(0-0)$ \\
\hline p-value* & & 0.0416 & 0.0012 & $<0.0001$ & $<0.0001$ & 0.6094 & $<0.0001$ & 0.0735 & 0.2687 \\
\hline
\end{tabular}

* Wilcoxon two-tailed normal approximation p-value. 
Table 20 Particle groups from TSP PTFE coated glass fiber filter samples.

\begin{tabular}{|c|c|c|}
\hline Name & Elements & Description \\
\hline Alumino-silicate & $\begin{array}{l}\mathrm{Al} \text { and } \mathrm{Si} \text { with } \mathrm{Na}, \mathrm{K} \text {, } \\
\mathrm{Ca}, \mathrm{Fe}, \mathrm{S} \text {, or other } \\
\text { elements }\end{array}$ & $\begin{array}{l}\text { - } \text { } \mathrm{Al}+\mathrm{Si}+0 \geq 50 \% \text { (Ebert \& Weinbrunch, 2000) } \\
\text { - AlSiKaolinite (Al,Si) } \\
\text { - AlSiIllite (Al Si K) } \\
\text { - AlSiMontmorillonite (Al Si Ca Na Mg Fe) } \\
\text { - AlSiAnorthite (Al Si Ca) } \\
\text { - AlSiAlbite (Al Si Na) } \\
\text { - AlSi plagioclase (Al Si Ca Na)(Moreno et al., 2004). }\end{array}$ \\
\hline Silicate & $\mathrm{Si}$ & $\begin{array}{l}\text { - } \mathrm{Si} \geq 50 \%(\text { Ebert and Weinbrunch 2000) } \\
\text { - Quartz-SiO }{ }_{2}\end{array}$ \\
\hline Sulfur & $\mathrm{S}$ & - S $\geq 20 \%$ (Ebert \& Weinbrunch, 2000) \\
\hline Other Minerals & $\mathrm{Ca}, \mathrm{Na}$ & $\begin{array}{l}\text { - } \mathrm{Ca} \geq 20 \% \text { (Ebert \& Weinbrunch, 2000) } \\
\text { - Gypsum (Ca S) } \\
\text { - Other Ca compounds: Ca Si(acid mine drainage), CaS, CaMg } \\
\text { - Sea related (S K Na or Na S) } \\
\text { - Chlorides (Na Cl) }\end{array}$ \\
\hline Soot Aggregates & $\mathrm{C}, \mathrm{S}, \mathrm{Al}, \mathrm{Si}$ & $\begin{array}{l}\text { - Contains C and characterized by fluffy morphology (Ebert \& Weinbrunch, } \\
\text { 2000)with S, Al, and Si (present in smaller quantities) (Feng et al. 2009) }\end{array}$ \\
\hline Fly Ash & $\begin{array}{l}\text { O, Si, Al, K, C, Fe, } \\
\text { Mn }\end{array}$ & $\begin{array}{l}\text { - Circular, smooth surface coated with UFPs including major elements } \mathrm{O}, \mathrm{Si} \text {, } \\
\mathrm{S}, \mathrm{Al} \text { and minor elements } \mathrm{K}, \mathrm{Ca}, \mathrm{Fe}, \mathrm{Mn} \text { (Feng et al. 2009) }\end{array}$ \\
\hline Metals & $\begin{array}{l}\text { Ti, Cr, Mn, Fe, Sn, Co, } \\
\mathrm{Zr}, \mathrm{Br} \text {, }\end{array}$ & - Metal $\geq 20 \%$ (Ebert \& Weinbrunch, 2000) \\
\hline
\end{tabular}

During the winter, there was a significant relationship between the non-mining site and higher levels of fly ash, $\chi^{2}(1, \mathrm{~N}=301)=4.8, \mathrm{p}=.0459$, and $\mathrm{CaS}, \chi^{2}(1, \mathrm{~N}=301)=16.7, \mathrm{p}<.0001$, compared to the MTM site. AlSi compound particles were more likely at the MTM sites in spring $\left(\chi^{2}(1, \mathrm{~N}=400),=5.9, \mathrm{p}=.0153\right)$. Higher counts of $\mathrm{Ca}, \chi^{2}(1, \mathrm{~N}=400)=35.8, \mathrm{p}<.0001$, and $\mathrm{CaSi}, \chi^{2}(1, \mathrm{~N}=400)=4.5, \mathrm{p}=.0343$ were significantly more likely around the non-mining site compared to the MTM sites in spring. After removing the effect of season, the MTM sites had significantly greater proportions of elements with $\mathrm{Si}$ (including $\mathrm{AlSi}, \chi^{2}(1, \mathrm{~N}=2,239)=84.0$, $\mathrm{p}<.0001$ and $\mathrm{Si}, \chi^{2}(1, \mathrm{~N}=2,239)=32.0, \mathrm{p}<.0001$, compounds $)$ and $\mathrm{K}, \chi^{2}(1, \mathrm{~N}=2,239)=5.4$, p.0188. The non-mining site had greater PM compounds with $\mathrm{S}$ and $\mathrm{Ca}$ (including $\mathrm{S}, \chi^{2}$ (1, $\mathrm{N}=2,239)=54.5, \mathrm{p}<.0001, \mathrm{Ca}, \chi^{2}(1, \mathrm{~N}=2,239)=42.8, \mathrm{p}<.0001, \mathrm{CaS}, \chi^{2}(1, \mathrm{~N}=2,239)=10.0$, $\mathrm{p}=.0016$, $\mathrm{S}$ with $\mathrm{K}, \chi^{2}(1, \mathrm{~N}=2,239)=8.7, \mathrm{p}=.0067$, and $\mathrm{S}$ with $\mathrm{K}$ and $\mathrm{Na}, \chi^{2}(1, \mathrm{~N}=2239)=67.3$, $\mathrm{p}<.0001)$ (Figure 13e). 
13a. Summer

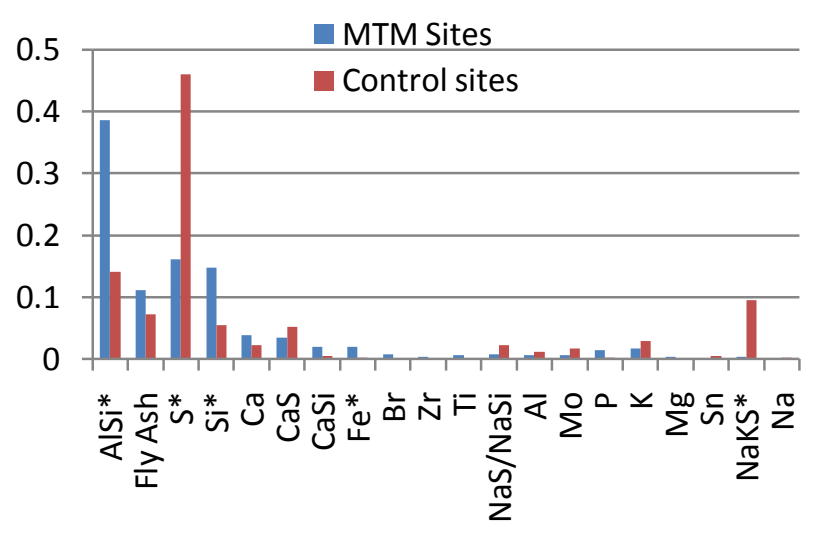

13b. Fall

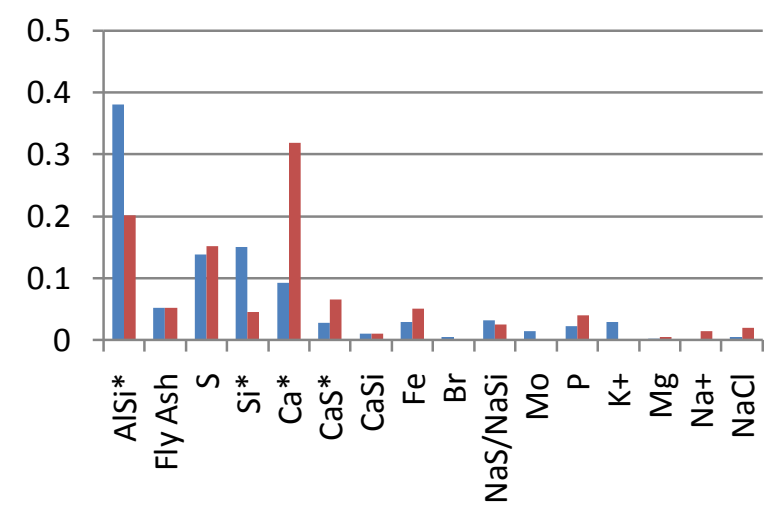

\section{3c. Winter}

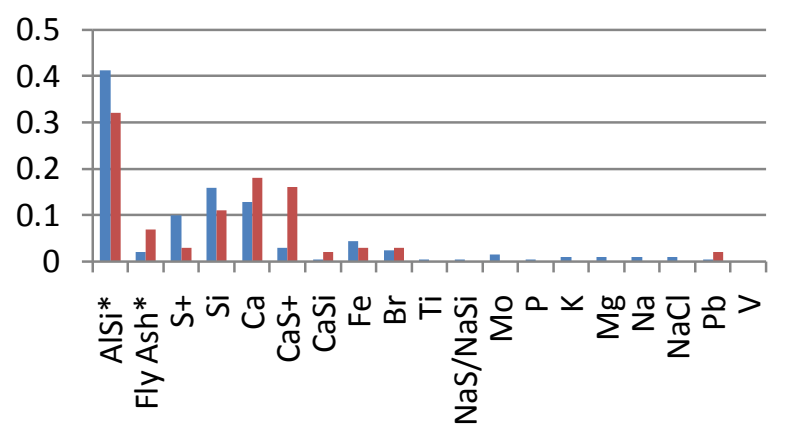

13d. Spring

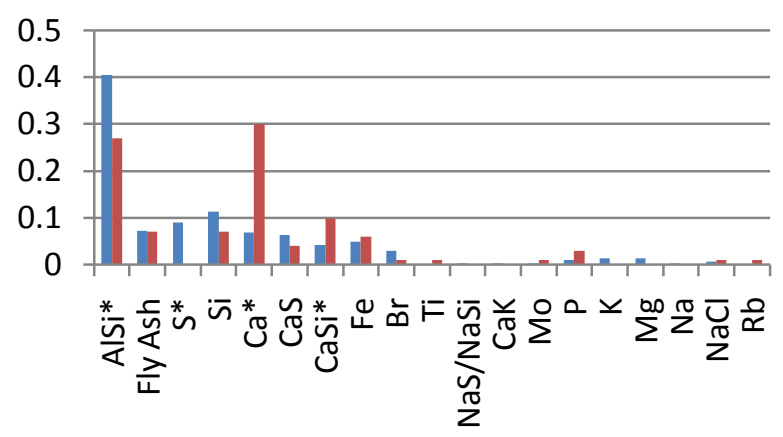

\section{3e. Overall comparison}

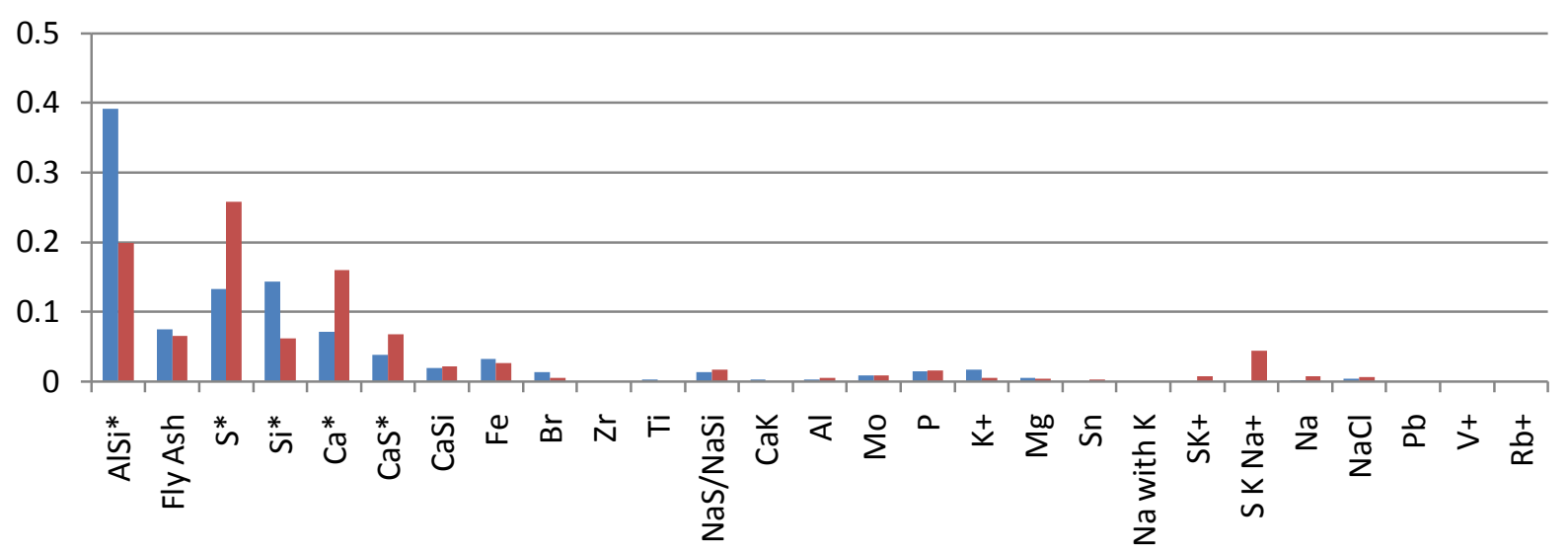

*Seasonal difference significant at $p<0.05$ corresponding to Pearson chi-square $\dagger$ Seasonal difference significant at $p<0.05$ corresponding to Fisher's exact test

Figure 13 Proportion of particles with the presence of a compound by season and site. 


\subsection{Discussion and Conclusions}

Results from this study revealed the most abundant elements contributing to PM collected on filter samples at a small number of MTM and non-mining sites. Weight percent concentrations were relatively constant across sampling seasons during the annual sampling period. Differences in elemental concentrations were observed between MTM and non-mining sites. Median weight percent concentrations indicated consistently greater concentrations of Al, $\mathrm{Si}$, and $\mathrm{K}$ at MTM sites. This indicates an elevation in the concentration of crustal elements among coarse PM, and K may be evident of potassium chlorate, which is used in explosives for mining. $\mathrm{S}$ and $\mathrm{Ca}$ were elevated in coarse $\mathrm{PM}$ at the non-mining site during the annual sampling period. S potentially indicates $\mathrm{SO}_{4}$, which was derived from fossil fuel combustions and oxidation of $\mathrm{SO}_{2}$. Ca poses few environmental and toxicity hazards and is expected to be present as a result of crustal materials in the air. An examination of particle composition showed Aluminosilicates (AlSi) and Si compounds in greater proportions at the MTM sites, and Ca, Ca with S, Na, and Na with K and S compounds in greater proportions at the non-mining site. While this analysis was primarily on coarse PM and pertained to TSP mass concentrations as discussed in Chapter 3, few conclusions can be made regarding the elemental composition of PM contribution to respiratory dose and health risks to those living in MTM and non-mining areas.

This study identified primarily crustal elements in all TSP samples from both mining and non-mining sites. The lack of anthropogenic elements is likely due to the SEM-EDX technique used, not as a result of anthropogenic elements being absent from the ambient air in the MTM and non-mining areas. Si is one of the most abundant elements in the earth's crust (28.2\%) followed by $\mathrm{Al}$ (8.23\%), Fe (5.63\%), Ca (4.15\%), Na (2.36\%), Mg (2.33\%), K (2.09\%), and Ti (0.565\%) (Hinds, 1999). Other crustal elements in smaller quantities include P, $\mathrm{Mn}, \mathrm{Cl}, \mathrm{Cr}$, and rare earth elements. Anthropogenic contaminants include Mo, V, Co, Ni, Pb, and Sn. The most notable differences in anthropogenic contaminants were observed during Fall 2011 when MTM sites contained elevated concentrations of Mo compared to the non-mining site.

Crustal derived aluminosilicates were present in higher concentrations at MTM sites. Aluminosilicates were irregularly shaped, coarse particles with high concentrations of Al and Si along with other elements (S, Fe, Ca, K, Na) originating from soil (Ebert \& Weinbrunch, 2000; Feng et al., 2009). AlSi with S, Fe, and Ca were typically mechanically-generated particles formed by crushing or grinding activities or the result of road, construction, farming, or mining 
activities (Martinez et al., 2008). Other AlSi particles were from clays and resuspended dust due to erosion of geological formations (Slezakova et al., 2008). Al and Si dust exposure directly affects the respiratory system by exacerbating respiratory problems like coughing and asthma and leading to silicosis (ATSDR, 2012). Silica was present at MTM sites as quartz potentially resulting from limestone and sandstone sources (Slezakova et al., 2008).

Sulfur particles were likely present in the air as the result of heavy industry, petroleum, or natural gas emissions, or other fossil fuel by products. Oxidants of $\mathrm{S}$ also form secondary particles from combustions sources, such as diesel engines (Martinez et al., 2008). Laboratorybased human exposure studies indicated increased bronchoalveolar lavage fluid percent with exposure to $\mathrm{SO}_{4}$ and induced inflammation with increased exposure to diesel engine particles, which contain S (Lippmann \& Chen, 2009). S with Na and K were sea-related, and NaCl were also either sea salt particles traveling from the coast or the result of salting roads during winter months (Moreno et al., 2004). Na and sea salt in concentrate ambient particulate matter result in minimal vascular and inflammatory responses (Lippmann \& Chen, 2009).
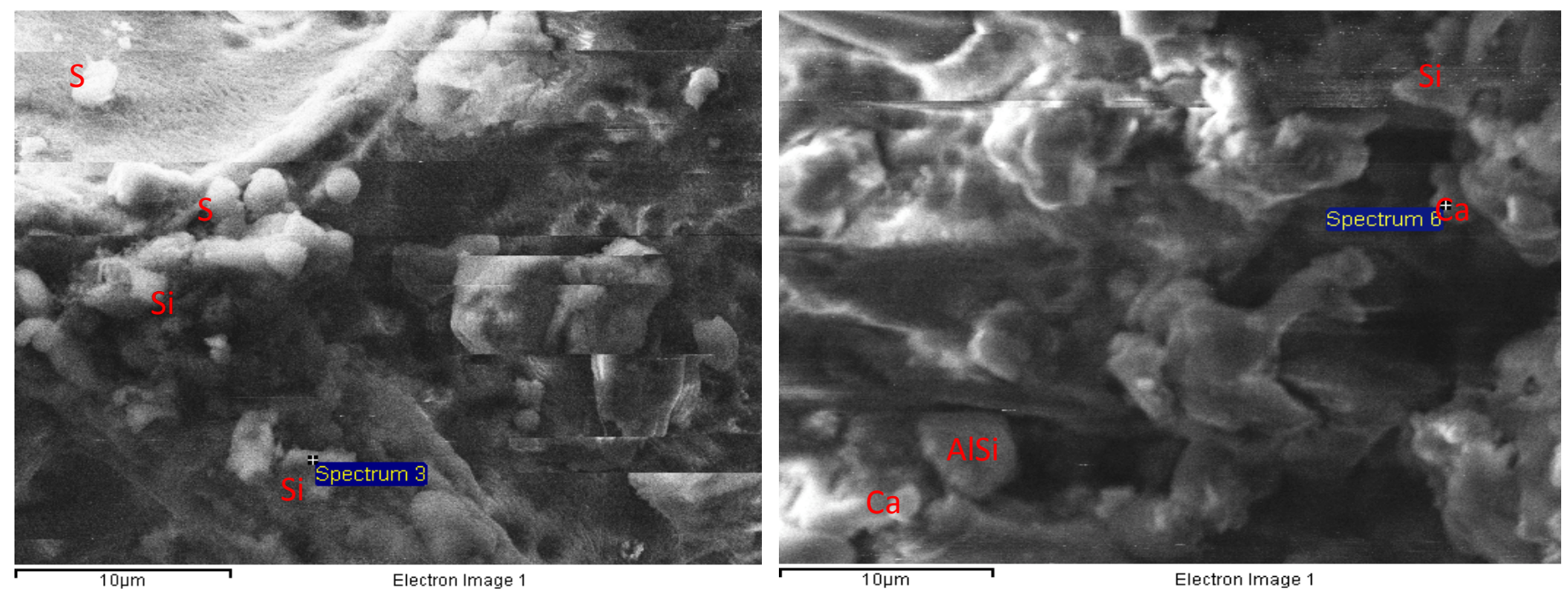

Figure 14 SEM images of particles showing high content of S, Si, Ca, and AlSi.

Calcium was abundant in particles of natural origin and with some impurities, such as Si. Calcium silicate is present in acid mine drainage and other calcium compounds included gypsum (CaS). Gypsum, which was identified by the presence of Ca along with S, can be traced to both natural and anthropogenic sources such as weathering of natural minerals or buildings (Slezakova et al., 2008). 
Fly ash particles are largely derived from coal combustion processes. The spherical morphological parameters of fly ash were primarily used to identify them along with their composition of Si, O, Ca, or S with trace amounts of Mo, Se, Mn, and Al (Feng et al., 2009).

Metals in the environment are from both natural and anthropogenic sources. Exposure to lower levels of metals in the earth's crust has limited health risks, but increased exposure is important from a toxicological viewpoint. Inhalation of $\mathrm{PM}_{2.5}$ with $\mathrm{Ni}, \mathrm{V}, \mathrm{Pb}$, and potentially $\mathrm{Al}$ are associated with health effects (Lippmann \& Chen, 2009; Martinez et al., 2008). The lungs are just one site of entry for metals, and inhalation results in an inflammatory response and respiratory and cardiovascular outcomes (ATSDR, 2012; Costa \& Dreher, 1997). Pb, which was found in a very small amount at the winter MTM site, is a toxic heavy metal with multiple health effects, even in low concentrations. $\mathrm{K}$ is present in explosives used to remove overburden from the mountaintop to expose coal underneath. Other metals (Se, Mo, Mn, Mg, and Fe) are essential metals for life in trace amounts, but increased amounts have the potential for toxicity. For example, Fe is associated with oxidative stress in the lungs and increased bronchoalveolar lavage fluid (Lippmann \& Chen, 2009). Mining is a source of Fe in the air and soil, and Ti, Mn, Fe, and Ca in feldspars trace back to the soil (Martinez et al., 2008; Slezakova et al., 2008). Fe, $\mathrm{Pb}, \mathrm{Ni}$, and $\mathrm{S}$ together indicate combustion and traffic origins. Minor toxic metals, such as In, V, and Ti occurred infrequently. Coal-fired power plants are known to emit metals and $\mathrm{Be}, \mathrm{Cd}, \mathrm{Pb}$, and Mg as part of fine PM. During the formation of coal, impurities, or substances from the surrounding soil, are included in the coal, such as S, Pb, Be, Cl, and Mn (Finkelman, 1999).

Potential limitations of this study include restrictions associated with the SEM-EDX technique. The elemental concentrations and compositions provided with the SEM-EDX only account for a sample of particles and do not indicate if an element identified in the sample occurred in trace or major concentrations in the TSP mass concentration (Slezakova et al. 2007). More detailed chemical information of the analyzed particles was missing including the presence of organic or inorganic $\mathrm{C}$ and information on the elemental structure of elements, such as if the determination of Si on a particle was in a crystalline form (associated with silicosis) or amorphous form (not associated with silicosis).

It is time consuming to obtain sufficient data for a representative sample of particles with the SEM-EDX (McMurry, 2000). Nevertheless, a sample size of 100 particles per filter was selected due to feasibility of resources and sample size validation by previous studies (Martinez 
et al. 2008). Analyzing 100 particles from multiple filters collected over a year-long sampling period helped ensure a representative PM sample. The analyzed samples were not adequate for connecting the results to potential health hazards and respiratory dose because they lacked size classification. The particles analyzed contributed to the TSP mass concentration of MTM and non-mining area samples, not the mass-based size distributions or number-based size distributions.

Analysis of individual fine PM was limited due to agglomeration of fine particles and SEM magnification. Under higher magnification, particles less than $0.1 \mu \mathrm{m}$ were difficult to identify. Submicron-sized particles were analyzed in the form of larger agglomerates, but accurate size data on fine particles that were part of the agglomerates were not obtained. Clustered soot aggregates were not identified due to their small size. However, the study would be improved by including more particles to better estimate concentrations and size distributions of filter samples. All SEM particle analysis were conducted by the same person to ensure no deviations in procedures occurred in the elemental analysis from worker variation.

Despite limitations of the SEM-EDX technique, it was used because previous studies have reported the method to be successful at obtaining chemical characterization of individual particles and effective and reliable for obtaining elemental particle data (Feng et al., 2009; Franck \& Herbarth 2002; Kasparian et al. 1998; McMurry 2000; Slezakova et al. 2008; Sobanska et al. 2003; Worobiec et al., 2009; Xie et al. 2005; Yue et al., 2006). The technique was advantageous to other methods of analysis because it was readily accessible, non-destructive, and did not require sample pre-treatment (Slezakova et al. 2007). In addition, the SEM provided information on particle morphology, which other optical microscopy techniques do not provide.

This study showed PM composition primarily differed based on the presence of mining activity around a site and not season. Therefore, it is expected that PM from MTM and nonmining sites will produce distinct physiological responses after inhalation. It is hypothesized that the heightened concentrations of crustal elements at MTM sites are attributed to the displacement of crustal materials by MTM activities. AlSi originates in the soil but is resupended from mining processes and earth moving activities. The increased S and Ca at non-mining sites indicated elevated emissions sources and secondary PM. However, conclusions regarding PM sources are only speculative because it cannot be determined if fluctuations in crustal elements were attributed to mining or processes that resuspend PM. 


\section{References}

Adamson IYR, Prieditis H, Hedgecock C, Vincent R. Zinc is the toxic factor in the lung response to an atmospheric particle sample. Toxicol Appl Pharmacol. 2000;166:111-119.

ATSDR (Agency for Toxic Substances and Disease Registry). Toxicological Profiles. 2012. Available at:http://www.atsdr.cdc.gov/toxprofiles/index.asp. Accessed 12 August 2012.

Chen Y, Craig L, Krewski D. Air quality risk assessment and management. Toxicol Environ Health. 2008;71(1):24-39.

Costa DL, Dreher KL. Bioavailable transition metals in particulate matter mediate cardiopulmonary injury in healthy and compromised animal models. Environ Health Perspect. 1997;105(5):1053-1060.

Ebert M, Weinbruch S. High-resolution scanning electron microscopy of atmospheric particles sampled at Jungfraujoch during the CLACE field experiment. International Foundation HFSJG, Activity Report 1999/2000. Available at: http://www.ifjungo.ch/reports/1999_2000/pdf/17.pdf. Accessed January 222012.

Feng X, Dang Z, Huang W, Shao L, Weijun L. Microscopic morphology and size distribution of particles in PM2.5 of Guangzhou City. J Atmos Chem. 2009;64:37-51.

Finkelman RB, Gross PMK. The types of data needed for assessing the environmental and human health impacts of coal. International Journal of Coal Geology. 1999;40:91-101.

Franck U, Herbarth O. Using scanning electron microscopy for statistical characterization of the diameter and shape of airborne particles at an urban location. Environ Toxicol. 2002; 17(2):98-104.

Ghio, A, Devlin, R. Inflammatory lung injury after bronchial instillation of air pollution particles.Am J Respir Crit Care Med. 2001;164:704-708.

Hinds WC. Aerosol Technology: Properties, Behavior, and Measurement of Airborne Particles. Vol 2. New York: John Wiley \& Sons, Inc.; 1999.

Hogg JC, vanEeden S. Pulmonary and systemic response to atmospheric pollution. Respirology. 2009;14; doi:10.1111/ j.1440-1843.2009.01497.x [Online 15 March 2009].

Kasparian J, Frejafon E, Rambaldi P et al. Characterization of urban aerosols using SEMmicroscopy, X-Ray analysis and Lidar measurements. Atmospheric Environment. 1998;32(17):2957-2967.

Kolker A, Engle M, Orem Wet al. Atmospheric particulate matter in proximity to mountaintop coal mines. In: Proceedings of the VM Goldschmidt Conference, June 24-29, 2012. 2012. Montreal. 
Lippmann M, Chen, L.-C. Health effects of concentrated ambient air particulate matter (CAPs) and its components. Critical Reviews in Toxicology. 2009; 39(10):865-913.

Martinez T, Lartigue J, Avila-Perez P et al. Characterization of particulate matter from the Metropolitan Zone of the Valley of Mexico by scanning electron microscopy and energy dispersive X-ray analysis. J Radioanal Nucl. 2008; 276(3):799-806.

Mastin JP. Environmental cardiovascular disease.CardiovascToxicol.2005;5(2):91 94.

McMurry PH. A review of atmospheric aerosol measurements. Atmospheric Environment. 2005;34:1959-1999.

Menke A, Muntner P, Batuman V, Silbergeld E, Guallar E. Blood level below .48umol/L (10ug/dL) and mortality among US adults. Circulation.2006;114:1388-1394.

Moreno T, Jones TP, Richards RJ. Characterization of aerosol particulate matter from urban and industrial environments: examples from Cardiff and Port Talbot, South Wales, UK. Sci Total Environ. 2004;34-335:337-346.

Oberdorster, G. Pulmonary effects of inhaled ultrafine particles. Int Arch Occup Environ Health.2001;74(1):1-8.

Richards RJ. Small particles, big problem. Biologist. 1997;44(1):249-251.

Schwartz J. Meas LM. Fine particles are more strongly associated than coarse particles with acute respiratory health effects in schoolchildren. Epidemiology. 2000;11:6-10.

Slezakova K, Pereira MC, Reis MA, Alvim-Ferraz MC. Influence of traffic emissions on the composition of atmospheric particles of different sizes - Part 1: concentrations and elemental characterization. J Atmos Chem. 2007;58(1):55-68.

Slezakova K, Pires JCM, Pereira MC, Martins FG, Alvim-Ferraz MC. Influence of traffic emissions on the composition of atmospheric particles of different sizes-Part 2: SEMEDS characterization. J Atmos Chem. 2008;60(3):221-236.

Sobanska S, Coeur C, Maenhaut W, Adams F. SEM-EDX characterization of tropospheric aerosols in the Negev desert (Israel). J Atmos Chem. 2003;44(3):299-322.

U.S. EPA (Environmental Protection Agency).Mid-Atlantic Mountaintop Mining. Available at: http://www.epa.gov/Region3/mtntop/. 2011. Accessed March 14, 2010.

WVDoT (West Virginia Department of Tourism). Pocahontas County. 2006. Available at: http://www.pocahontascountywv. com/files/quick_county_facts.pdf. Accessed 2 November 22011. 
Wilson MR, Lightbody JH, Donaldson K, Sales J, Stone V. Interactions between Ultrafine Particles and Transition Metals in Vivo and in Vitro. Toxicology and Applied Pharmacology. 2002;184(3):172-179.

Worobiec A, Potgieter-Vermaak S, Brooker A, Darchuk L, Stefaniak E, Van Grieken R. Interfaced SEM/EDX and micro-Raman Spectrometry for characterization of heterogeneous environmental particles-fundamental and practical challenges. Michrochemical Journal. 2006;94:65-72.

Xie RK, SeipHM, Leinum JR, Winje T, Xiao JS. Chemical characterization of individual particles (PM10) from ambient air in Guiyang City, China. Sci Total Environ. 2005; 343(1-3):261-272.

Yue W, Li X, Liu Jet al. Characterization of PM(2.5) in the ambient air of Shanghai City by analyzing individual particles. Sci Total Environ. 2006;368(2-3):916-925. 


\section{Chapter 5}

Inorganic Constituents of Atmospheric Particulate Matter in West Virginia Coal Mining Areas 


\subsection{Introduction}

Residents of Appalachian coal mining areas have greater health disparities including cardiovascular, kidney, and respiratory diseases (Hendryx, 2009; Hendryx \& Ahern, 2008; Hendryx \& Zullig, 2009). Among those living in surface mining areas where mountaintop mining (MTM) is practiced, there is an increased risk of total mortality, birth defects, chronic cardiovascular disease mortality, and cancer (Ahern et al., 2011; Esch \& Hendryx, 2011; Hendryx, 2011; Hendryx et al., 2011). The association between mining areas and health disparities suggests environmental contaminants from coal mining processes may contribute to adverse human health outcomes through environmental exposure pathways, such as water, soil, and air. However, the ecological studies reporting an association between mining and health outcomes use aggregate county level health data and lack direct environmental measures.

Examination of the atmospheric inputs into ambient particulate matter (PM) provides insight into the source, transport, and fate of atmospheric contaminants and signifies potential human exposure. Preliminary analysis of TSP atmospheric PM in mining areas indicated the concentrations of anthropogenic elements (V, Ni, As, and Cd) were similar at mining and nonmining areas in June 2011. Crustal elementals (Al, Ti, Fe, Ga, Rb, and rare earth elements) were present in larger concentrations around mining areas (Kolker et al., 2012). The higher presence of locally derived Si material at mining areas suggested contamination from removal of highsilicate crustal materials on the earth’s surface during MTM processes (Kolker et al., 2012).

Natural and anthropogenic sourced materials are transported in the atmosphere as PM. Atmospheric PM may be inhaled by living organisms or removed from the atmosphere and relocated to earth surfaces and structures through wet and dry environmental particle deposition (Hinds, 1999). Wet deposition refers to the deposition of PM to the environment with the assistance of atmospheric water droplets including precipitation, fog, and snow. Dry deposition transpires through a variety of mechanisms including gravitational sedimentation, impaction, and diffusion. Particles that deposit in the environment become attached to plants, entrapped in soils, or deposited in bodies of water or on other surfaces resulting in human health and ecological impacts.

Knowledge is limited regarding the environmental dry deposition of total suspended particles (TSP) to the environment in coal mining areas and the loading rate to the surrounding ecosystem. Mining areas contain PM contaminants attributed to coal-related activities, and 
investigating TSP environmental dry deposition rates in mining areas is critical to specify contaminant contributions to the environment and other surfaces. The purpose of this study is to quantify environmental dry deposition to the environment with direct measurement techniques for inorganic materials in areas with MTM, mining areas without MTM, and non-mining areas.

\subsection{Methods}

\subsubsection{PM Sampling}

Sampling sites included: (1) mining sites in Sylvester and Lindytown, WV around active coal mining sites (including surface mining and MTM), (2) an internal control site at Twin Falls State Park in Mullens, WV in a coal mining area without extensive MTM, and (3) an external control site in Green Bank, WV (Pocahontas County) without any coal mining activity in the vicinity (Figure 15). Sample sites were selected in rural, residential areas based on site accessibility, convenience, and prior sampling visits. Residents made their private property available for air sampling, as well as water and topsoil sampling.

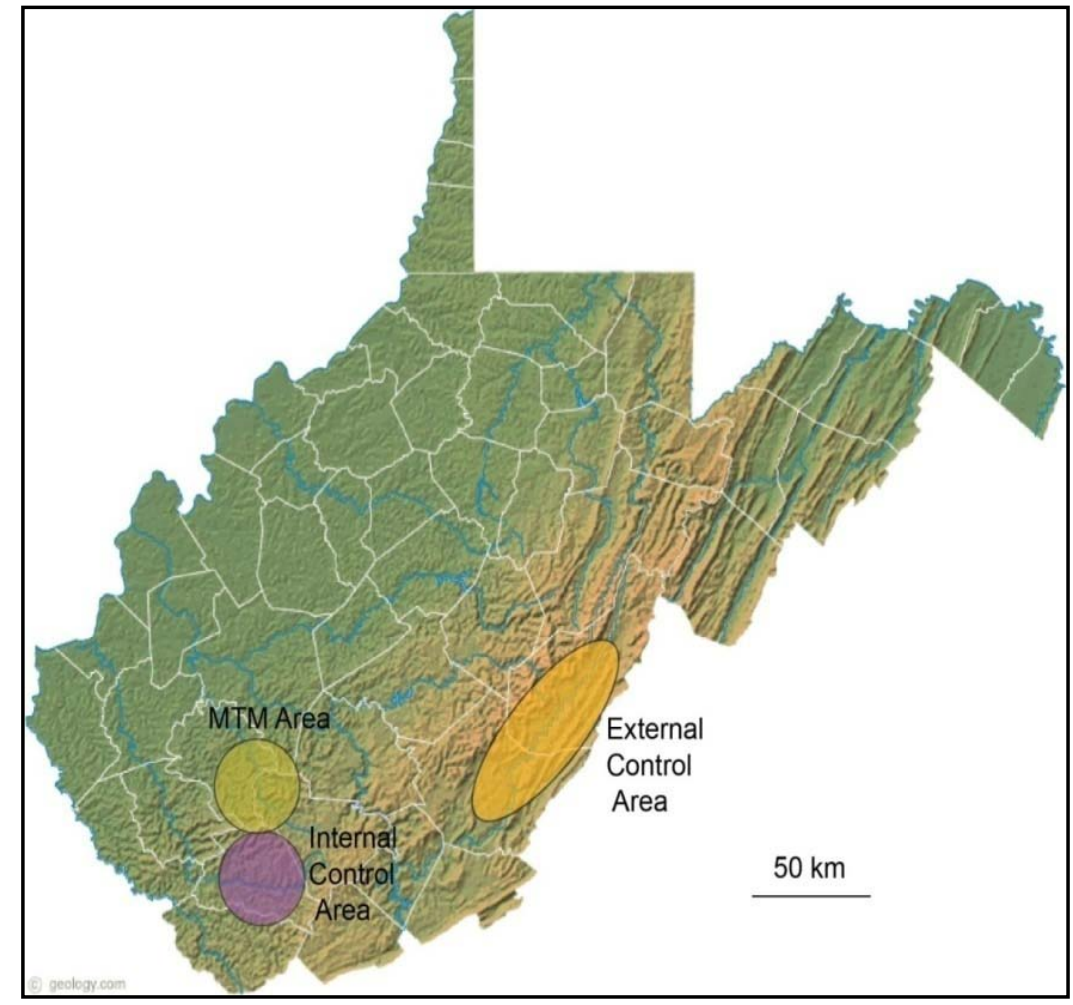

Figure 15 Mining, internal control, and external control sites in West Virginia. 


\subsubsection{Data Collection}

Environmental dry deposition fluxes were estimated with a passive, greased, surrogate surface collector deployed during sampling periods from February to August 2012. The surrogate surface collector, designed by Todd Hinkley of the U.S. Geological Survey (emeritus), consisted of an aluminum body and a glass disk that fit flush into the aluminum body allowing for a smooth surface across the top of the sampler. The aerodynamic, disk-shaped, powdercoated aluminum body (diameter $\sim 25 \mathrm{~cm}$ ) held the $12.3 \mathrm{~cm}$ diameter glass plate coated with a minimally-thick layer of Apiezon Grease, Type L to collect particles, without contributing additives. The glass plates and aluminum bodies were cleaned in a laminar flow hood and carried to the field in sealed acid-cleaned containers. Table 22 presents a description of sampling sites and collection periods. The samplers were deployed for periods of 72-185 hours to collect sufficient PM for chemical analysis.

Table 22 Summary of the site characteristics and collection periods.

\begin{tabular}{|c|c|c|c|c|}
\hline Nearest Town & Type of Site & $\begin{array}{c}\text { Collection Start } \\
\text { Date }\end{array}$ & $\begin{array}{c}\text { Collection End } \\
\text { Date }\end{array}$ & $\begin{array}{c}\text { Collection Time } \\
\text { Hours }\end{array}$ \\
\hline Sylvester & $\begin{array}{l}\text { Personal Residence } \\
\text { Surface mining area }\end{array}$ & 26 February 2012 & 2 March 2012 & 96.6 \\
\hline Mullens & $\begin{array}{l}\text { Twin Falls State Park } \\
\text { Internal control }\end{array}$ & 26 February 2012 & 2 March 2012 & 122.3 \\
\hline Green Bank & $\begin{array}{c}\text { Library } \\
\text { External control }\end{array}$ & 2 March 2012 & 10 March 2012 & 185.2 \\
\hline Lindytown & $\begin{array}{l}\text { Personal Residence } \\
\text { Surface mining area }\end{array}$ & 8 May 2012 & 12 May 2012 & 91.2 \\
\hline Mullens & $\begin{array}{l}\text { Twin Falls State Park } \\
\text { Internal control }\end{array}$ & 8 May 2012 & 12 May 2012 & 96.8 \\
\hline Artie & $\begin{array}{l}\text { Personal Residence } \\
\text { Surface mining area }\end{array}$ & 21 August 2012 & 24 August 2012 & 72.2 \\
\hline
\end{tabular}

The samplers were securely mounted on a tripod two meters above the ground surface (Figure 16). Tripods were placed below porch overhangs or other open-air structures to prevent preferential removal of soluble trace elements during precipitation events. In addition, the protective overhang or roof prevented water from leaching more soluble elements from the surface of the deposition plate. 


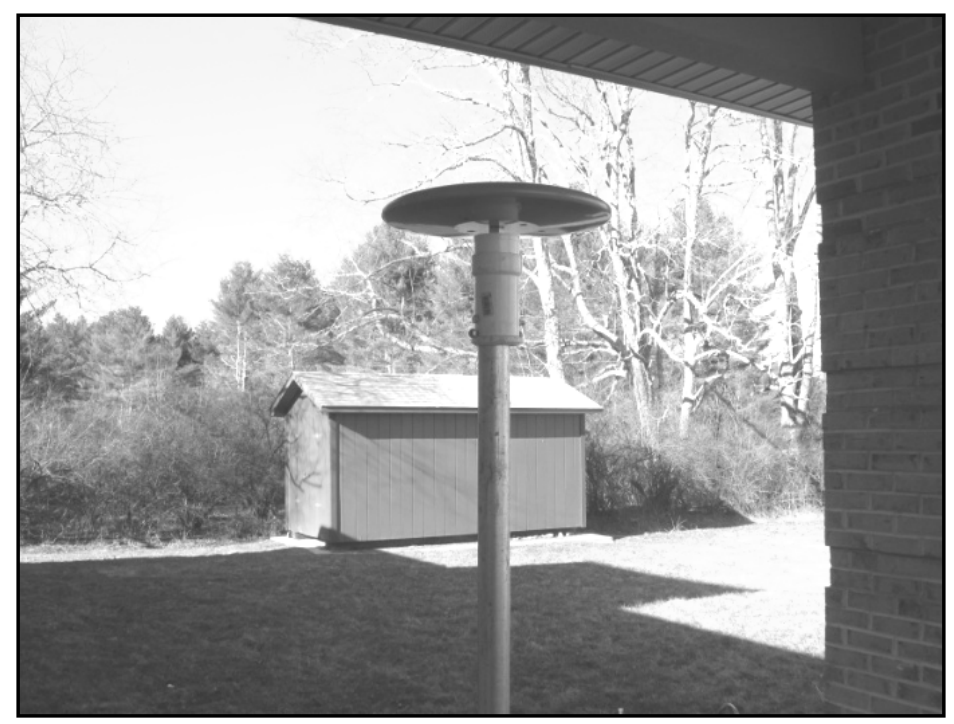

Figure 16 Glass plate fit into aluminum body secured on tripod mounts.

The discs were handled following clean sampling procedures to protect them from contamination. The greased glass plates were transported to the U.S. Geological Survey in Reston, Virginia post-sampling where the grease was dissolved in hexane and transferred to acidcleaned Teflon containers. The grease was analyzed for trace elements using a PerkinElmer Elan DRC II ICP-MS (Inductively Coupled Plasma Mass Spectrometry) at the U.S Geological Survey in Denver, Colorado. Prior to analysis, the grease was digested in a mixture of double-distilled $\mathrm{HNO}_{3}$ and ultra-pure $\mathrm{H}_{2} \mathrm{O}_{2}$ in a Multiwave 3000 microwave system up to $160{ }^{\circ} \mathrm{C}$. Field blanks, lab blanks, reagent blanks, and laboratory matrix spikes were used to evaluate the quality of the analyses. All data were blanked corrected, and elements in which the blank exceed $50 \%$ of the median value from all samples were discarded from interpretation.

\subsubsection{Analysis}

The change in concentration of trace elements in the grease compared to the blanks determined the deposited loading concentration. The average of the pre-and post-sampling area was combined with the sampling time to calculate flux. Flux is a measure of the concentration of elements collected per unit area. Flux is dependent on area, unlike flow, which is a measure of concentration per unit volume. The flux (average flux, standard deviation) was compared between all sites, as was the variation in flux between seasons. The environmental dry deposition concentrations of crustal-dominated elements ( $\mathrm{Al}, \mathrm{Ca}, \mathrm{K}, \mathrm{Rb}, \mathrm{Mg}, \mathrm{Ti}$, and rare earth 
elements) and anthropogenically-dominated elements were compared between sites. In this study, $\mathrm{Co}, \mathrm{Ni}, \mathrm{Pb}, \mathrm{Sn}$, and V were classified as anthropogenically-dominated elements because they were considered largely the result of contribution from anthropogenic sources.

\subsection{Results}

A plot of dry deposition flux estimates for atmospheric PM at the mining, internal control, and external control sites (combined for May-August 2012 sampling) is presented in Figure 17. Consistently higher flux estimates were found around the mining sites relative to the control sites. Crustal elements (Ca, $\mathrm{Al}, \mathrm{K}$, and $\mathrm{Mg}$ ) had relatively higher deposition rates at all sampling sites compared to the other elements. Seasonal patterns at the internal control site showed generally elevated measurements in February 2012 compared to May 2012. Comparisons between the mining sites indicated the February (Sylvester) and August (Artie) samples generally had higher flux measures than the May (Lindytown) sample. The recovery efficiencies from laboratory matrix spikes averaged 80.2\% and ranged from 59.6-91.4\% suggesting that the calculated fluxes for these elements were conservative. No laboratory matrix spikes for $\mathrm{Al}, \mathrm{Ca}, \mathrm{K}$, and $\mathrm{Mg}$ were conducted, but it was assumed they behaved similarly.

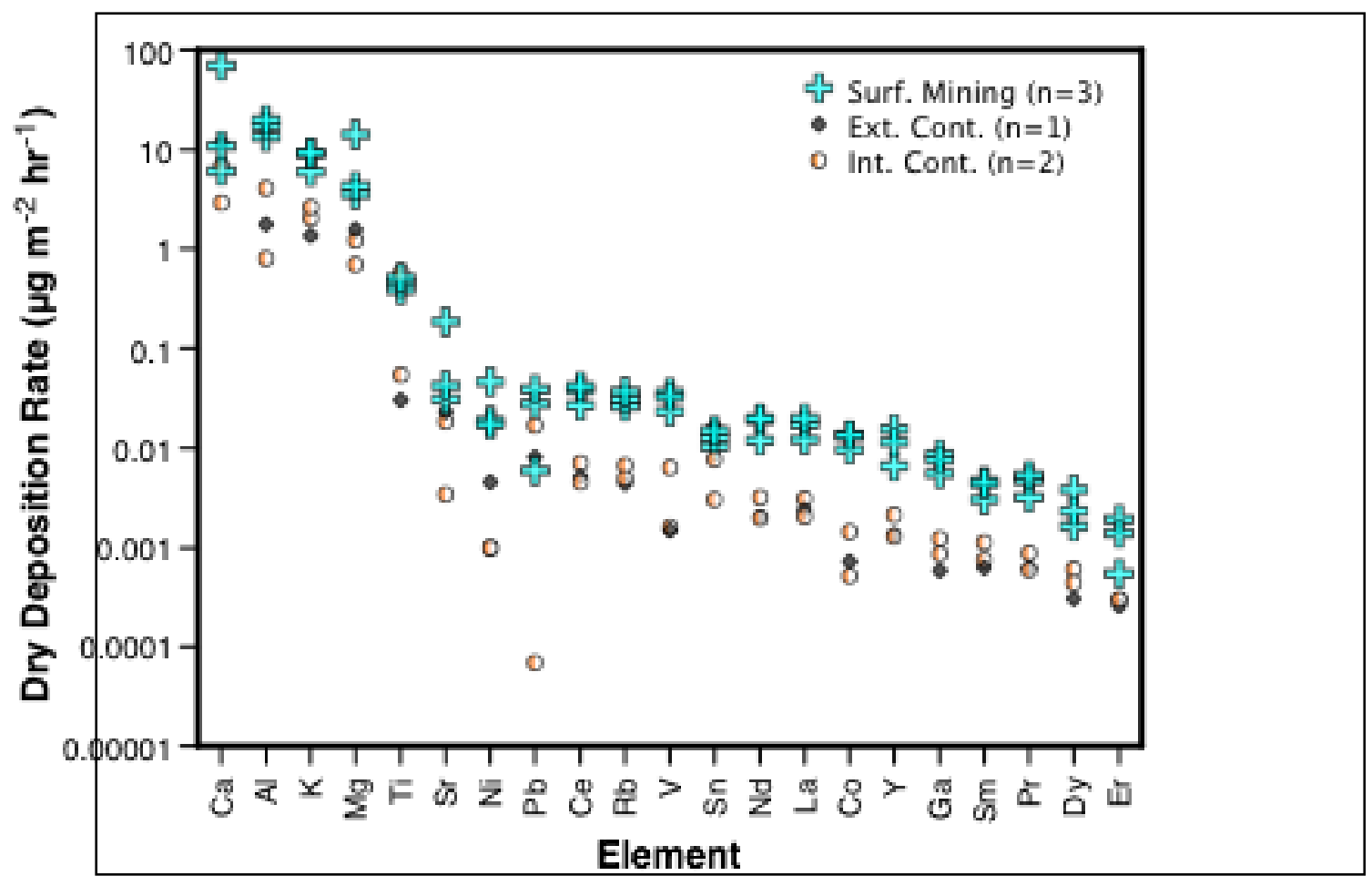

Figure 17 Environmental dry deposition flux at the mining, internal control, and external control sites. 
The ratio between the average flux in surface mining sites compared to control sites was fairly consistent among crustal elements $(5.8 \pm 1.5)$ (Table 23). The control site group includes the combined internal control and external control data. The elevated ratio for anthropogenic elements $\mathrm{Ni}(12.7)$ and $\mathrm{V}$ (9.8) may indicate the presence of local oil combustion sources in the vicinity of mining sites that were less influential around control sites. The ratio of flux estimates between the mining sites and control sites was highest for Co (13.7).The mean ratio for Sn (1.4) suggested no additional source of Sn around the mining sites compared to the control sites.

Table 23 Average flux estimates for surface mining, internal control, and external control sites during sampling.

\begin{tabular}{|c|c|c|c|c|}
\hline & & Average (SD) & & Flux Ratio \\
\hline & $\begin{array}{l}\text { Surface Mining } \\
\qquad \mu \mathrm{g} \mathrm{m}^{-2} \mathrm{hr}^{-1}\end{array}$ & $\begin{array}{c}\text { Internal } \\
\text { Control } \\
\mu \mathrm{g} \mathrm{m}^{-2} \mathbf{h r}^{-1}\end{array}$ & $\begin{array}{c}\text { External } \\
\text { Control } \\
\mu \mathrm{g} \mathrm{m}^{-2} \mathbf{h r}^{-1}\end{array}$ & Surface Mining: Control \\
\hline $\mathrm{Al}$ & $16.74(3.19)$ & $2.44(2.25)$ & 1.77 & 7.55 \\
\hline $\mathrm{Be}$ & $0.002(0.002)$ & $0.0004(0.00)$ & 0.0003 & 5.44 \\
\hline $\mathrm{Ca}$ & $28.88(35.4)$ & $4.85(2.74)$ & 11.7 & 4.06 \\
\hline $\mathrm{Ce}$ & $0.04(0.008)$ & $0.01(0.002)$ & 0.005 & 6.41 \\
\hline $\mathrm{Co}^{*}$ & $0.01(0.002)$ & $0.001(0.0006)$ & 0.0007 & 13.69 \\
\hline Dy & $0.003(0.001)$ & $0.0005(0.0001)$ & 0.0003 & 5.70 \\
\hline $\mathrm{Er}$ & $0.001(0.001)$ & $0.0003(0.00)$ & 0.0003 & 4.46 \\
\hline Ga & $0.01(0.002)$ & $0.001(0.0002)$ & 0.0006 & 8.13 \\
\hline $\mathrm{K}$ & $8.11(1.81)$ & $2.31(0.28)$ & 1.35 & 4.08 \\
\hline $\mathrm{La}$ & $0.02(0.004)$ & $0.002(0.0007)$ & 0.0024 & 6.56 \\
\hline $\mathrm{Mg}$ & $7.36(6.0)$ & $0.95(0.38)$ & 1.57 & 6.35 \\
\hline $\mathrm{Nd}$ & $0.02(0.004)$ & 0 & 0 & 7.04 \\
\hline $\mathrm{Ni}^{*}$ & $0.03(0.02)$ & $0.001(0.00)$ & 0.005 & 12.68 \\
\hline $\mathrm{Pb}^{*}$ & $0.02(0.02)$ & $0.001(0.012)$ & 0.008 & 2.88 \\
\hline $\operatorname{Pr}$ & $0.004(0.001)$ & $0.0001(0.0002)$ & 0.0006 & 6.21 \\
\hline $\mathrm{Rb}$ & $0.03(0.005)$ & $0.01(0.001)$ & 0.004 & 5.89 \\
\hline $\mathrm{Sm}$ & $0.004(0.001)$ & $0.001(0.0003)$ & 0.0006 & 4.79 \\
\hline $\mathrm{Sn}^{*}$ & $0.01(0.002)$ & $0.01(0.003)$ & 0.017 & 1.39 \\
\hline $\mathrm{Sr}$ & $0.09(0.09)$ & $0.01(0.011)$ & 0.023 & 5.77 \\
\hline $\mathrm{Ti}$ & $0.46(0.06)$ & $0.31(0.36)$ & 0.03 & 2.11 \\
\hline $\mathrm{V}^{*}$ & $0.03(0.007)$ & $0.004(0.0033)$ & 0.001 & 9.82 \\
\hline $\mathrm{Y}$ & $0.01(0.004)$ & $0.002(0.0006)$ & 0.0013 & 7.08 \\
\hline
\end{tabular}




\subsection{Discussion and Conclusions}

The concentration of environmental dry deposited trace elements at a limited number of rural West Virginia sites was determined. Results must be taken with consideration and assumed to be preliminary due to the small number of sampling sites and limited sampling periods. During the sampling periods, areas in the vicinity of mining sites exhibited higher flux estimates and higher concentrations of crustal and anthropogenically-dominated inorganic materials compared to sites in non-mining areas.

Environmental dry deposition estimation techniques often use particle concentrations and average deposition velocity to indirectly calculate dry deposition fluxes but this modeling method underestimates the contribution of coarse particles to dry deposition (Holsen et al. 1993) . Indirect calculation of dry deposition flux also requires many assumptions to be made in the numerical deposition models and requires high resolution meteorological parameters and sizesegregated concentration data.

The use of surrogate surfaces to directly measure dry deposition flux provides a better estimate of dry deposition to the environment and is a viable option when studying less reactive species (Holsen et al. 1993). Smooth surrogate surface samplers have comparable dry deposition fluxes with multistep-modeled dry deposition estimates in both urban and nonurban areas (Holson et al., 1993). Particle size information was not collected in this study, but it is well documented that the contribution of larger PM $(>10 \mu \mathrm{m})$ is responsible for most of the dry flux (Holsen et al., 1993).

Local soil, mineral dust, and emissions contribute to the PM around sampling areas. One potential explanation for the higher environmental dry deposition fluxes around the mining sites is increased PM from coal mining activities, attributed emissions, and MTM blasting activities. $\mathrm{Be}, \mathrm{Co}$, and other metals are alleged to be present in the air around MTM sites from blasting activities, and the flux ratios indicated elevated Be and Co in the mining samples (MSHA, 2010). As, Cd, Hg, S, and Se are typical tracers for coal combustion, but these elements were below the ICP-MS detection limits and excluded from the analysis (Surprenant et al., 1981). Since the coal combustion tracers did not reach the detection limits, this indicates little contribution from coal combustion sources in our samples. Elevated $\mathrm{Ni}$ and $\mathrm{V}$ at mining sites are likely present as the result of oil combustion sources. These sources include vehicles or machinery running on diesel 
fuel or oil combustion emissions from lube oil evaporating, cooling, and condensing as PM (Surprenant et al., 1981).

Another potential explanation for the increased environmental dry deposition fluxes around the mining sites is the effect area meteorology (humidity, wind speed, and temperature) has on deposition velocity and dry deposition flux. Vertical mixing of lower and upper air layers in the troposphere affects deposition based on minimal or excess air movement caused by the temperature differentials (Hinds, 1999). Higher wind speeds decrease total PM deposition as winds transport air and inhibit particle settling. The mining sites had lower wind speeds resulting in more air stagnation and less PM transport due to their location in steep valleys. However, without some turbulence, it would be difficult to deposit fine PM because gravitational settling would be too slow to overcome the aerodynamic and quasi-laminar resistances.

The atmosphere is a pathway for the transport of elements into the water, soil, vegetation, and other surfaces. Surface and ground water samples from the Coal River Valley area, where environmental dry deposition mining area samples were taken, indicated elevated conductivity ( $>1,000$ microSiemens) and $\mathrm{pH}(8-9)$ compared to the conductivity ( $<200$ microSiemens) and $\mathrm{pH}$ (6-7) at the non-mining areas(Orem et al., 2012). The alkaline water at the mining sampling sites indicated neutralized acid mine drainage by lime or calcium silicate. Elevated ammonium and phosphate were present in water samples collected around the mining area sites, with ammonium linked to the ammonium nitrates used in MTM blasting activities (Orem et al., 2012). In other water studies with samples from areas around MTM activity, water was characterized by elevated Al, Ca, Fe, Mg, Mn, Pb, S, Se, and $\mathrm{H}_{2} \mathrm{~S}$ (Lindberg et al., 2011; Palmer et al., 2010). However, further research must be conducted to determine if the dry deposition rates were adequate to produce measurable contributions to water-borne contaminants.

Additional atmospheric PM samples were collected using a variety of sampling techniques including window wipes to examine cumulative deposition and a high volume air sampler in conjunction with a cascade impactor. Benzopyrene, a known carcinogen from cigarette smoke, was found on window wipe samples from approximately half of the mining samples collected in June and August 2011 (Kolker et al., 2012). Organic analysis of the mining window wipe cumulative deposition samples reported alkylated low molecular weight compounds and low molecular weight PAHs (including anthracene, fluoranthene, pyrene, and chrysene) which were not present at the non-mining samples. Window wipes from mining, 
internal control, and external control sites in June and August 2011 indicated heavy enrichment of anthropogenic elements $\mathrm{As}, \mathrm{Bi}$, and $\mathrm{Cd}$ at all three locations relative to upper crustal average abundance (Kolker et al., 2012). However, enrichments of these three anthropogenic elements were lower at the mining area sites compared to the internal controls due to increased loading of crustal particles at mining sites, including Si, which diluted these elements in the ambient PM. The cumulative deposition results differ from the current study of environmental dry deposition where both crustal and anthropogenic-dominated elements were greater around the mining sites. HMW alkanes (motor oils) determined from organic analysis of the high volume sampler samples may have a direct connection to coal and coal washing and processing.

A major limitation of this study was the relatively small data set size. Results are based on measurements from six dry deposition samples and are not generalizable to all mining areas and seasons. A second limitation was the placement of deposition units under a porch or overhang resulting in underestimated environmental deposition. Deposition plates must be covered during precipitation events to prevent preferential loss of more soluble compounds due to dissolving of PM in the snow or rainwater, but it was not possible to manually cover the deposition plates over the multi-day sampling period. As a result of the placement of the deposition samplers under an overhang, loss of Apiezon Grease on the surrogate surfaces was an unlikely explanation for flux differences between mining and non-mining areas. The matrix spikes showed consistent underperformance of recovery efficiencies (about $80 \%$ for most elements) indicating the results under represented total environmental dry deposition.

Another limitation of the study was that an analysis for direct emission organic compounds and secondary organics was not performed. The substrate used to collect the particles was grease, and PAHs that were present in coal and released by fuel combustion and VOCs were not identified. Furthermore, organics are removed from the collection equipment after a few days of sampling and obtaining all organics from the sample is open to error. Highly reactive species on filters lead to chemical reactions that change the nature of PM and degrade PAHs.

Future studies will involve sampling top soil from gardens or other exposed yard spaces as comparisons for air samples, since it is expected that soils contain a proportion of the deposited particulate material. Sampling soils will provide information on human exposure to contaminants because pollutants from the air are taken up by vegetation and produce grown in 
backyard gardens and ingested by humans. Environmental dry deposition was determined because it accounts for a larger deposition flux than wet deposition. Still, since West Virginia receives sufficient precipitation and is not an arid region, wet deposition would be feasible to measure in order to obtain estimates of PM removed from the atmosphere mainly by precipitation.

Smooth surrogate surfaces to directly measure environmental dry deposition fluxes at select mining and non-mining area sites showed elevated atmospheric inputs at mining sites. These elevated dry deposition fluxes indicate potential human exposure and increased contamination as well as environmental toxicity due to potential ecological system impacts. The composition of these particles suggests contamination from coal-related activities including combustion, blasting, and moving dirt. Surface mining methods are generally more economical and safer for workers than underground mining, but air contamination impacts nearby areas and residents. 


\section{References}

Ahern MM, Hendryx M, Conley J, Fedorko E, Ducatman A, Zullig KJ. The association between mountaintop mining and birth defects among live births in central Appalachia, 19962003. Environ Res. 2011;111(6):838-846.

Esch L, Hendryx M. Chronic cardiovascular disease mortality in mountaintop mining areas of central Appalachian states. J Rural Health. 2011;27(4):350-357.

Hendryx M. Mortality from heart, respiratory, and kidney disease in coal mining areas of Appalachia. Int Arch Occup Environ Health. 2009;82:2:243-249.

Hendryx M. Poverty and mortality disparities in central Appalachia:mountaintop mining and environmental justice. Journal of Health Disparities Research and Practice. 2011;4(3): 44-53.

Hendryx M, Ahern MM. Relations between health indicators and residential proximity to coal mining in West Virginia. Am J Public Health. 2008;98(4):669-671.

Hendryx M, Wolfe L, Luo J, Webb B. Self-reported cancer rates in two rural areas of West Virginia with and without mountaintop coal mining. J Community Health.2011;37(2):320-327.

Hendryx M, Zullig KJ.2009. Higher coronary heart disease and heart attack morbidity in Appalachian coal mining regions. Prev Med. 2009;49:(5).

Hinds WC. Aerosol Technology: Properties, Behavior, and Measurement of Airborne Particles. Vol 2. New York: John Wiley \& Sons, Inc.; 1999.

Holsen TM, Noll KE, Fang GC, Lee WJ, Lin J. Dry deposition and particle size distributions measured during the Lake Michigan urban air toxics study. Envion Sci Technol. 1993;27: 1327-1333.

Kolker A, Engle M, Orem W, Tatu C, Hendryx M, McCawley M, et al. Atmospheric particulate matter in proximity to mountaintop coal mines. In: Proceedings of the VM Goldschmidt Conference, June 24-29, 2012. 2012. Montreal.

Lindberg TT, Bernhardt ES, Bier R, Helton AM, Merola RB, Vengosh A, et al. 2011. Cumulative impacts of mountaintop mining on an Appalachian watershed. PNAS. 2011. Available at: http://www.nicholas.duke.edu/news/pnas\%20201112381.pdf. Accessed 14 August 2012.

MSHA. Effects of blasting on air quality. In: Administration UDoLMSHA, editor. Arlington, VA; 2010. 
Orem WH, Tatu C, Crosby LM, Varonka MS, Bates AL, Engle M et al. Water chemistry in ares with surface mining of coal, West Virginia, USA. In: Proceedings of The Geological Society Annual Meeting, November 6, 2012. Charlotte, NC.

Palmer MA, Bernhardt ES, Schlesinger WH, Eshleman KN, Foufoula-Georgiou E, Hendryx M, et al. Mountaintop mining consequences. Science. 2010;327:148-149.

Surprenant NF, Battye W, Roeck D, Sandberg SM. Emissions assessment of conventional stationary combustion systems: Volume V: industrial combustion sources. TRW, Inc. 1981; Report PB-81-225559. 
Chapter 6

Summary of the Research 


\subsection{Summary of Key Findings}

The purpose of this particulate matter analysis project was to assess the potential health hazard of PM by characterizing atmospheric PM collected from sites in mining and non-mining areas in West Virginia. The atmospheric PM data from the four related studies on: 1) particle size distribution from a brief sampling period to determine inhaled deposited dose, 2) particle size distribution to determine inhaled deposited dose over a year-long period, 3) PM elemental composition, and 4) environmental dry deposition provided information concerning air qua lity in high and low disease rate areas of southern West Virginia with and without mining activity. The MTM areas were specifically selected for these studies due to vast health disparities reported in MTM areas. However, direct links between mining and health outcomes have been lacking, as is research on the plausibility of mining attributed health effects. Air quality impacts around MTM areas have not been examined and characteristics of PM around MTM areas were not included in prior research on possible environmental and human health impacts of MTM. This project directly evaluated PM in the vicinity of MTM sites by characterizing the deposited lung dose from mass-based and number-based particle size distributions, PM elemental composition, and environmental dry deposition.

A review of the utility of $\mathrm{PM}_{10}$ and $\mathrm{PM}_{2.5}$ mass concentration measurements compared to measures of size distribution to determine respiratory deposition was indicated in Chapters 2 and 3. A semi-empirical modeling approach represented the fraction of inhaled particles reaching each region of the lung and accounted for the respiratory deposition efficiency and clearance mechanisms in each region. Analyzing $\mathrm{PM}$ with $\mathrm{PM}_{10}$ and $\mathrm{PM}_{2.5}$ measures of exposure may fail to detect a difference in dose, which is present when accounting for size distributions with respiratory deposition.

Significantly higher number concentrations and deposited number concentrations were reported at the MTM sites compared to the non-mining site. The elevated concentrations and dose measures were correlated with previously documented health outcomes (Ahern et al., 2011; Esch \& Hendryx, 2011; Hendryx, 2011; Hendryx et al., 2011). Statistically significant differences between the two areas for $\mathrm{PM}_{10}$ and $\mathrm{PM}_{2.5}$ were present only for a small number of sampling periods, but the medical and toxicological significance of this differential is likely to be small. It was also illustrated that measuring the deposited fraction of dose is now technically 
feasible for mass-based and number-based size distributions. PM concentration varied over the sampling period, but PM sources were relatively constant.

The components of ambient PM analyzed in Chapter 4 were primarily crustal elements. Individual particle analysis determined $\mathrm{Al}$ and Si were present in greater weight percent concentrations in the vicinity of the MTM sites. At the non-mining area, Ca and S were higher compared to MTM areas. Results from characterizing particle compounds found significant differences between the MTM and non-mining sites in similar elements as the individual element analysis. Other differences to note between the sites were greater $\mathrm{Ti}, \mathrm{Mg}$, and $\mathrm{K}$ around the MTM site in summer and an elevated proportion of particles with Na at the non-mining site. PM composition differed by site, but seasonal discrepancies were small.

Chapter 5 quantified the concentration of inorganic materials depositing to the environment at mining and non-mining sites. Mining sites had higher flux estimates and elevated concentrations of crustal and anthropogenically-dominated inorganic materials, which may be attributed to coal mining activities based on the presence of elements acting as coal indicators. Environmental dry deposition fluxes indicate potential surface contamination including dermal exposure and ingestion by humans and impacts to ecological system. Integrating the environmental dry deposition data with soil and water sampling data will expand awareness of potential MTM impacts to the environment and human health.

\subsection{Discussion}

\subsubsection{Characteristics of PM Relevant to Health}

Significant differences in number and deposited number between the MTM and nonmining areas were correlated with previously documented differences in population health outcomes. The particle number concentrations in the MTM and non-mining areas were higher than number concentrations reported using similar sizing equipment in Copenhagen, Denmark and Los Angeles, California. The levels of particle number concentrations at the MTM area in WV were almost 50 times larger than number concentrations associated with hospital admissions for cardiovascular disease and respiratory conditions in the elderly and children in Copenhagen (Anderson et al., 2008). If health reactions at the West Virginia areas sampled were similar to those in Copenhagen, paediatric asthma hospital admissions and cardiovascular disease and respiratory disease hospital admissions in the elderly should also be a problem in the mining and 
non-mining areas of West Virginia under study.

Mining activity and use of fossil fuel combustion sources around MTM areas are potential explanations for the greater particle number concentrations in the vicinity of the MTM sites. Number - and mass-based PM size distributions specified a peak around 0.02-0.03 $\mu \mathrm{m}$, suggesting the presence of secondary PM transported from coal-fired power plants located northwest and south of the sampling areas in Cincinnati, OH, Columbus, OH, Lexington, KY and the Ohio River Valley area. A peak in the size distributions around 0.05-0.07 $\mu$ m consists of coagulated soot and accumulation mode particles (Wilson and Suh, 1997). Coarse mode particles are likely mechanically generated or secondary long-range transported particles including dirt from overburden removal and coal dust (Kolker et al. 2012).

This study indicates that accounting for the fraction of the particulate that deposits in the lung, thus directly contributing to dose, is a more sensitive indicator of epidemiological disease patterns than mass concentration measures such as $\mathrm{PM}_{2.5}$. $\mathrm{PM}_{10}$, although different statistically between the MTM and non-mining areas during summer months, was unlikely to result in medically significant results for the higher disease rate area. Elevated particle number concentrations and particle size distributions leading to an increased particle dose, along with chemical constituents of PM, are a more plausible explanation for health outcome differences between the two areas than particle mass.

PM is a mixture that changes composition in the atmosphere and characterizing elements in ambient air to detail the more toxic components helps to characterize a PM sample.

MTM sites contained higher concentrations of PM composed of crustal derived aluminosilicates that were likely mechanically-generated particles or the result of road, construction, farming, or mining activities. Therefore, it was speculated that a portion of AlSi at the mining sites was partially attributed to MTM processes, and K, which was present in significantly higher concentrations around the MTM area, indicated explosives used to remove overburden. Coalfired power plants are known to emit metals and $\mathrm{Be}, \mathrm{Cd}, \mathrm{Pb}$, and $\mathrm{Mg}$ as part of fine $\mathrm{PM}$, but these elements were not detected in substantial concentrations as part of this study. Sulfur and calcium were present in greater concentrations at the non-mining sites. Sulfur was likely present in the air as oxides of sulfur from heavy industry, petroleum, or natural gas emissions, or other fossil fuel by products. Calcium is a crustal element that is likely sourced from weathering of natural minerals or buildings. 
The lungs are just one site of entry for contaminants. Dry particles depositing to surfaces in mining areas had elevated concentrations of crustal and anthropogenically-dominated inorganic materials. These elevated atmospheric inputs around mining sites indicate increased potential human exposure through skin absorption or ingestion. The composition of particles around mining areas suggests contamination from coal-related activities including combustion, blasting, and moving dirt.

Residents of the MTM area in this study had increased cardiovascular health problems, cancer, kidney disease, and lung disease compared to people living in the non-mining area (Esch \& Hendryx, 2011; Hendryx, 2009; Hendryx et al., 2011; Hendryx \& Zullig, 2009).

CDC age-adjusted mortality rates from 2005-2009 for cancer of the lung/bronchus, all forms of cardiovascular disease, and all forms of respiratory disease (Table 24) show that age-adjusted death rates are higher in Boone and Raleigh Counties compared to Pocahontas County (with the exception of lung cancer deaths in Raleigh) (CDC Wonder, 2012). Still, death rates in Pocahontas County are higher than the WV state average, and all WV figures are higher than national rates.

Table 24 Population and county-level mortality covariate rates, 2005-2009.

\begin{tabular}{|l|c|c|c|c|c|}
\hline Mortality Rate & $\begin{array}{c}\text { United } \\
\text { States }\end{array}$ & $\begin{array}{c}\text { West } \\
\text { Virginia }\end{array}$ & $\begin{array}{c}\text { Boone } \\
\text { County }\end{array}$ & $\begin{array}{c}\text { Raleigh } \\
\text { County }\end{array}$ & $\begin{array}{c}\text { Pocahontas } \\
\text { County }\end{array}$ \\
\hline Lung Cancer Mortality* & 50.5 & 66.9 & 108.1 & 60.0 & 82.2 \\
CVD Mortality* & 257.0 & 306.9 & 352.1 & 325.5 & 315.6 \\
Respiratory Disease Mortality* & 74.8 & 103.7 & 120.1 & 109.4 & 124.4 \\
Smoking Rate (\%) & 21.2 & 28.6 & 30.0 & 24.0 & 25.0 \\
Obesity Rate (\%) & 27.8 & 32.4 & 30.0 & 32.0 & 31.0 \\
\hline
\end{tabular}

*Age-adjusted rate per 100,000

Smoking and obesity rates in Pocahontas are lower than the state average, even though the death rates are higher. While age, smoking, and obesity likely contribute to the increased death rates in these areas, the high level of UFPs in all areas, but especially in mining areas, may be a contributing factor. Moreover, previous studies demonstrate this through increased rates of chronic cardiovascular disease mortality in MTM residents compared to other non-MTM or nonmining areas and higher risk of CVD, angina or coronary heart disease, heart attack, and chronic heart mortality rates in Appalachian coal mining counties compared to non-mining counties (Esch \& Hendryx, 2011; Hendryx, 2009; Hendryx \& Zullig, 2009). 


\subsubsection{Evaluating Standard PM Measures}

Epidemiologist Sir Bradford Hill developed guidelines to assess causation given a reported association between an independent variable and an outcome (Bradford Hill, 1965). These criteria include:

1) Temporal relationship;

2) Biological plausibility;

3) Consistency;

4) Strength of association;

5) Dose-response relationship;

6) Coherence of evidence;

7) Reasoning by analogy;

8) Study design; and

9) Specificity.

Epidemiological literature reports an association between elevated ambient $\mathrm{PM}_{10}$ and $\mathrm{PM}_{2.5}$ concentrations and increased cardiopulmonary morbidity and mortality outcomes (Pope \& Dockery, 2006). Additional evidence reports health effects are more closely associated with the ambient $\mathrm{PM}_{2.5}$ than $\mathrm{PM}_{10}$ (Wilson \& Suh, 1997). $\mathrm{PM}_{10}$ and $\mathrm{PM}_{2.5}$ mass concentration are the current standards for measuring PM exposure. However, epidemiology studies associating health outcomes with $\mathrm{PM}_{10}$ and $\mathrm{PM}_{2.5}$ fail to fulfill multiple causal criteria and lack substantial evidence for a causal relationship. $\mathrm{PM}_{2.5}$ standards were developed primarily based on epidemiology studies, as opposed to toxicological studies and attention to biological and particle mechanisms (Moolgavkar, 2005). Toxicological studies report health effects from PM deposition through mechanisms of oxidative stress, respiratory and vascular inflammation, platelet activation, peripheral thrombosis, exacerbation of myocardial ischemia, perturbation of heart rate, vasoconstriction, decreased defenses against infection, and translocation of PM to other tissues from the respiratory tract (Pope \& Dockery, 2006). Toxicological conclusions support a dose-response rather than mass concentration-response relationship because a biological response results from respiratory deposition not exposure.

The current study aimed to optimize exposure assessment by using more accurate, biologically relevant mass-based and number-based size distributions to determine respiratory dose. The partially size-classified $\mathrm{PM}_{10}$ and $\mathrm{PM}_{2.5}$ mass concentration exposure measurements are used as surrogates for dose. Dose refers to the particles that are inhaled and adhere to the lung surface whereas exposure alludes to particles that reach the lung but do not necessarily 
deposit. Uptake of PM depends on respiratory deposition and where deposition occurs in the lungs, which is heavily influenced by particle size. $\mathrm{PM}_{10}$ measures include particles of a wide range of sizes. Dosimetry from a $\mathrm{PM}_{10}$ measure in one location is expected to be quite different from the dosimetry in an unrelated location, even if $\mathrm{PM}_{10}$ concentration measures are similar (Moolgavkar \& Luebeck, 1996).

Increases in $\mathrm{PM}_{10}$ or $\mathrm{PM}_{2.5}$ by as little as $10 \mu \mathrm{g} / \mathrm{m}^{3}$ were associated with excess hospital admissions for heart disease, COPD, pneumonia, morbidity, mortality, and decreased life expectancy (Correia et al., 2013; Pope \& Dockery, 2006). However, there are limitations to this “dose-response” relationship. For example, a review of epidemiological studies in Pope and Dockery (2006) indicated the level of response varies with the same PM mass exposure. In addition, results do not identify a PM threshold level below which there is no evidence of an adverse or excess risk (Moolgavkar \& Luebeck, 1996). The varied level of response and lack of exposure threshold may be because PM levels are not present in toxic quantities despite a reported association between $\mathrm{PM}_{10}$ or $\mathrm{PM}_{2.5}$ and disease.

PM caused health effects at locations such as Denora, PA in 1948 and London in 1952 because PM levels were toxic and contributed to mortality. Similar or analogous PM levels to those contributing to mortality would be a possible cause of health outcomes. However, in Pope and Dockery's study of air pollution and mortality outcomes among 8,111 adults in six U.S. cities (1993), PM levels were not present in toxic quantities, but they were still reported to be associated with mortality. For example, $\mathrm{PM}_{10}$ levels as low as $28-30 \mu \mathrm{g} / \mathrm{m}^{3}$ were associated with health risks despite these levels being classified as “good” on the EPA’s Air Quality Index. In some cases, the PM levels were so low, health risks should not be present, but they were reported.

The lack of consistency of effects and weak strength of association in results are additional limitations of $\mathrm{PM}_{10}$ or $\mathrm{PM}_{2.5}$ measures. For example, Pope and Dockery (2006) report small adjusted relative risk ratios (less than 1.4) for cardiovascular-related mortality from longterm exposure to a $10 \mu \mathrm{g} / \mathrm{m}^{3}$ increase in $\mathrm{PM}_{2.5}$. Multiple studies, including Dominici et al. (2003), refute the conclusions of Pope and Dockery (2006) and report negative or no risk associated with $\mathrm{PM}_{10}$. Linear models of the mass concentration-response relationship suggest health effects at the lowest measureable mass concentrations, but health risks may not exist at very low exposures, such as below $15 \mu \mathrm{g} / \mathrm{m}^{3}$ (Pope \& Dockery, 2006). Evidence refuting EPA's 
standards is less publicized, but contributes to the notion that $\mathrm{PM}_{10}$ and $\mathrm{PM}_{2.5}$ may explain less variance in health outcome models than previously thought.

$\mathrm{PM}_{10}$ and $\mathrm{PM}_{2.5}$ exposure studies have limitations in study design that raise concerns regarding the quality of evidence for cause and effect. A recent study funded by the EPA reported a $10 \mu \mathrm{g} / \mathrm{m}^{3}$ decline in $\mathrm{PM}_{2.5}$ over a seven-year period was associated with four months increased life expectancy when controlling for socioeconomic status, smoking prevalence, and demographic characteristics (Correia et al., 2013). Other effect modifiers and confounders, such as obesity, co-morbidities, population shifts, migration, lifestyle changes, weather, season, and co-pollutants, better explain the increase in life expectancy than the limited covariates included in the study regression model (Moolgavkar \& Luebeck, 1996). Number concentration is associated with increased health outcomes and despite recorded declines in PM mass reported by Correia et al.(2013), the current study reported particle number concentrations at a level associated with increased health outcomes throughout West Virginia study areas (Anderson et al., 2008).

Furthermore, an ecological fallacy results from epidemiological studies that measure PM exposure with a single monitoring station and then impute results to individuals residing at a variety of distances from the monitoring station. Central-site ambient PM monitors used to measure ambient $\mathrm{PM}_{2.5}$ concentrations are poorly correlated with personal exposure to $\mathrm{PM}_{2.5}$ (Meng et al., 2005). The central-site monitors underestimate ambient PM exposures and inaccurately account for variations in daily exposures (Meng et al., 2005). When measuring $\mathrm{PM}_{10}$ concentrations, which are more variable across areas, this can lead to misrepresentations of PM data. 


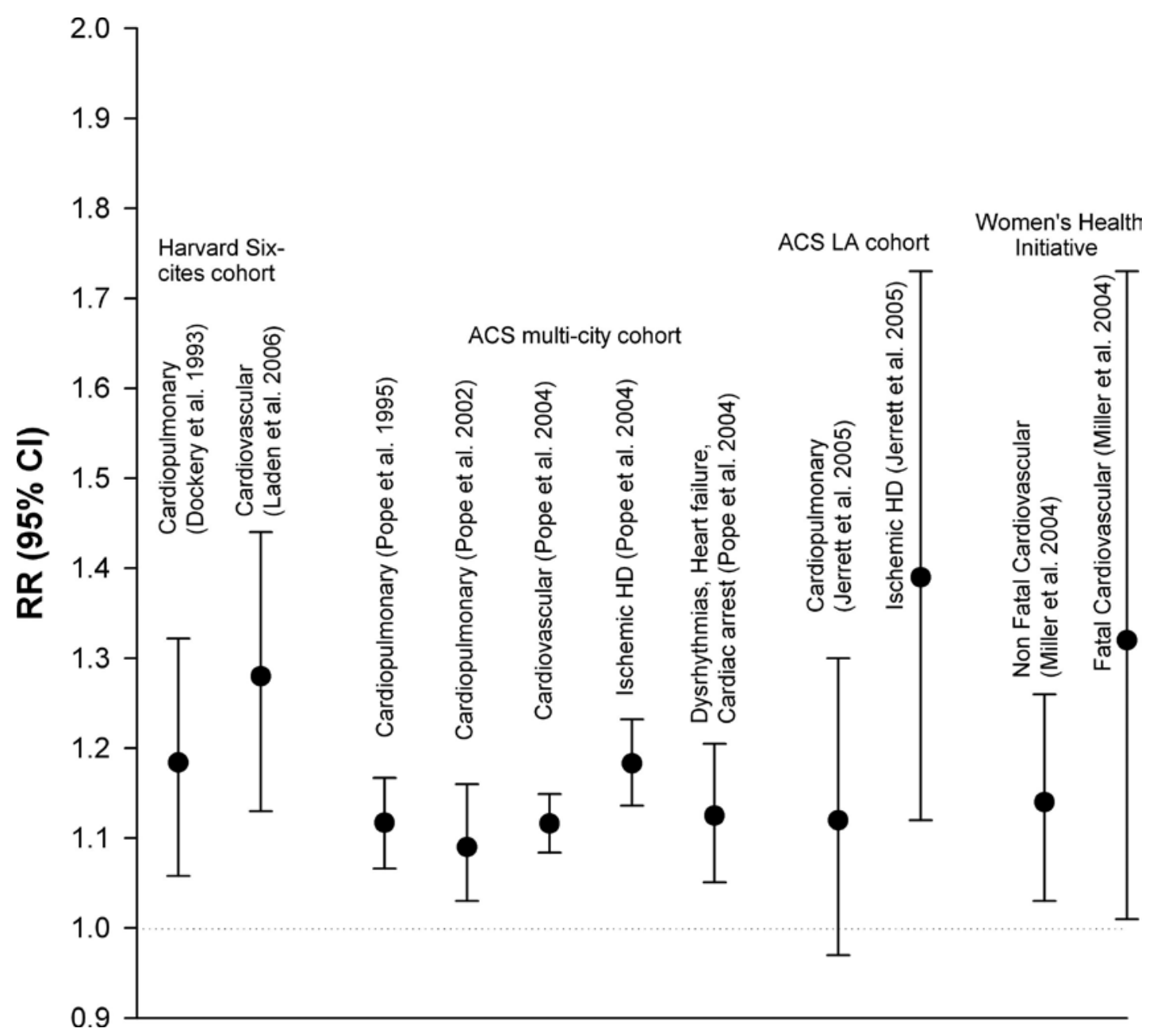

Figure 19 Adjusted relative risk ratios found in select studies from Pope and Dockery, 2006.

Ultrafine particles are the majority of PM in the atmosphere by particle number and contribute little mass to $\mathrm{PM}_{10}$ and $\mathrm{PM}_{2.5}$ mass concentrations. Exposure to equal masses of different sized PM found increased lung injuries and oxidative stress were induced with decreasing particle size (Li et al., 2003). The relationship between particle size and respiratory deposition efficiency was discussed noting that the majority of $\mathrm{PM}_{10}$ by mass deposits in the extrathoracic region resulting in a smaller health effects risk, and small particles penetrate to the alveolar region where respiratory deposition efficiency is high for PM 0.01-0.1 $\mu \mathrm{m}$ (Sioutas et al., 2005; Wilson \& Suh, 1997). While the mechanisms explaining the small differences in mass concentrations associated with morbidity and mortality are poorly understood, the differences in particle number of the small mass differential may be responsible for the health effects (Moolgavkar \& Luebeck, 1996). 


\subsection{Future Research and Limitations}

Future research on the human health risks from exposure to MTM area PM is needed to obtain detailed individual health outcome data among individuals living in close proximity to MTM areas. With the information from the four studies presented, we only speculate that the correlation between increased particle count, deposited respiratory count, elemental concentrations and MTM affects the health outcomes in the area, but this association must be examined directly. Spatial epidemiology would be especially practical in future studies to explore high disease areas in relation to mining activity. Furthermore, studies of direct inflammatory effects to humans living in MTM areas and direct measures of respiratory dose and the composition of deposited respiratory PM would enhance the presented studies. Information on organic materials, including the semi-volatile organic fraction of pollutants is needed to more completely examine inflammatory respiratory effects.

The increased crustal concentrations are evidence of MTM affecting the atmosphere; however, this study did not determine particles source.PM samples were from around MTM and non-mining areas, but not necessarily from mining sources. We expected some PM to be from MTM activity due to the close proximity of the sampling site to MTM, aluminosilicates and K in the PM analyzed, and USGS reports of a high presence of alkylated low molecular weight compounds and low molecular weight PAHs. Obtaining samples directly from MTM sources will help determine if the ambient samples in our study include MTM PM. Sampling PM at additional sites would enable conclusions to be extended to more areas since results from these studies are only applicable to the select site locations and times and are not generalizable to all MTM and non-mining areas.

Future research would include an internal control site to make comparisons between sites in close proximity to MTM activity and sites in MTM areas but without nearby MTM activity. The internal control site was included in the environmental dry deposition study, but was not identified in time to collect other measures of particle properties. $\mathrm{PM}_{10}$ and $\mathrm{PM}_{2.5}$ mass concentrations obtained by EPA standard methods would help build the case for improved exposure standards, especially if the results of these $\mathrm{PM}_{10}$ and $\mathrm{PM}_{2.5}$ mass concentrations reflected the results from the estimates used in this study. 
People spend the majority of their time indoors, and indoor air pollution poses health risks to people. Indoor emission sources including oil, gas, coal, or wood combustions sources, tobacco products, household cleaning products, and furniture or cabinetry, for example, can emit pollutants. It is suspected that high concentrations of pollutants in the ambient, outdoor air may impact indoor air quality when outdoor air enters a home by infiltration and ventilation processes. Future research would examine the indoor air quality in MTM and non-mining area homes and if a correlation exists between the indoor and outdoor air in these areas.

The sampling techniques used in this study were selected due to their feasibility for both fieldwork and collecting numerous samples. Less complicated methods were used first for sampling and an argument may be made to use more complicated sampling methods to check the results of the instrumentation used in the study. While alternate sampling techniques to check results may be appropriate for concurrent sampling or future sampling, more complex sampling methods may not provide any additional information and require more time and resources. For example, a MOUDI (Multiple Orifice Uniform Deposit Impactor) provides aerodynamic, size segregated samples that can be measured gravimetrically and shape differentiated particles can be counted from the size-classified MOUDI samples. Furthermore, elemental analysis can be conducted on the MOUDI samples. However, optically sizing particles is difficult since PM is impacted on the filter, particulate has diverse morphology, and distinguishing individual particles can be difficult due to agglomerated PM. The SMPS provides quick readings of particle number concentrations while microscopic and gravimetric analysis of MOUDI filters may be very time consuming. Furthermore, deploying a MOUDI may take 5-6 days making it impracticable for multiple sampling within a brief time period. The SMPS was used to provide number-based size distributions and determine respiratory deposition since central site monitors are not representative of UFPs with their high spatial variability.

In the presence of UFP with a high number concentration, the particles tend to coagulate and, as a result, the aerosol particles are bigger in size and lower in number. It has been argued that real time instruments can be misleading because coagulation and agglomeration are highly likely with UFPs. However, this study was not conducted in a controlled environment with generated aerosols, so agglomeration was a natural feature of particles in the areas under study. Our estimates from real-time instruments may lead to an underestimation of particle size 
distribution, number concentration, deposition, and biological effects since particles that agglomerate are often large to remain airborne and will not contribute to human respiratory dose.

Surface mining is a heavily regulated activity, but current permitting focuses primarily on water quality around mining sites. The Clean Water Act of 1972 was enacted to regulate discharged pollutants and protect waterways. The Clean Water Act also regulates the distribution of permits for mining activities, and plays a role in regulating coal mining valley fill permits to protect streams. The Army Corps of Engineers has the power to issue permits for discharge of fill materials and states have the power to regulate these permits to prevent violation of state water quality standards. The Surface Mining Control and Reclamation Act of 1977 provided guidelines on reclamation procedures, restoring the contour of mountaintops, and placement of overburden in streams. The air quality issues specific to MTM areas are neither regulated by these aforementioned legislations nor by the Clean Air Act. Current air regulations fail to adequately protect residents near mining sites from poor air quality. The 1997 National Ambient Air Quality Standards (NAAQS) were set by the U.S. EPA using PM $_{2.5}$ epidemiological information rather than toxicological data to set regulations (U.S. EPA, 2004). Amended legislation may go as far as setting updated NAAQS that are evaluated and created with toxicology results in addition to epidemiological data. Revisions to regulations and improved enforcement for air quality parameters should be addressed along with stricter regulations on mining activity.

\subsection{Conclusions}

This project assessed the potential health hazard of PM by characterizing atmospheric $\mathrm{PM}$ at coal and non-mining sites to identify particle elemental composition, mass concentration, mass-based and number- based size distributions to determine inhaled deposited dose, and environmental dry deposition. Characterizing PM is challenging due to spatial and temporal heterogeneity of particles and the equipment needed to properly assess particle parameters associated with health outcomes. This study used an integrated approach to combine particle size data with chemical composition data to analyze potential PM sources and health effects in areas with known differences in morbidity and mortality rates. Particle size distributions between the MTM and non-mining sites over the June 2011-May 2012 period showed homogeneity in particle mass, but not particle number. The SEM analysis confirmed that 
elemental components of PM were consistent at sites over seasons indicating a relatively stable source, but MTM areas had elevated crustal elements. The environmental dry deposition study determined flux measurements at the mining areas were elevated for most of the elements under study compared to non-mining areas.

This research extends exposure assessment literature by directly assessing the inhaled dose and concentration of particles that residents of high disease rate areas receive. The findings demonstrate the need to address air quality issues and regulate mining-related sources of PM in MTM areas to decrease health disparities in the Appalachian coal mining areas. The differences in particle number and size distribution, elemental concentration, and environmental dry deposition of elements to the environment suggest these particle parameters may be responsible for the differential impacts on human health between the mining and non-mining areas. 


\section{References}

Ahern MM, Hendryx M, Conley J, Fedorko E, Ducatman A, Zullig KJ. The association between mountaintop mining and birth defects among live births in central Appalachia, 19962003. Environ Res. 2011;111(6):838-846.

Anderson ZJ, Wahlin P, Raaschou-Nielsen O, Ketzel M, Scheike T, Loft S. Size distribution and total number concentration of ultrafine and accumulation mode particles and hospital admissinos in children and the elderly in Copenhagen, Denmark. Occup Envion Med. 2008;65:458-466.

Bradford-Hill, A. The environment and disease: association or causation? Proceedings of the Royal Society of Medicine.1965; 295-300.

CDC Wonder. CDC Compressed Mortality 2005-2009. 2012. Available at: http://wonder.cdc.gov/mortsql.html. Accessed 4 December 2012.

Correia AW, III Pope CA, Dockery DW, et al. Effect of air pollution control on life expectancy in the United States. Epidemiology. 2013;24:23-31.

Dominici F, Daniels M, McDermott A, et al. Shape of the exposure-response relation and mortality displacement in the NMMAPS Database. In Revised Analysis of Time-Series of Air Pollution and Health. Special Report; Health Effects Institute. Boston, MA. 2003;9196.

Esch L, Hendryx M. Chronic cardiovascular disease mortality in mountaintop mining areas of central Appalachian states. J Rural Health. 2011;27(4):350-357.

Dockery DW, Pope CA 3rd, Xu X, et al. An association between air pollution and mortality in six U.S. cities. N Eng J Med. 1993;329(24): 1753-1759.

Hendryx M. Poverty and mortality disparities in central Appalachia:mountaintop mining and environmental justice. Journal of Health Disparities Research and Practice. 2011;4(3): 44-53.

Hendryx M. Mortality from heart, respiratory, and kidney disease in coal mining areas of Appalachia. Int Arch Occup Environ Health. 2009;82:243-249.

Hendryx M, Wolfe L, Luo J, Webb B. Self-reported cancer rates in two rural areas of West Virginia with and without mountaintop coal mining. $J$ Community Health. 2011;37(2):320-327.

Hendryx M, Zullig KJ. Higher coronary heart disease and heart attack morbidity in Appalachian coal mining regions. Prev Med. 2009;49:5

Li N, Sioutas C, Cho A, et al. Ultrafine particulate pollutants induce oxidative stress and mitochondrial damage. Environ Health Perspect. 2003;4:455-460. 
Hudda N, Cheung K, Moore KF, Sioutas C. Inter-community variability in total particle number concentrations in the eastern Los Angeles air basin. Atmos Chem Phys. 2010; 10:1138511399.

Kolker A, Engle M, Orem W, Tatu C, Hendryx M, McCawley M, et al. Atmospheric particulate matter in proximity to mountaintop coal mines. In: Proceedings of the VM Goldschmidt Conference, June 24-29, 2012. 2012. Montreal.

Meng QY, Turpin BJ, Polidori A, et al. PM2.5 of ambient origin: estimates and exposure errors relevant to PM epidemiology. Environmental Science \& Technology. 2005;39(14);51055112.

Moolgavkar SH. A review and critique of the EPA's rationale for a fine particle standard. Regulatory Toxicology and Pharmacology. 2005;42(1):123-144.

Moolgavkar SH, Luebeck EG. A critical review of the evidence of particulate air pollution and morgality. Epidemiology. 1996;7(4):420-428.

Palmer MA, Bernhardt ES, Schlesinger WH, Eshleman KN, Foufoula-Georgiou E, Hendryx M, et al. 2010. Mountaintop mining consequences. Science. 2010;327:148-149.

Pond G, Passmore M, Borsuk F, Reynolds L, Rose C. Downstream effects of mountaintop coal mining: comparing biological conditions using family-and genus-level macroinvertebrate bioassessment tools. Journal of North American Benthological Society. 2008;27(3):717737.

Pope CA 3rd, Dockery DW. Health effects of fine particulate air pollution:lines that connect. $J$ Air \& Waste Manage Assoc. 2006;56:709-742.

Sioutas C, Delfino RJ, Singh M. Exposure assessment for atmospheric ultrafine particles (UFPs) and implications in epidemiologic research. Environ Health Perspect. 2005;113:947-955.

U.S. EPA. Air Quality Criteria for Particulate Matter. EPA/600/P-99/002aF. U.S. Environmental Protection Agency: Washington, DC, 2004.

Wilson WE, Suh HH. Fine and coarse particles: concentration relationships relevant to epidemiological studies. J Air \& Waste Manage Assoc. 1997;47:1238-1249. 
Appendix 


\section{Appendix A: Schematic of Particle Sizing Equipment}

FigureA.1Flow of aerosol through the Aerodynamic Particle Sizer (APS)

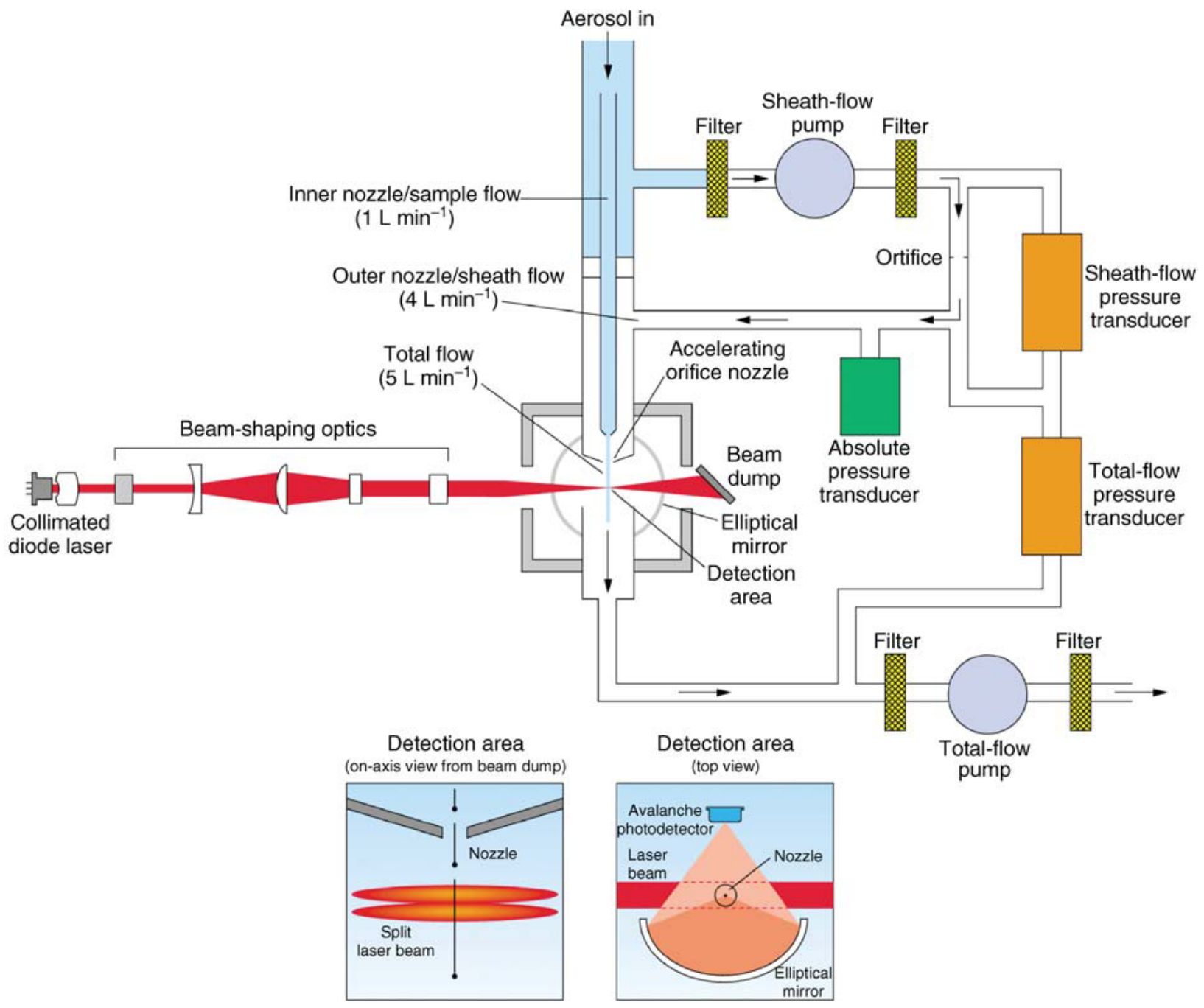

Aerosol is accelerated through a nozzle and particles are focused on the center of the air flow by outer sheath flow. Particles pass through two laser beams and scatter light each time they cross a beam. The light is detected by a photodetector to electronically calculate the time interval for the particle to cross the two laser beams and determine particle velocity. 
Figure A.2 Flow of aerosol through the Electrostatic Classifier componenet of the Scanning Mobliity Particle Sizer.

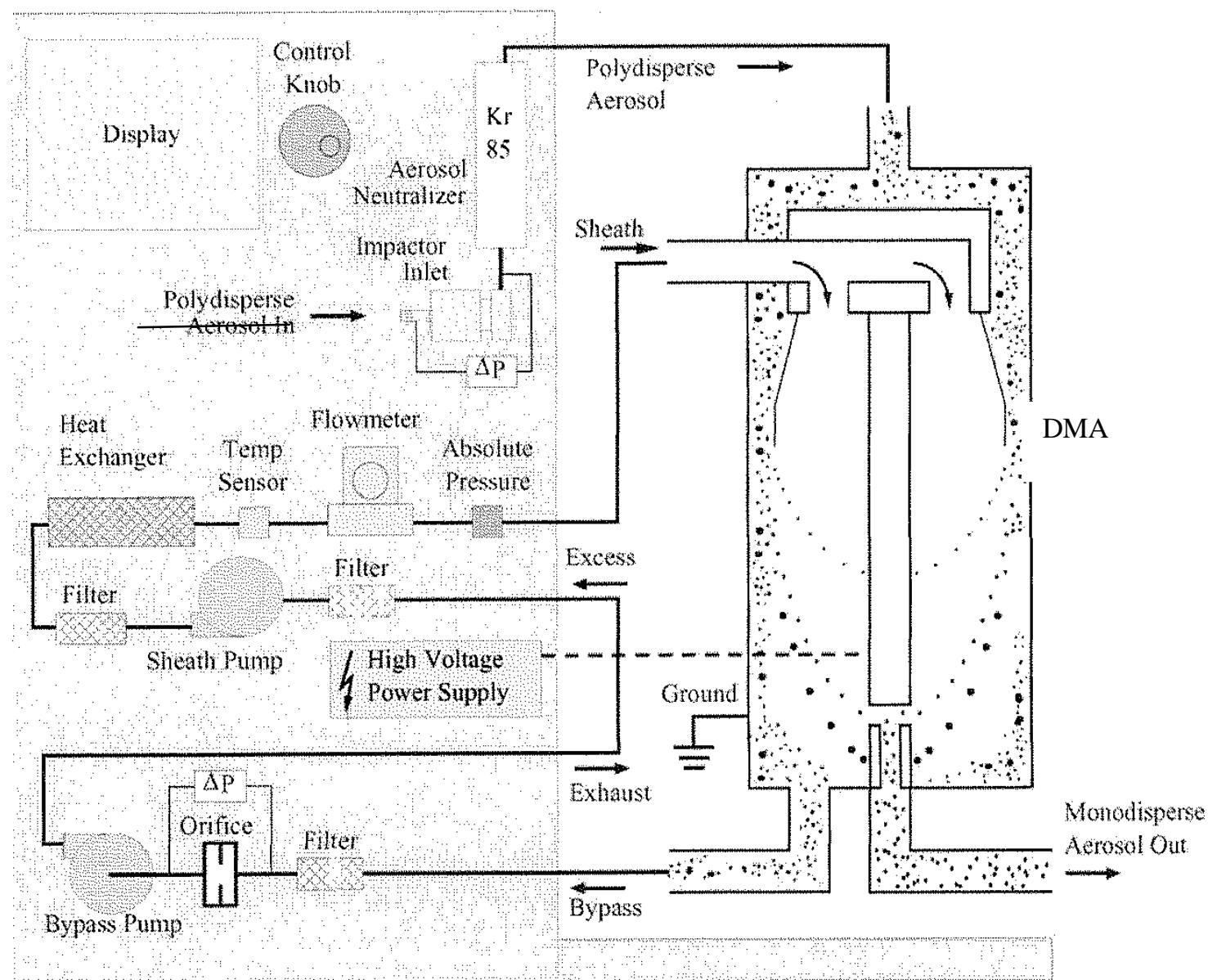

Polydisperse aerosol passes through an impactor to remove large particles and is then neutralized before entering the Differential Mobility Analyzer (DMA). In the DMA, particles are separated by electrical mobility, whichi s inversely related to particle size. Particlies with a specific electricial mobility and positive chare move toward the negatively charged rod int eh middle of the DMA. Particles not in a particular size range exit the instrument and the voltage then changes to classifiy another size range of particles. 
Table A.3 Flow of aerosol through the Condensation Particle Counter (CPC)

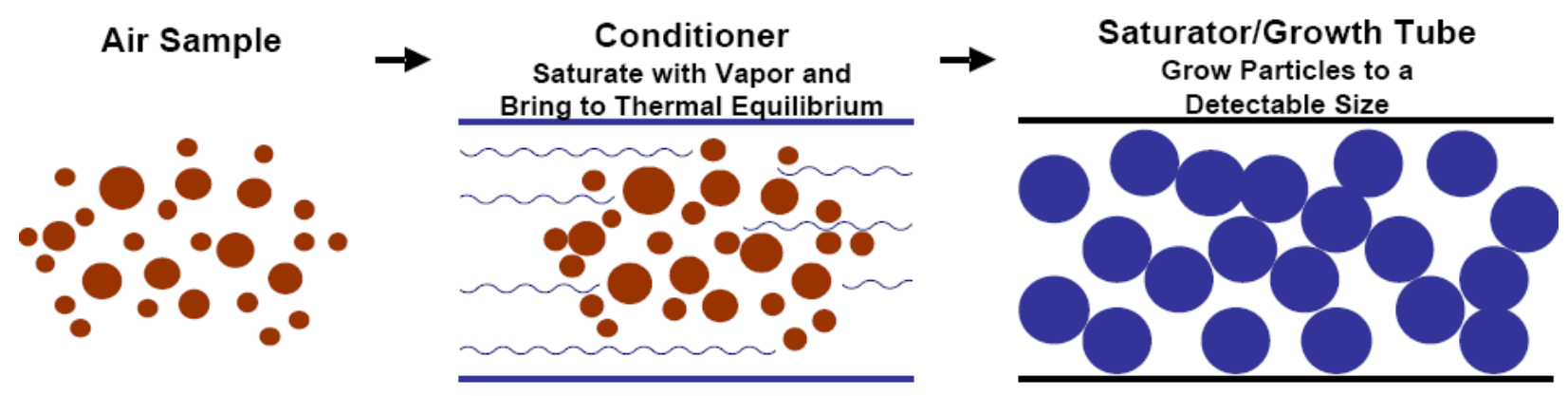

Particles coming from the EC are too small to scatter enough light to be detected, so they are grown by condensing water vapor onto particles. The CPC uses water for condensation and keeps the conditioner region cool while the saturator/growth tube is hot. After a particle reaches supersaturation, the vapor condenses on the particle to grow the particle. Droplets then move to an optical particle counter that uses a laser beam to count particles. 


\section{Appendix B: Justification for Selecting Annual Sampling Sites}

The three sampling sites used in Chapter 3 were selected from the study in Chapter 2 that involved brief sampling during June, 2011. Three sites were selected from the nine sites for continued sampling based on representativeness of mining activity at the area, site accessibility, and typical particle measurements of the area. Among the three Raleigh County sites, Site C was excluded because the number and deposited number were higher than at other two Raleigh sites (Sites A and B) due to the heavy mining activity at Site C. Site A was selected for continued sampling to represent Raleigh County because it was farthest from an active MTM site during the June, 2011 sampling period and was a greater distance from the main road than nearby Site B. The increased distance of Site A from a main road helped minimize PM caused by road dust and traffic. In Boone County, Site D was selected for extended sampling despite having a significantly greater deposited percent than the other two Boone County sites (Sites E and F). The counts, deposited respiratory counts, and TSP mass concentration did not differ between the three Boone sites, but Site D was the most accessible site and was most similar to Site A in Raleigh County. Site E was close to a main road and Site F was in a secluded area of the valley. In the non-mining county, Site $\mathrm{G}$ was chosen because it did not have a significantly lower $\mathrm{PM}_{10}$ concentration, as found at Site H, or a significantly greater respiratory deposition percent. Site $\mathrm{G}$ was also selected because it was the most accessible of the three Pocahontas County sites. 